International Scientific-Technical and Production Journal

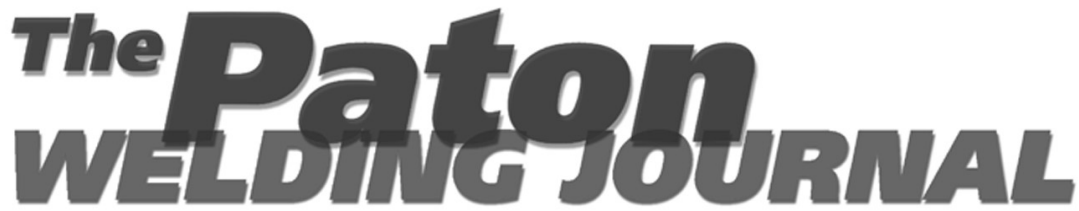

January 2015 No.1

Published since 2000

English translation of the monthly «Avtomaticheskaya Svarka» (Automatic Welding) journal published in Russian since 1948

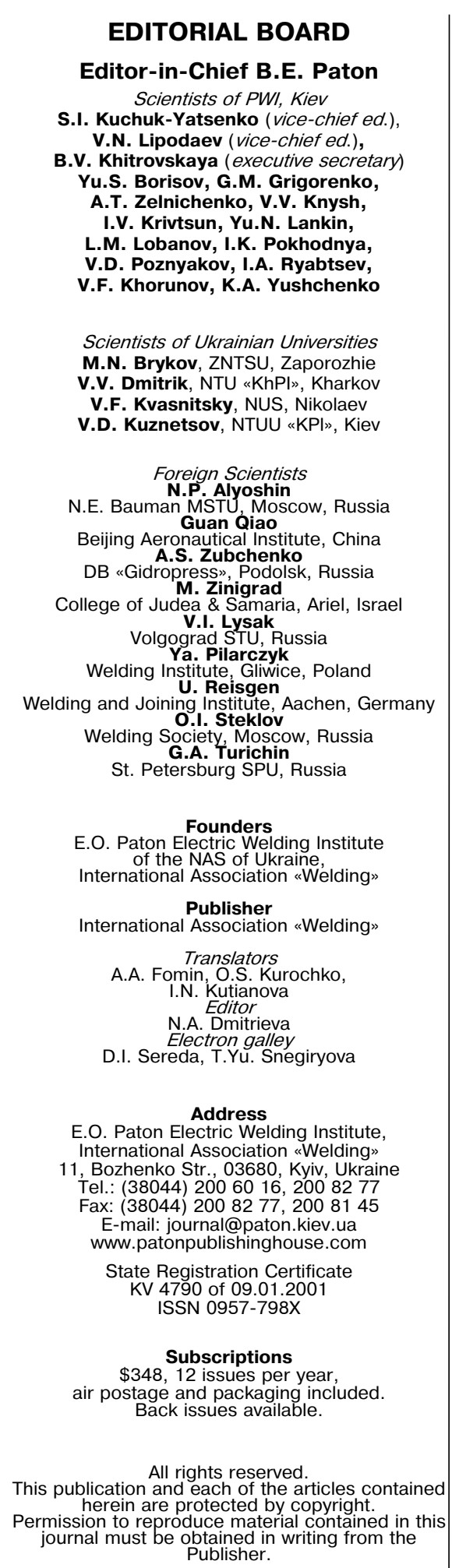

\title{
CONTENTS
}

\section{SCIENTIFIC AND TECHNICAL}

Majstrenko A.L., Nesterenkov V.M., Dutka V.A., Lukash

V.A., Zabolotny S.V. and Tkach V.N. Modeling of heat

processes for improvement of structure of metals and

alloys by friction stir method

Kuchuk-Yatsenko S.I., Rudenko P.M., Gavrish V.S. and

Gushchin K.V. Comparative evaluation of power and technological characteristics in continuous flash-butt welding of thick-walled parts at direct and alternating current

Velikoivanenko E.A., Rozynka G.F., Milenin A.S. and

Pivtorak N.I. Evaluation of operability of the main

pipeline with local wall thinning at repair by arc

surfacing

Goncharov I.A., Galinich V.I., Mishchenko D.D. and

Sudavtsova V.S. Prediction of thermodynamic

properties of $\mathrm{Al}_{2} \mathrm{O}_{3}-\mathrm{SiO}_{2}$ system melts

\section{INDUSTRIAL}

Lobanov L.M. and Volkov V.S. Peculiarities in manufacture of thin-walled welded transformablevolume structures for space application

Knysh V.V., Solovej S.A., Grishanov A.A., Linnik G.O. and Malgin M.G. Application of welded studs for fastening of railway bridge deck

Tsaryuk A.K., Elagin V.P., Davydov E.A., Gavrik A.R., Pasechnik A.I., Polonets S.A., Dedov V.G. and Gorelov $V . P$. Peculiarities of welding and control in manufacture of heat-exchange modules of exhaust-heat boiler of steam-gas electric plant of 150 MW capacity

Makhnenko O.V., Milenin A.S. and Saprykina G.Yu.

Evaluation of operability of WWR-M reactor primary circuit piping with welded joint defects 


\title{
MODELING OF HEAT PROCESSES FOR IMPROVEMENT OF STRUCTURE OF METALS AND ALLOYS BY FRICTION STIR METHOD
}

\author{
A.L. MAJSTRENKO ${ }^{1}$, V.M. NESTERENKOV ${ }^{2}$, V.A. DUTKA ${ }^{1}$, V.A. LUKASH ${ }^{1}$, \\ S.V. ZABOLOTNY ${ }^{1}$ and V.N. TKACH ${ }^{1}$ \\ ${ }^{1}$ V.N. Bakul Institute for Superhard Materials, NASU \\ 2 Avtozavodskaya Str., 04074, Kiev, Ukraine. E-mail: alcon@ism.kiev.ua \\ ${ }^{2}$ E.O. Paton Electric Welding Institute, NASU \\ 11 Bozhenko Str., 03680, Kiev, Ukraine. E-mail: office@paton.kiev.ua
}

\begin{abstract}
Developed was a computer model of temperature field in tool and parts in process of their friction stir welding. Modeling of the temperature field was carried out for both successive stages of welding process, i.e. plunging of pin of tool operating element into part (1st stage) and progressive motion of plunged pin in part (2nd stage). The mathematical model represents itself a nonlinear equation of transient heat conduction, which takes into account progressive pin movement during the 2nd stage of welding. Two constituents describe the heat sources, appearing in welding. The first one considers power of heat sources, caused by friction of tool with parts on contact surfaces, the second one takes into account heat generation, promoted by mechanical deformation of part material. Mathematical modeling and experimental examination of temperature field were carried out for tool from cubic boron nitride (cubonit) and hard alloy as well as copper parts during FSW. Adequacy of developed model was determined based on correlation of numerical and experimental results. It is shown that application of superhard materials (cubonit and hard alloy) for manufacture of tool operating elements gives a possibility to provide thermo-mechanical resistance of tool during welding. A possibility is also shown for increase of strength of welded joints of parts from magnesium alloy ML10, gained as a result of application of FSP for modifying of structure of surface layers in parts to be welded with their further electron beam welding. 27 Ref., 1 Table, 14 Figures.
\end{abstract}

$\boldsymbol{K} \boldsymbol{e} \boldsymbol{y} \boldsymbol{w} \boldsymbol{o r d s}:$ mathematical modeling, friction stir welding, temperature field, tools from superhard materials, structure modification, electron beam welding

Patenting [1] of a method of friction stir welding (FSW) allowed its wide application in different branches of industry for joining of alloys, which are difficult-to-weld using traditional methods (zinc-containing aluminum alloys, copper, magnesium cast alloys); metals and alloys, which do not form eutectics and hard solutions as well as due to its advantages in comparison with other methods of parts joining by welding [2, 3]. FSW is carried out at temperature significantly lower than melting one $\left((0.4-0.5) T_{\text {melt }}\right)$. This results in significant reduction of residual stresses and temperature deformations; refinement of microstructure of joint zone that has positive effect on material strength of the parts in zone of their joining. FSW is mainly used for joining of sheet parts along their contact line or welding-on of one sheet part over another [3, 4].

This method is also distributed and improved due to the necessity of joining of parts from dissimilar materials as well as materials, having high hardness and melting temperature. Welding of such materials requires developing of a tool of more perfect structure [5, 6] and application of materials with increased thermo-mechanical and chemical resistance $[7,8]$ for manufacture of its operating elements. Mathematical modeling and experimental examination of thermal condition of tool and parts during welding $[9,10]$ is relevant for selection of optimum tool structures, relevant welding modes and producing of quality welded joint of parts as a result of FSW. At that mathematical modeling in combination with other types of researches allows for reconstructing the most complete pattern of physical-mechanical processes, appearing in FSW.

Mathematical model of temperature field during FSW. Present work is dedicated to numerical modeling of temperature field during welding-on of copper plates to metallic basis by FSW method using heat-resistant tools from cubonit and hard alloy. The whole FSW process can be conventionally divided on two main stages. During the 1st stage a pin of operating element, rotating with high rate around own axis, is gradually plunged into the parts being welded. At the 2nd stage, the pin, being plunged into the 
parts, keeps rotating around own axis and is successively moved to upper surfaces of the parts in direction determined according to technological conditions till welding completion.

Series of physical-mechanical processes can be observed during FSW. Friction in contact zone takes place at the 1st stage at the beginning of contact of pin to part surface. Elements of pin surface carry particles of part material due to pin rotation and effect of friction force. As a result it is deformed taking a form of material stirring in that part of its volume, which is located close to zone of pin to part contact. Besides, plunging of pin into the part also results in its deformation. Both described phenomena of part deformation took place simultaneously, that result in viscoplastic flow of part material relatively to the surface of operating element. At the 2nd stage, when pin plunged into the part is moved parallel to its surface, friction also takes place over the surface of shoulder to part contact. Stirring of material of the parts occurs in its volume close to the surface of pin to part contact as well as shoulder to part contact.

Significant rise of temperature is observed at both stages as a result of friction in part volume zone, located in the vicinity of pin and shoulder surfaces (zone of thermo-mechanical effect). Effect of friction forces promotes for deformation of part material in this zone and its viscoplastic flow, large mechanical deformations occur. Friction force and deformation of the parts result in intensive heat emission and rise of temperature of operating element and parts, that is a reason of change of physical-mechanical properties of the latter, and in turn, influences the processes of deformation, heat emission and heat transfer.

Therefore, the processes of friction, deformation, viscoelastic flow of part material and heat conduction are interrelated in FSW. Thus, in strict formulation the mathematical modeling of temperature field during FSW requires consideration of problem of heat conduction and problems of viscoelastic flow and deformation connected between them. However, only heat conduction problem can be considered in operational development of computer program, taking into account effect of heat sources, promoted by friction forces and viscoplastic deformation, as well as taking into account pin rotation around own axis and its progressive movement in shoulder with respect to the part.

Results of experimental and theoretical investigations [11-13] show that patterns of distribution of temperature and mechanical loads are not symmetric in respect to $A B C D$ plane (Figure 1),

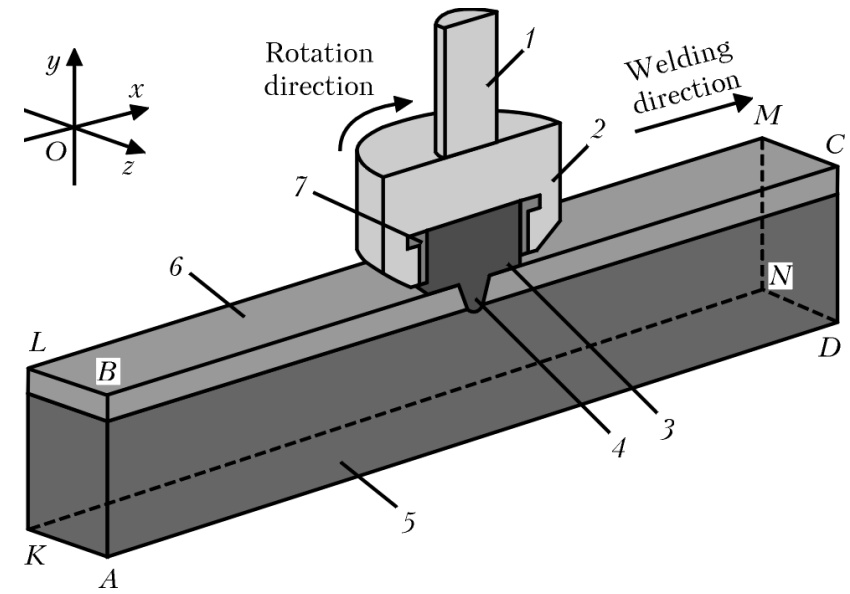

Figure 1. Calculation area (longitudinal section of $A B C D$ plane): 1 - steel shaft of drive; 2 - steel holder; 3,4 shoulder and pin of operating element; 5, 6 - parts to be welded; 7 - hard alloy yoke

which goes through pin rotation axis parallel to welding direction. However, considering that linear rate of pin rotation is 2-3 orders more than its progressive rate, it can be assumed, for simplification of problem formulation and reduction of calculation time, that temperature field in pin with shoulder is symmetric in respect to indicated plane.

Heat transfer equation is used for mathematical modeling of temperature field during FSW:

$$
\rho c_{p}\left(\frac{\partial T}{\partial t}+\vec{v} \operatorname{grad} T\right)=\operatorname{div}(\lambda \operatorname{grad} T),
$$

where $\rho, c_{p}, \lambda$ are the density, specific heat capacity at constant pressure and coefficient of material heat conduction, respectively; $\vec{v}$ is the rate vector; $T$ is the temperature; $t$ is the time.

As indicted in works [10,14], heat emission, produced as a result of deformation of part material during FSW, makes $4.4 \%$ from total heat emission quantity. Considering this as well as taking into account vicinity of part deformation zone to pin with shoulder surface, effect of heat sources, caused by friction and deformation, similarly to $[10,15,16]$ were set in form of effect of general source on surfaces of contact of pin and shoulder to part:

$$
-\lambda \frac{\partial T}{\partial n}=\left[\beta \mu p_{n}+(1-\beta) \eta \tau\right] \omega R,
$$

where $\beta$ coefficient is determined by formula; $p_{n}$ is the normal forces in contact point; $\tau$ is the material yield limit; $\omega$ is the circumferential rate in points of contact surface; $R$ is the distance of studied contact point from pin rotation axis; $\eta$ is the coefficient of mechanical efficiency;

$$
\beta=1-\exp \left(-\frac{\omega R}{\beta_{0} \omega_{0} R_{\mathrm{sh}}}\right),
$$


and its values lies in the ranges from 0 to 1 . Friction coefficient $\mu$ is computed by formula

$$
\mu=\mu_{0} \exp \left(-\lambda_{0} \beta \omega R\right) .
$$

Here $R_{\mathrm{sh}}$ is the shoulder radius; $\omega_{0}$ is the typical value of angular rate; $\mu_{0}$ is the constant value of friction coefficient; $\beta_{0}$ is the constant coefficient with value in $[0 ; 1]$ interval; $\lambda_{0}$ constant equal $1 \mathrm{~s} / \mathrm{m}$. Heat flows are absent in $A B C D$ plane (see Figure 1):

$$
\lambda \frac{\partial T}{\partial n}=0 .
$$

Conditions of convective heat exchange are set on surface of shoulder and part, which contact with external environment of temperature $T_{\text {env }}$ :

$$
-\lambda \frac{\partial T}{\partial n}=\alpha\left(T-T_{\text {env }}\right)
$$

with corresponding value of coefficient of convective heat exchange $\alpha$. Besides, conditions of heat emission according to Stefan-Boltzmann law are set on the surfaces of parts and shoulder, located in the vicinity of zones with high temperature:

$$
-\lambda \frac{\partial T}{\partial n}=\varepsilon \sigma_{0}\left(T^{4}-T_{\mathrm{env}}^{4}\right),
$$

where $\varepsilon$ is the surface emissivity coefficient; $\sigma_{0}$ is the Stefan-Boltzmann constant.

Condition of transfer of heat energy through indicated surfaces are set on the edges of calculation area $A K L B$ and $D N M C$ (see Figure 1), considering progressive movement of parts with rate $\vec{v}$ in relation to pin with shoulder:

$$
-\lambda \frac{\partial T}{\partial n}=c_{p} \rho v_{n}\left(T-T_{0}\right)
$$

where $v_{n}$ is the projection of rate vector $\vec{v}$ on normal line to surface. At the initial moment of time, temperature of calculation area equals room temperature.

As can be seen from equation (1), mass transfer is considered in mathematical formulation of heat conduction problem. Though, due to the fact that rotation rate of pin with shoulder (equal $\omega R \approx 0.1-1.0 \mathrm{~m} / \mathrm{s}$ ) is significantly larger of their progressive speed $v_{\mathrm{w}}$ along welding line $\left(v_{\mathrm{w}}=\right.$ $=0.002-0.004 \mathrm{~m} / \mathrm{s}$ ), the model takes into account these movements in the following way. Temperature field in pin with shoulder is virtually axially symmetric in rotation of pin with shoulder around own axis with large rate. Therefore, heat conduction equation (1) considers only progressive speed of part movement in relation to pin with shoulder, i.e. $v=\left(-v_{\mathrm{w}}, 0,0\right)$.
The mathematical model realizes consideration of pin with shoulder rotation by means of averaging of temperature along each line $L_{i}(i=$ $=1,2, \ldots, N)$ of rotation of surface points of pin and shoulder, where $N$ is the quantity of rotation lines. It has the following computer implementation. Average temperature value $T_{i}$ is computated with the help of corresponding contour integral of the first order after each time step along each rotation line:

$$
\begin{gathered}
T_{i}=\frac{1}{L_{i}} \int_{L_{i}} T(x, y, z, t) d l, \\
\left(\begin{array}{c}
L_{i}=\int_{L_{i}} d L \\
L_{i}
\end{array}\right), \quad i=1,2, \ldots, N .
\end{gathered}
$$

After that, temperature equal $T_{i}$ is taken in each of nodes $T_{i, k}$ lying in this rotation line:

$$
T_{i, k}=T_{i}, \quad k=1,2, \ldots, K_{i},
$$

where $K_{i}$ is the quantity of points of division of $i$-th lines. Boundary conditions of heat transfer are set on the surfaces of contact of part with massive bodies (supports) and shoulder (with drive connection elements) by means of entering of effective heat exchange coefficient $\alpha_{\mathrm{ef}}$ :

$$
-\lambda \frac{\partial T}{\partial n}=\alpha_{\mathrm{ef}}\left(T-T_{\mathrm{env}}\right) .
$$

$\alpha_{\text {ef }}$ value is determined based on equation of heat balance taking into account temperature dependence of thermal-physical properties and geometry parameters of contact bodies.

Finite element method in combination with Bubnov-Galerkin method and time finite-difference scheme of Crank-Nicolson were used for solving of heat conduction problem (1)-(11). The computations were carried out with the help of updated version of software package [17] in Visual Fortran 6.5 medium on modeling of 3D temperature field, where progressive tool movement (second member in the left part of equation (1)) as well as rotation of pin with shoulder (formula (9), (10)) are considered.

The calculation area (see Figure 1) was selected based on size of parts to be welded and indicated above conditions of problem symmetry. $A B C D$ is the symmetry plane. All parts of the calculation area in computer realizing are stationary. However, modeling of movement of those parts, which stir during FSW, is carried out with the help of corresponding developed algorithms, described below .

Modeling of heat sources at the first stage of FSW. Modeling of effect of heat sources at the stage of pin plunging into the parts being 
welded is carried out in the following way. It is assumed that the pin is moved uniformly down during real plunging into the parts. At that, heat sources act on the surface of plunged part of the pin at each moment of time. Computer modeling considers the pin completely plunged into the part (Figure 2), heat sources act only on the surface of part 2 of pin plunged at current moment of time. Modeling of increase of pin plunged part 2 is discrete and made with the help of rise of time step and step of finite-element division of $E F G$ contact surface of pin 2 to part. Calculate area of vertical projection of pin plunged part 2 on plane $x \mathrm{Oz}$ (see Figure 1) at each moment of time depending on pin plunge and compute normal force for each element of surface of pin to part contact.

Plunging of pin promotes for spreading up of area of effect of heat sources in shoulder direction on the surface of pin to part contact, as shown in Figure 2. This stage is finished at the moment of complete plunging of pin into the part.

Modeling of temperature field at the second stage of FSW. Progressive movement of pin with shoulder relatively to parts being welded takes place at this stage of FSW. Modeling of movement of part points with rate $\vec{v}=\left(-v_{\mathrm{w}}, 0,0\right)$, i.e. movement in direction negative to axis $O x$ (see Figure 1), is carried out for realizing of such relative movement. In this case, boundary condition (2) is realized taking into account whole contact surface of pin and shoulder to part. Temperature in the part, which could not exceed its melting temperature $T_{\text {melt }}$, is controlled, similar to pin plunge stage. Condition (8) as well as conditions of axial symmetry of temperature field in pin and shoulder (9), (10) are realized. The rest boundary conditions, indicated in problem formulation, are realized at both stages of FSW.

Results of numerical and experimental investigations of FSW. Developed computer software was used for modeling of temperature field during FSW of copper parts, i.e. upper part 6 is welded on the lower one 5 (see Figure 1). Investigated welded parts were manufactured from copper; pin with shoulder were made from cubonit; yoke produced from hard alloy VK8; holder and shaft of drive were from steel 40 . Dimensions of elements of calculation area were used at computations: radius of pin base made $0.0045 \mathrm{~m}$, height $-0.0065 \mathrm{~m}$; radius of shoulder lower part $-0.0125 \mathrm{~m}$; dimensions of the rest elements are proportional to those indicted in Figure 3. Dimensions of parts were made: upper $0.005 \mathrm{~m}$ thick (being welded-on), lower $0.027 \mathrm{~m}$ thick, length of part make $0.1 \mathrm{~m}$ and width $0.05 \mathrm{~m}$. Since all the parts of calculation spatial

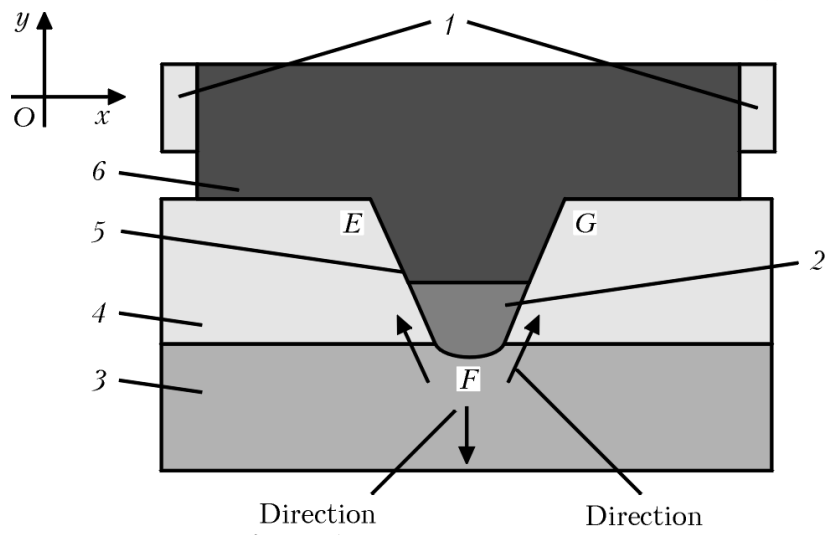

of pin plunge

of heat distribution

Figure 2. Fragment of calculation area for modeling of heat sources at stage of ping plunge into part: 1 - hard alloy yoke; 2 - part of pin volume, plunged into part at specific moment of time; 3, 4 - parts to be welded; 5, 6 - pin and shoulder of operating element, respectively

scheme are stationary in the computer model, then for examination of temperature mode of parts the calculation area of the latter was taken 2 times longer (2 times more in $O x$ axis direction). Pin rotation rate $n_{\text {rev }}=1180 \mathrm{rpm}$ and average welding speed $v_{\mathrm{w}}=0.563 \mathrm{~mm} / \mathrm{s}$.

Thermal-physical properties of copper, cubonit, hard alloy and steel 40 were selected from works [18-21]. Information on temperature dependence of copper yield strength (Figure 4) was taken from [22, 23]. Values of constant parameters are the following: $\mu_{0}=0.4, \beta_{0}=0.4$ and $\lambda_{0}=1 \mathrm{~s} / \mathrm{m}$ were taken similar to [10]; $\omega_{0}=$ $=2 \pi n_{\mathrm{rev}}, R_{\mathrm{sh}}=0.0125 \mathrm{~m}$. Coefficient of convective heat exchange $\alpha$ on upper surface of upper part and side surfaces of both parts was taken equal $20 \mathrm{~W} /\left(\mathrm{m}^{2} \cdot \mathrm{deg}\right)$ by procedure [24].

Boundary conditions of convective $(\alpha=$ $\left.=30 \mathrm{~W} /\left(\mathrm{m}^{2} \cdot \mathrm{deg}\right)\right)$ and radiation $(\varepsilon=0.6)$ heat exchanges with ambient environment at room temperature were set on side surface of steel holder and external surfaces of shoulder and hard

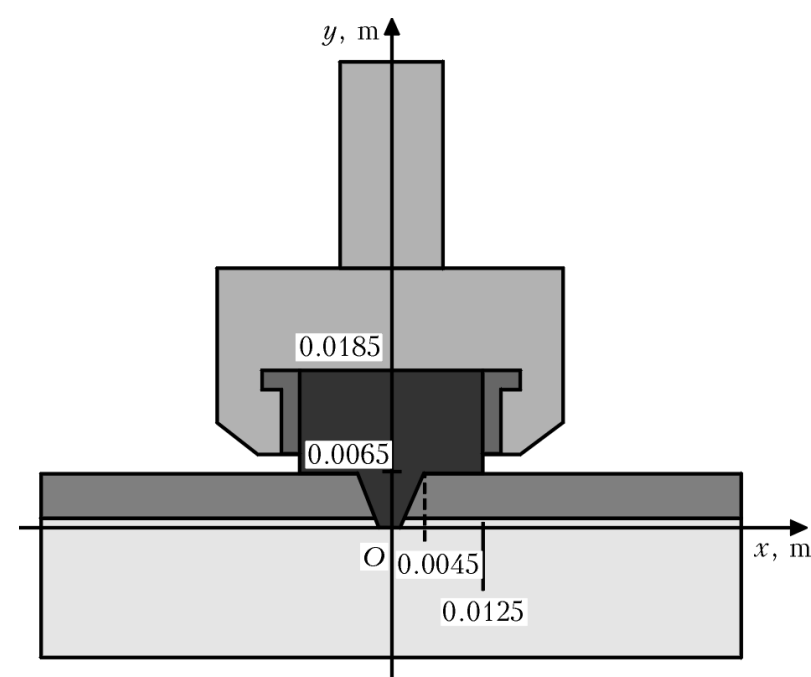

Figure 3. Dimensions of elements of calculation area 


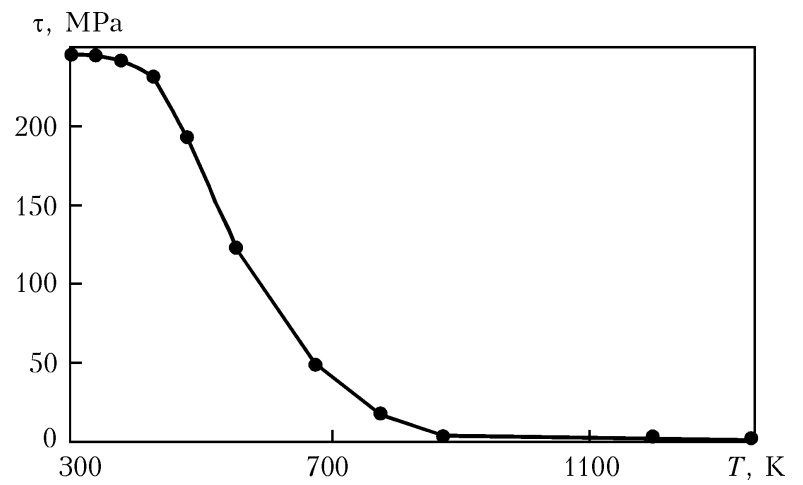

Figure 4. Temperature dependence of copper yield strength

alloy yoke. Boundary conditions of heat exchange with effective coefficient of heat exchange $\alpha_{\mathrm{ef}}$, which is changed depending on temperature in the range of $60-80 \mathrm{~W} /\left(\mathrm{m}^{2} \cdot \mathrm{deg}\right)$, were set on lower surface of lower part, upper surface of steel holder and external surface of drive rod, in the places of contact of indicated elements with massive bodies.

It is obvious fact that temperature field in welding zone significantly depends on technological mode of FSW, in particular, mechanical forces effecting pin with shoulder from drive side. It is necessary to know mechanical stresses on surface of pin and shoulder for determination of power of heat sources. The computer model determines these stresses by mechanical forces effecting pin with shoulder during FSW. There is an experiment on measurement of these forces as well as temperature in separate points of upper part. As can be seen from Figure 5, the 1st stage (pin plunging) is finished for the moment of $124 \mathrm{~s}$. Up to this time, the pin is completely plunged into upper part; the pin is only effected by vertical force, which is gradually reduced and becomes almost 2 times lower its maximum value. Process of welding is started for the moment of 124 s. Pin-shoulder system at this moment of time is effected by tangential force and rise of vertical force is observed, the latter reduces to

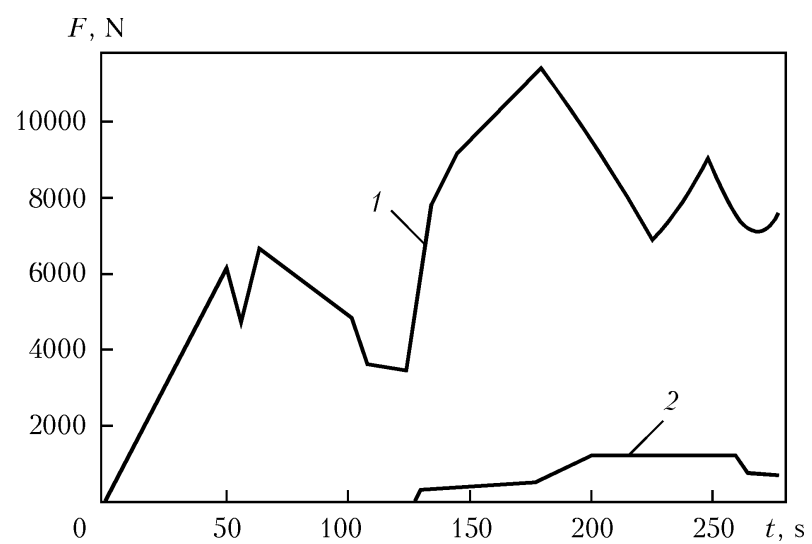

Figure 5. Mechanical loads effecting pin and shoulder during FSW (experiment): 1, 2 - vertical and horizontal constituents of force, respectively

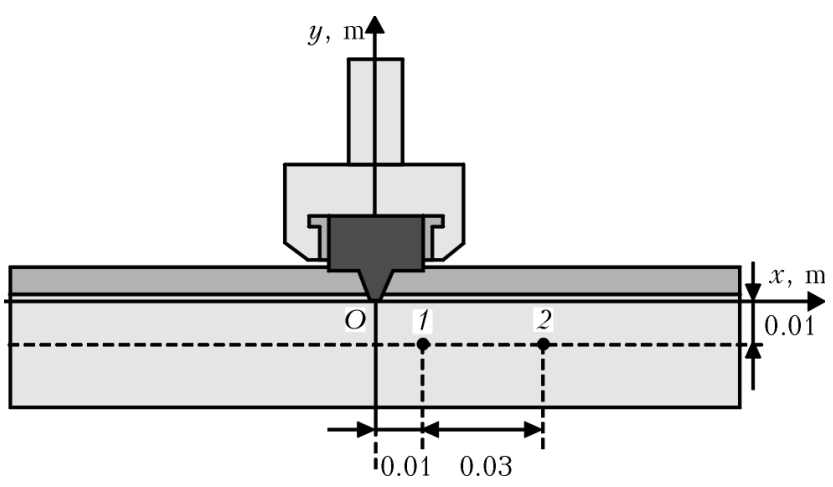

Figure 6. Scheme of positioning of thermocouples $(1,2)$ in temperature measurement during FSW

the end of welding process after achievement of its maximum. In $50 \mathrm{~s}$ after beginning of progressive movement of the parts relatively to the pin, longitudinal feed of machine drive was increased for the purpose of welding speed advance. This results in rise of forces (see Figure 5) effecting the pin with shoulder. Vertical force at the 1st stage of FSW is only applied to the pin and it promotes appearance of heat sources on the surface of pin to part contact. Vertical and horizontal forces are applied to pin as well as shoulder at the 2nd stage; now they are the reason of effect of heat sources on surface of contact of pin to part and shoulder to part. Redistribution of heat sources on the surface of contact of pin and shoulder to part takes place at this stage as can be seen below from computation results.
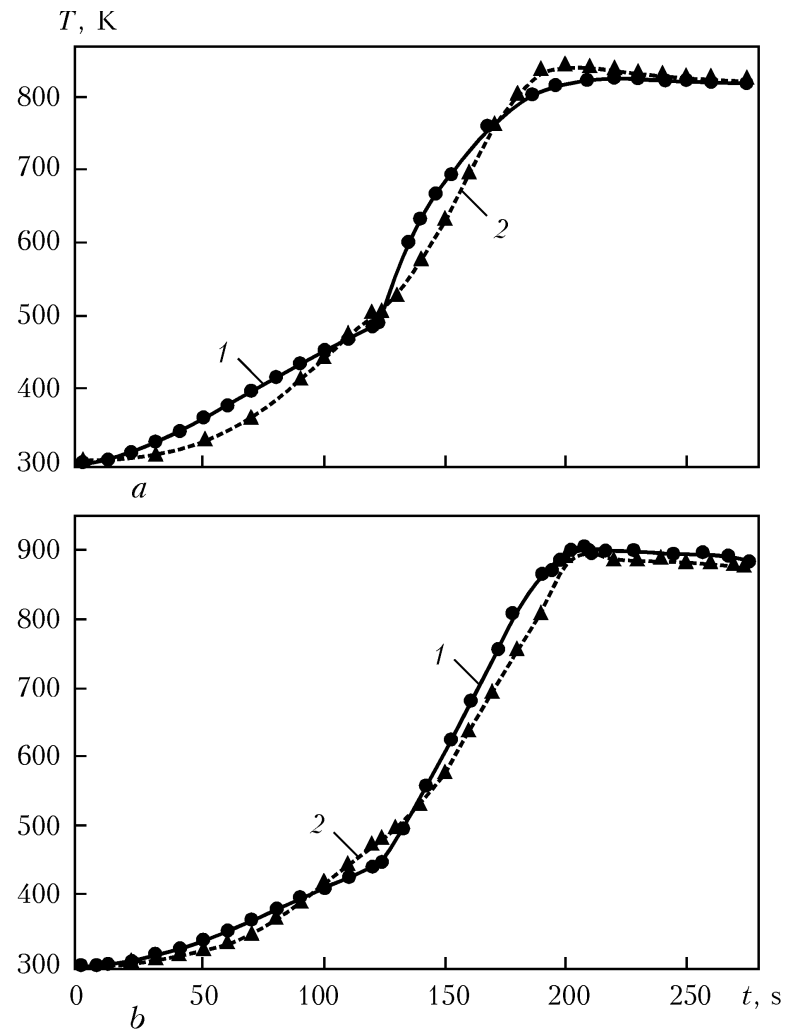

Figure 7. Results of computations (1) and measurement (2) of temperature during FSW: $a, b$ - temperature of the 1st and 2nd thermocouples, respectively 

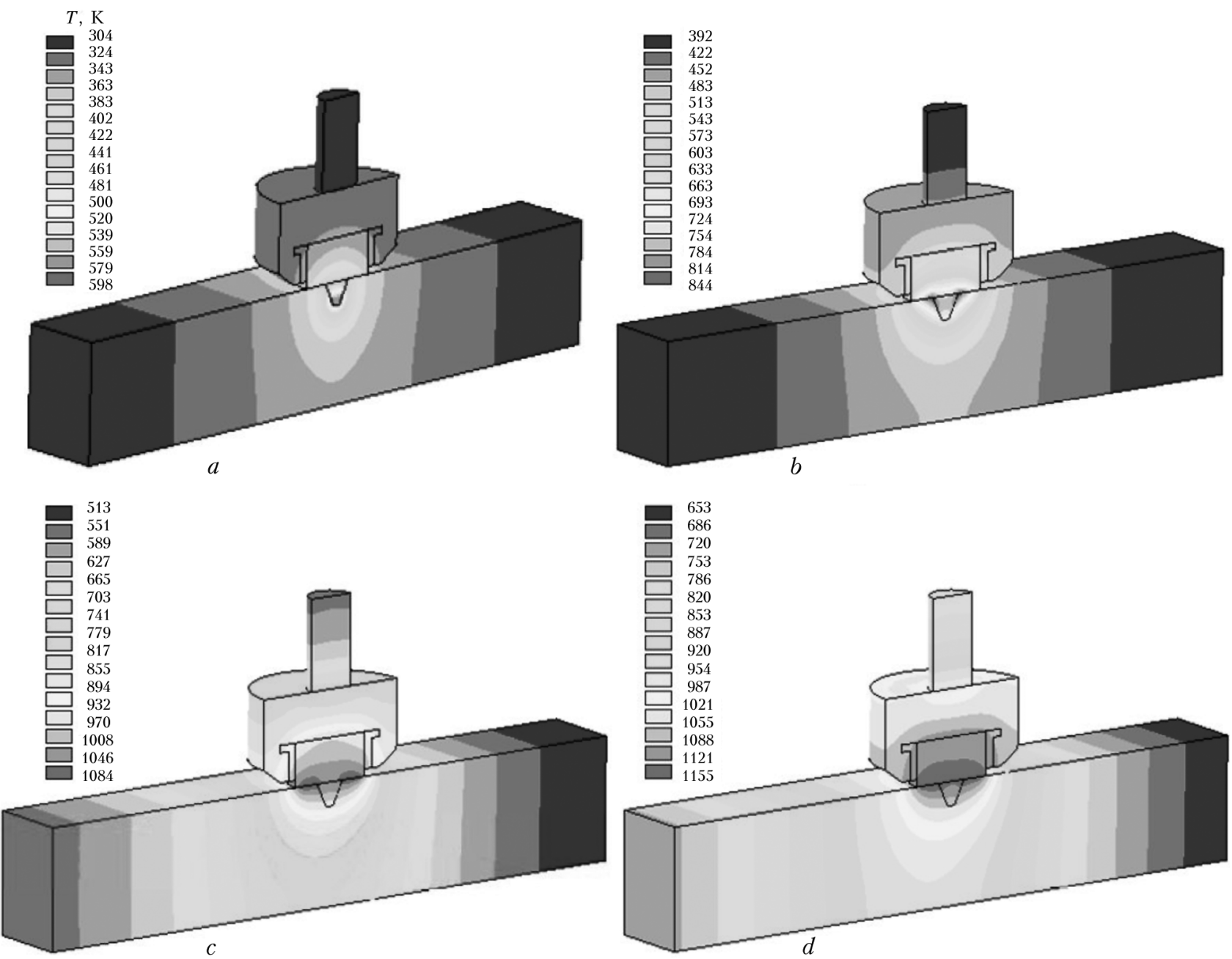

Figure 8. Temperature field at different moments of time: $a-t=60 ; b-124 \mathrm{~s}(1$ st stage of FSW); $c-180 ; d-$ 274 s (2nd stage)

Figure 6 shows a scheme for positioning of thermocouples at the points of $A B C D$ plane (see Figure 1), where temperature during FSW was measured. The results of computer and laboratory experiments are represented in Figure 7 . Their

good agreement can be seen that indicate adequacy of computer model of FSW process.

The results of computations can be used for prediction of condition of temperature field in those zones of investigated area, where the tem-
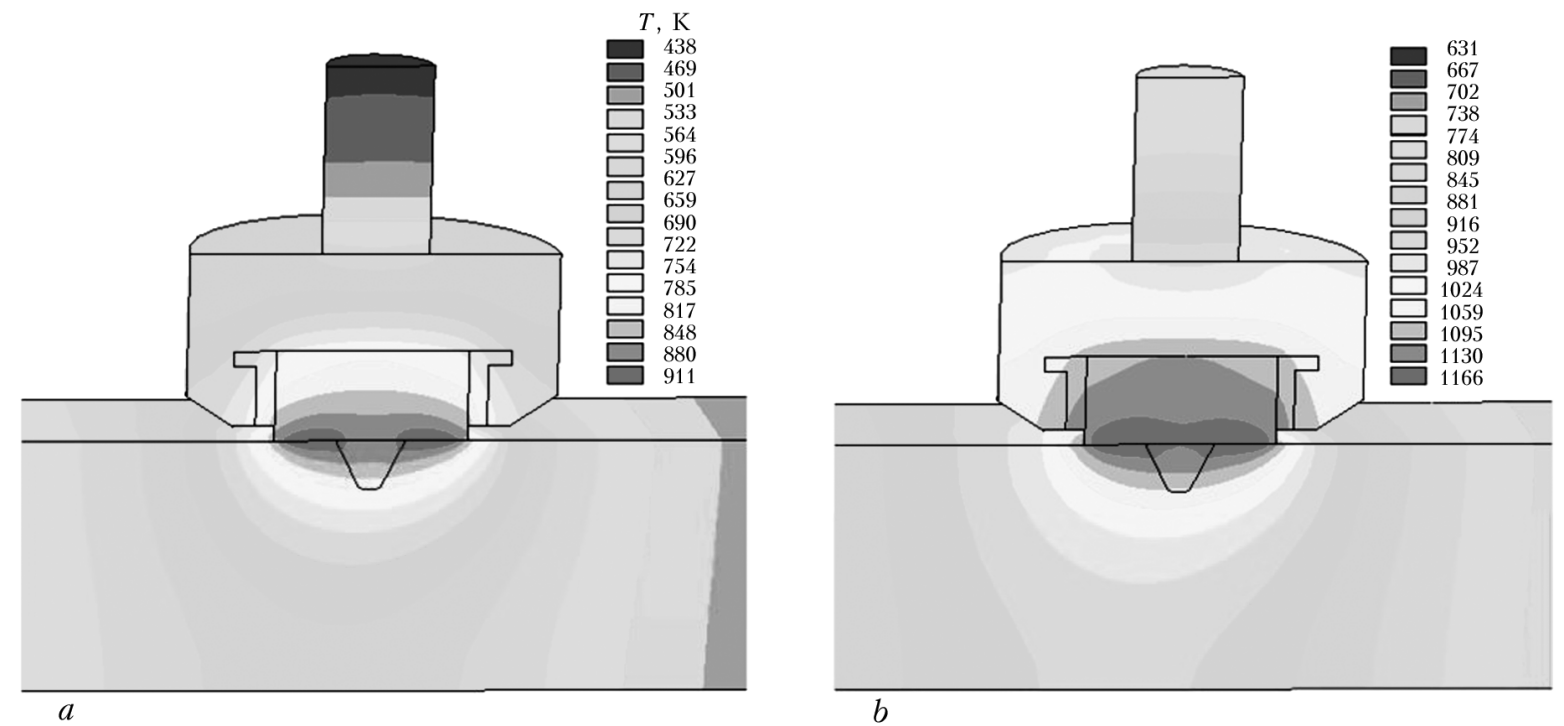

Figure 9. Fragments of patterns of temperature distribution at the 2nd stage of FSW in $25(a)$ and 125 (b) s after beginning of pin horizontal movement 
$T, \mathrm{~K}$

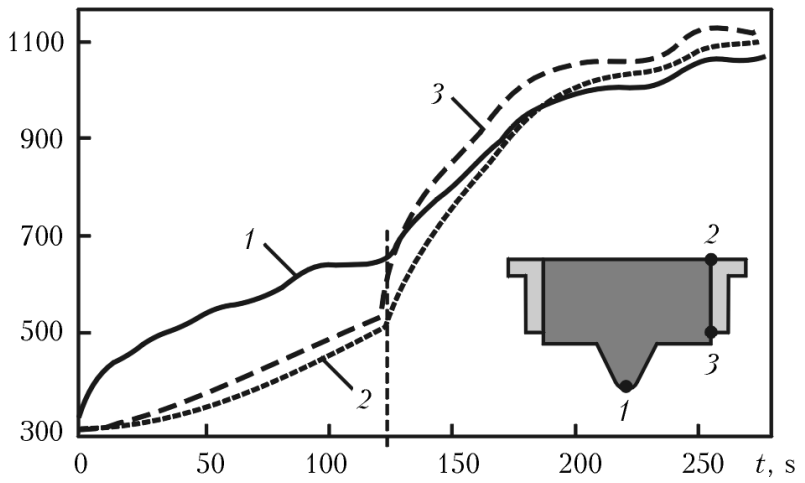

Figure 10. Measurement of temperature in pin tip (1) and two limiting points of surface of hard alloy yoke $(2,3)$ during FSW: vertical dashed line - ending of the 1st stage and beginning of the 2nd stage

perature is difficult or impossible to be measured. Besides, they give the possibility to receive some idea of evolution of temperature field during FSW. Thus, Figure 8 shows the patterns of distribution of temperature in $A B C D$ plane (see Figure 1) in successive discrete moments of time at both stages of FSW process. It can be seen that the maximum temperature lies in the zone of effect of heat sources, caused by friction and deformation of part material. The maximum temperature at the 1st stage depending on pin plunge into the part is gradually shifted from pin tip (its lower point on rotation axis) (Figure $8, a$ ) along its side surface to shoulder plane (Figure 8 , b). The maximum temperature at the moment of stop of pin plunge $(124 \mathrm{~s})$ lies in shoulder zone of joining of pin with shoulder (Figure $8, b$ ). From the moment of complete pin plunge, i.e. at the 2nd stage of FSW process, the zone of maximum temperatures is already on the shoulder surface (Figures $8, c, d ; 9$ ), that agree with the results of other authors $[25,26]$. The main amount of heat is generated in zone of shoulder to part contact at this stage, therefore, the maximum temperature (see Figure 9) is continuously maintained in this zone during the 2nd stage. This information is very important for providing of heat resistance of pin, shoulder as well as yoke (including if its cooling is necessary for prevention of tool overheating). It follows from this

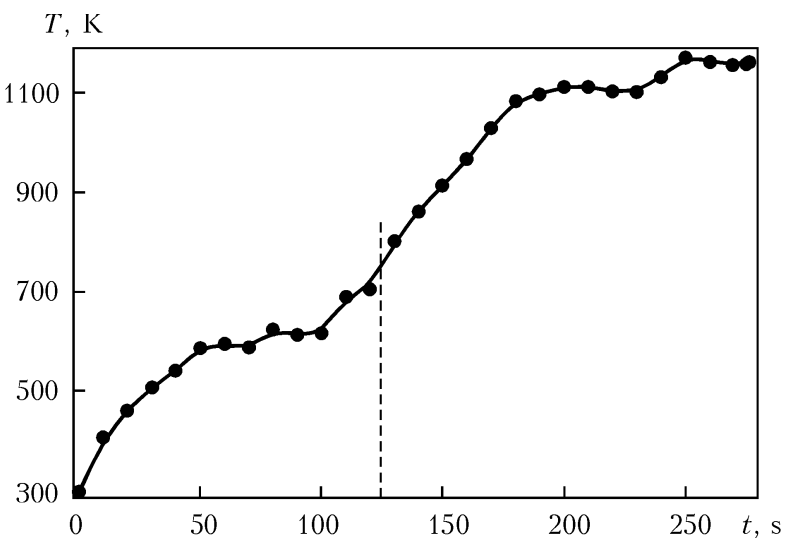

Figure 11. Time change of maximum temperature in operating element during FSW

that heat resistance of shoulder should not be lower than pin heat resistance.

Information on temperature in the most loaded zones of the tool is very important in tool operation under high temperature conditions. Such zones are pin tip, its side surface, shoulder surface being in contact with parts as well as surface of contact of pin with hard alloy yoke. This is also important in computation of heat resistance of tool for FSW. As can be seen from Figure 10, tip of the pin is more heated than surface of hard alloy yoke at the 1st stage. However, heating of the yoke becomes more intensive than pin heating at the beginning of the 2nd stage. Temperature of inner surface of the yoke becomes more than in pin tip and achieves 1090-1130 K level. Difference between this and initial (room) temperature makes $78 \%$ of the difference between copper melting temperature $(1356 \mathrm{~K})$ and room one, that agrees with data of work [2] on temperature in FSW.

According to calculations, total level of thermal (heating to 1090-1130 K temperature) and mechanical loads, mainly promoted by horizontal constituent of force (with maximum value of $1200 \mathrm{~N}$ ), with which the tool effects the part during whole process of welding (see Figure 5, curve 2), are lower than critical one for hard alloy VK6, from which the yoke is manufactured. Thus, compression yield strength for hard alloys VK6 and VK8 in temperature range 1000-1100 K is reduced from 13 to $3 \mathrm{MPa}$ [21] and based on

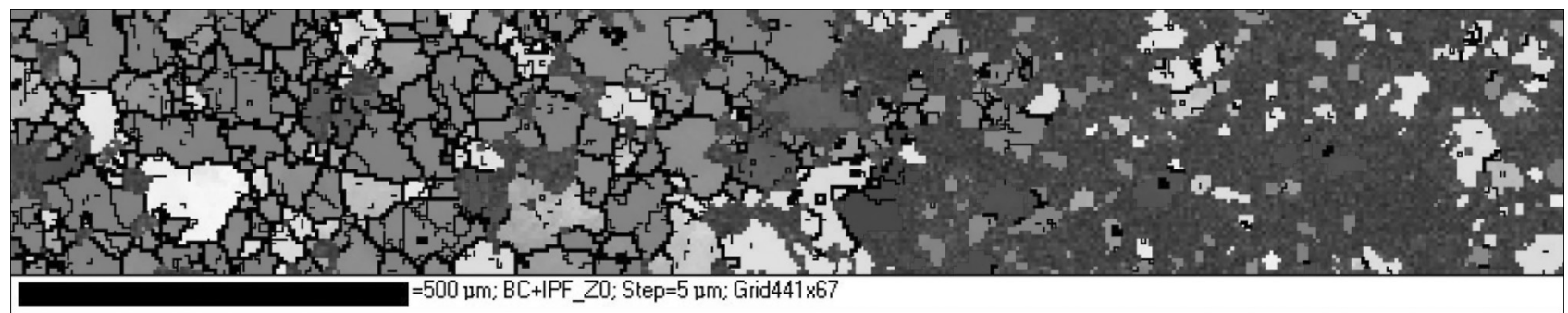

Figure 12. Structure of ML10 alloy at layer boundary in initial and modified conditions (after friction stir processing to $6 \mathrm{~mm}$ depth) 
the results of performed calculations the maximum value of normal pressure on the surface of yoke between points 2 and 3 (see Figure 10) achieves $2.54 \mathrm{MPa}$.

It allows making a conclusion on providing of mechanical durability of the tool from superhard materials for FSW of copper parts in considered welding mode. Obviously that significant increase of horizontal constituent of force (and, thus, speed of progressive pin movement) can result in exceed of yield strength of material of hard alloy yoke for normal forces and as a consequence failure of tool in whole. Therefore, parameters of FSW mode should be thoroughly selected taking into account specific relationship between speed of pin movement and speed of its progressive movement [2].

Temperature in welding zone is very important in selection of material for manufacture of tool operating element using FSW. Material of the operating element should have necessary heat resistance for providing of tool safety. Figure 11 shows that the maximum temperature in operating element is stabilized in 1050-1080 K interval (in copper to copper welding-on). This value is significantly lower than heat resistance of boron nitride, which lies in 1570-1770 K interval [27]. Thus, application of operating element from $\mathrm{cu}_{-}$ bic boron nitride with mentioned above modes of FSW process allows providing resistance of the tool.

Received technological capabilities were also used for modifying of structure of cast magnesium alloy ML10. It happens due to the effect of friction stir process on change of structural condition of surface layer of cast magnesium alloy ML10 parts welded by EBW. Modifying lied in 10-12 times grain refinement of treated layer to $6-8 \mathrm{~mm}$ depth in comparison with base metal. Structure (Figure 12) of samples from ML10 alloy with modified surface layer was examined with the help of scanning electron microscope ZEISS EVO equipped with energy-dispersive analyzer INCA PENTA Fetx3.

Change of parameters of structure of modified samples from magnesium ML10 alloy depends on parameters of tool movement (rates of rotation

Mechanical properties of welded joints of cast magnesium alloy ML10

\begin{tabular}{||l|c|c|c|c||}
\hline \multicolumn{1}{|c|}{ Sample type } & $\sigma_{\mathrm{t}}, \mathrm{MPa}$ & $\sigma_{0.2}, \mathrm{MPa}$ & $\delta, \%$ & $\psi, \%$ \\
\hline Base metal & 230.6 & 140.0 & 5.9 & 11.1 \\
\hline After EBW & 197.9 & 134.3 & 6.5 & 12.0 \\
\hline $\begin{array}{l}\text { After EBW of parts } \\
\text { with surface layers } \\
\text { modified by FSP }\end{array}$ & 216.8 & 153.9 & 6.6 & 12.5 \\
\hline
\end{tabular}

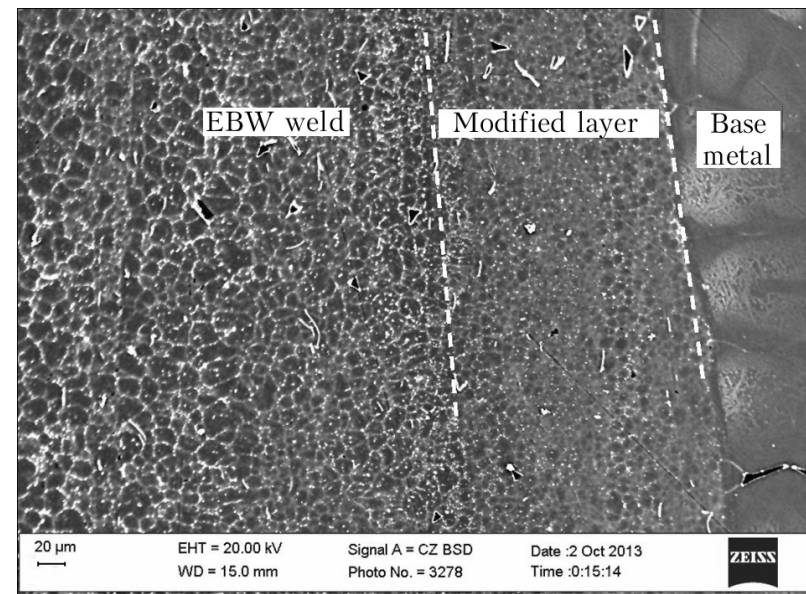

Figure 13. View of structure of welded joint from ML10 alloy with preliminary modification of surface layer $\left(v_{\mathrm{W}}=\right.$ $\left.=20 \mathrm{~mm} / \mathrm{min} ; n_{\mathrm{rev}}=630 \mathrm{rpm}\right)$ and successive EBW

and feed). Image of grain boundaries of mating layers in modified and base metal of alloy ML10, produced by method of diffraction of reflected electrons with the help of scanning electron microscope and shown in Figure 12, indicates high level of effect of modification process on change of alloy structural condition in form of significant 10-12 times grain refinement, i.e. up to $2-3 \mu \mathrm{m}$ size. Namely this peculiarity of structure change of alloy was used for further joining of parts by EBW in vacuum for the purpose of increase of weld strength (Figure 13). The peculiarity was obtained as a result of preliminary modification of surface layer of alloy structure (to $6 \mathrm{~mm}$ depth) using friction stir processing (FSP). Fractographic examination of structure of welded joint using scanning electron microscope showed that due to preliminary FSP of surface layers of part edges with successive EBW, welding already takes place over the alloy with formed finegrained structure (grain size $2-3 \mu \mathrm{m}$, see $\mathrm{Fi}$ gure 13). And alloy grain size in zone of weld metal re-solidification through liquid phase rises only to $5-6 \mu \mathrm{m}$, that $4-5$ times smaller than base

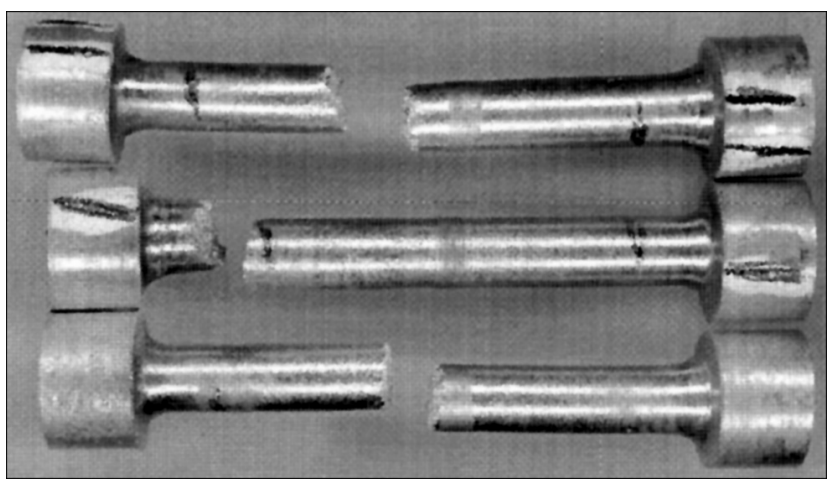

Figure 14. View of samples from alloy ML10 with FSPmodified structure of alloy layers adjacent to welded butt and then being EB-welded $\left(U_{\mathrm{acc}}=60 \mathrm{kV} ; I_{\mathrm{b}}=50 \mathrm{~mA}\right.$; $v_{\mathrm{EBW}}=20 \mathrm{~mm} / \mathrm{s} ; \Delta I_{\mathrm{f}}=5 \mathrm{~mA} ; l_{\mathrm{Op}}=200 \mathrm{~mm}$ ) after mechanical uniaxial tension tests 
metal grain size. However, the main idea is in intermediate structured fine-grained area free of hot cracks forming between re-solidification zone and base metal. Figure 13 shows structure of ML10 alloy in the modified layer as well as conventional boundaries of joining of layers after FSP.

Pull test of welded joints from magnesium alloy ML10 on cylinder samples with test portion diameter $d_{0}=3 \mathrm{~mm}$ was carried out after EBW without application of FSP and after using of hybrid technology (FSP + EBW). The tests showed that samples of ML10 after EBW without FSP fractured along fusion line. An opposite situation is observed in failure of samples treated using hybrid technology (FSP + EBW), i.e. failure takes place out of HAZ (Figure 14).

Results of comparative tensile tests of samples with welded joints, produced by standard EBW method and using hybrid technology (FSP + EBW), confirm its efficiency (see the Table).

\section{Conclusion}

Comparison of computation results and measurement of temperature field in parts to be welded allowed determining an adequacy of model based on its correspondence to experimental data. It is shown that the maximum temperature at welding stage is on shoulder surface that is important in designing of operating elements of tool for FSW. It is also shown that application of such superhard materials as cubic boron nitride and hard alloy, for manufacture of operating elements of the tool designed for FSW, provides for thermo-mechanical resistance of the tool. Developed computer software gives the possibility of on-line prediction of thermal condition during FSW of sheet parts and modifying of structure of light alloys.

Developed tools were used for preliminary FSP of surface layers of cast magnesium alloy ML10 for the purpose of their modifying. The aim of the latter is formation of alloy fine-grained structure (grain size 2-3 $\mu \mathrm{m}$ ) for its further EBW. Alloy grain size as a result of re-solidification of weld metal after EBW grows only to 5-6 $\mu \mathrm{m}$ that is $4-5$ times smaller than base metal grain size. This increases the weld joint strength in comparison with base metal strength.

1. Thomas, W.M., Nicholas, E.D., Needham, J.C. et al Friction stir butt welding. Int. pat. 5,460,317 US. Publ. Dec. 1991

2. Shtrikman, M.M. (2007) State-of-the-art and development of friction welding process of linear joints (Review). Svarochn. Proizvodstvo, 10, 25-32.

3. Zelenin, V.I., Poleshchuk, M.A., Zelenin, E.V. et al (2010) Repair of copper mold plates for steel continuous casting by method of friction stir surfacing. In: Rock cutting and metal-working tools: Technique and technology of its fabrication and application, Issue $13,476-479$.

4. Backer, J.D., Bolmsjo, G., Christiansson, A.K. (2014) Temperature control of robotic friction stir welding using the thermoelectric effect. Int. J. Adv. Manuf. Technol., 70, 375-383.

5. Ding, R.J., Oeigoetz, P.A. Auto-adjustable pin tool for friction stir welding. Pat. 005893507A US. Publ. Apr. 13, 1999.

6. (2007) Friction stir welding and processing. Ed. by R.S. Mishra, M.W. Mahoney. ASM Int. www.asminternational.org.

7. Rai, R., De, A., Bhadeshia, H.K.D.H. et al. (2011) Review: Friction stir welding tools. Sci. and Technol. of Welding and Joining, 16(4), 325-342.

8. Steel, R.J., Peterson, J., Sanderson, S. et al. (2012) Friction stir welding of $20 \mathrm{~mm}$ thickness 1018 steels. In: Proc. of 22nd Int. Offshore and Polar Engineering Conf. (Rhodes, Greece, June 17-22, 2012), 238-243.

9. Buffa, G., Fratini, L., Shivpuri, R. (2008) Finite element studies on friction stir welding process of tailored blanks. Computers and Structures, 86, 181-189.

10. Nandan, R., Roy, G.G., Lienert, T.J. et al. (2007) Three-dimensional heat and material flow during friction stir welding of mild steel. Acta Materialia, 55, 883-895.

11. Threadgill, P.L., Leonard, A.J., Shercliff, H.R. et al. (2009) Friction stir welding of aluminium alloys. Int. Mater. Rev., 54(2), 49-93.

12. Kumbhar, N.T., Bhanumurthy, K. (2008) Friction stir welding of Al6061 alloy. Asian J. Exp. Sci., 22(2), 63-74.

13. Carron, D., Bastid, P., Yin, Y. et al. (2010) Modelling of precipitation during friction stir welding of an Al-Mg-Si alloy. Tech. Mechanik, 30(1-3), 29-44.

14. Bastier, A., Maitournam, M.H., van Dang, K. et al. (2006) Steady state thermomechanical modeling of friction stir welding. Sci. and Technol. of Welding and Joining, 11, 278-288.

15. Yakimov A.V Slobodyanik, P.T Usov, A.V. (1991) Thermal physics of mechanical treatment. Kiev; Odessa: Lybid.

16. Nandan, R., DebRoy, T., Bhadeshia, H.K.D.H. (2008) Recent advances in friction stir welding Process, weldment structure and properties. Progress in Materials Sci., 53, 980-1023.

17. Majstrenko A.L. Dutka, V.A. Pereyaslov, V.P et al. (1999) Mathematical modeling of thermal state of technological assembly unit elements during process of high-speed electric sintering of diamond-containing composite materials. Sverkhtv. Materialy, 4, 26-35.

18. Shulzhenko, A.A., Bozhko, S.A., Sokolov, A.N. et al. (1993) Synthesis, sintering and properties of cubic boron nitride. Kiev: Naukova Dumka.

19. Vargaftik, N.B. (1956) Thermophysical properties of materials: Refer. Book. Moscow; Leningrad: Tekhnoenergoizdat.

20. (1958) Reference book on steels and methods of their tests. Ed. by V.K. Grigorovich. Moscow: Metallurgizdat.

21. Tumanov, V.I. (1971) Properties of alloys of tungsten carbide-cobalt system. Moscow: Metallurgiya.

22. http://www.cniga.com.ua/index.files / cuprum.htm

23. (1976) Tables of physical values: Refer. Book. Ed. by I.K. Kikoin. Moscow: Atomizdat.

24. (1982) Heat and mass exchange. Thermotechnical experiment: Refer. Book. Ed. by V.A. Grigoriev, V.I. Zorin. Moscow: Energoizdat.

25. Uyyuru, R.K., Kailas, S.V. (2006) Numerical analysis of friction stir welding process. J. Materials Eng. and Performance, 15(5), 505-518.

26. Buffa, G., Fratini, L., Micari, F. et al. (2012) On the choice of tool material in friction stir welding of titanium alloys. Proc. of NAMRI/SME, 40,1-10.

27. Lavrinenko, V.I., Smokvina, V.V. Solod, V.Yu. (2013) Peculiarities of morphology of cubic boron nitride powders and their directed application in polishing tools. Such. Tekhnol. v Mashynobuduvanni, Issue 8, 56-65. 


\title{
COMPARATIVE EVALUATION OF POWER AND TECHNOLOGICAL CHARACTERISTICS IN CONTINUOUS FLASH-BUTT WELDING OF THICK-WALLED PARTS AT DIRECT AND ALTERNATING CURRENT
}

\author{
S.I. KUCHUK-YATSENKO, P.M. RUDENKO, V.S. GAVRISH and K.V. GUSHCHIN \\ E.O. Paton Electric Welding Institute, NASU \\ 11 Bozhenko Str., 03680, Kiev, Ukraine. E-mail: office@paton.kiev.ua
}

\begin{abstract}
In the recent years the DC sources are widely applied in the equipment for flash-butt welding. At the same time there is a positive experience in AC application in such equipment. The aim of the present work consisted in comparative evaluation of power and technological characteristics of welding processes in using two power sources. The flash-butt welding of low-alloy steel plates of $25 \mathrm{~mm}$ thickness using continuous flashing was performed using AC and DC power sources. The influence of high-frequency pulsations of voltage in DC welding on reactance of welding circuit, conductivity of diodes of rectifier and stability of flashing process was studied. The phenomenon of overvoltages as a result of transition processes in welding circuit in flashing was explained. It was shown that at the same heating of specimens the consumption of electric power in DC welding is $15 \%$ higher than at alternating one. The macrorelief of flashing surface in DC welding is better by its quality than that at alternating one. 4 Ref., 1 Table, 10 Figures.
\end{abstract}

Key words: flash-butt welding, continuous flashing, direct current, alternating current, power parameters, high-frequency pulsations, technological characteristics

In the last decade the application of equipment for flash-butt welding (FBW) using sources of direct current has been widely spread. This was contributed by the new designs of powerful rectifiers, providing currents in welding circuit of machines of up to $100 \mathrm{kA}$ and higher. The most part of this equipment is designed for resistance welding (spot, projection ones). The application of direct current provides in this case a uniform loading of three phases of mains, and in some cases gives some technological advantages, in particular, more uniform distribution of current in the zone of heating of parts being welded and increase in efficient capacity generated in the welding zone.

These advantages are extremely important also in FBW, especially for parts with large cross sections and thicknesses of walls when high power is consumed calculated in hundreds of kilowatts-amperes. In industry the machines for FBW of $400-500 \mathrm{kV} \cdot \mathrm{A}$ capacity are successfully used providing currents in welding circuit of up to $80 \mathrm{kA}$ [1]. However, the field of their application is mainly limited with welding of rails. Here, as the basic technology the welding with interrupted preheating by resistance and the fol- lowing short-period flashing is used, for which not more than 10-15\% of the total energy input is consumed. In this case the application of direct current except of three phase loading of mains at a constant set power of $400-500 \mathrm{kV} \cdot \mathrm{A}$ allows considerable reducing of welding duration due to increase of current density during resistance preheating.

At the E.O. Paton Electric Welding Institute the technologies with continuous flashing without resistance preheating of parts of different steels and alloys with large cross sections of up to $100,000 \mathrm{~mm}^{2}$ and wall thickness of up to $100-$ $150 \mathrm{~mm}$, which are successfully implemented in industry (welding of pipes of oil-gas assortment of $50-1420 \mathrm{~mm}$ diameter with wall thickness of 5-30 mm, rails, metallurgical rolled metal). In welding of parts with large cross sections the task of increasing the power values at continuous flashing is also very urgent, especially in searching for possibilities of decreasing resistance of the secondary contour $Z_{\text {sh.c }}$. All the developed technologies of welding the parts with large cross sections using continuous flashing [2] are based on using equipment with a low resistance $Z_{\text {sh.c }}$, which provides excitement of flashing at low voltages and specific set power values.

The aim of this article is the comparative evaluation of power and technological charac- 
SCIENTIFIC AND TECHNICAL

Comparison of power characteristics in continuous FBW of steel plates of $25 \times 50 \mathrm{~mm}$ section using DC and AC power sources

\begin{tabular}{||c|c|c|c|c|c|c||}
\hline \hline Power source & $\begin{array}{c}U_{2 j}, \mathrm{~V} \\
\text { (op.c/welding) }\end{array}$ & $I_{2}, \mathrm{kA}$ & $Q_{1}, \mathrm{~kW} \cdot \mathrm{s}$ & $Q_{\mathrm{ex}}, \mathrm{kW} \cdot \mathrm{s}$ & $Q_{j}, \mathrm{~kW} \cdot \mathrm{s}$ & Efficiency factor \\
\hline $\mathrm{DC}$ & $6.7 / 4.7$ & $\frac{2.0-2.6}{2.3}$ & $\frac{1310-1509}{1414}$ & $\frac{1060-1241}{1148}$ & $\frac{929-1073}{1015}$ & $\frac{0.70-0.74}{0.70}$ \\
\hline $\mathrm{AC}$ & 6.8 & $\frac{1.6-2.1}{1.8}$ & $\frac{1052-1320}{1188}$ & - & $\frac{878-1054}{971}$ & $\frac{0.77-0.84}{0.80}$ \\
\hline $\begin{array}{l}\text { Note. } U_{2 j}-\text { secondary voltage on jaws (clamps) of welding machine (parts being welded); } I_{2}-\text { measured average current in the secondary } \\
\text { circuit for direct current and efficient for alternating current; } Q_{1}-\text { efficient power in the primary circuit of welding transformer; } Q_{j}- \\
\text { efficient power on jaws of welding machine (parts being welded); efficiency factor }=Q_{j} / Q_{1} .\end{array}$
\end{tabular}

teristics in welding of parts of low-alloyed steels using continuous flashing at direct (rectified) (DC) and alternating (AC) current. As the basic technology, welding the circumferential welds of pipes of modern pipelines using continuous flashing, thick-walled pipes of $1220-1420 \mathrm{~mm}$ diameter, $25 \mathrm{~mm}$ thickness of steels of strength class X70-X80 was used. The typical program of changing the main parameters in FBW of such pipes is given in Figure 1. The multi-year experience of developments of technologies of pipe welding shows that specific power values remain similar both in flashing along the entire area of pipe section, and also in its separate sectors cut out around the perimeter of pipe. Therefore, welding of specimens of $25 \times 50 \mathrm{~mm}$ section, cut out from a pipe, using the DC and AC source was performed at the following modes:

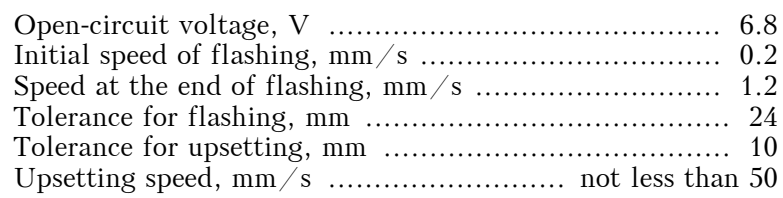

The edges of specimens, the same as in welding of full-scale pipes, had edges bevel to provide the flashing excitement. Here unlike welding of pipes the change in speed of flashing $v_{\mathrm{fl}}$ to detect

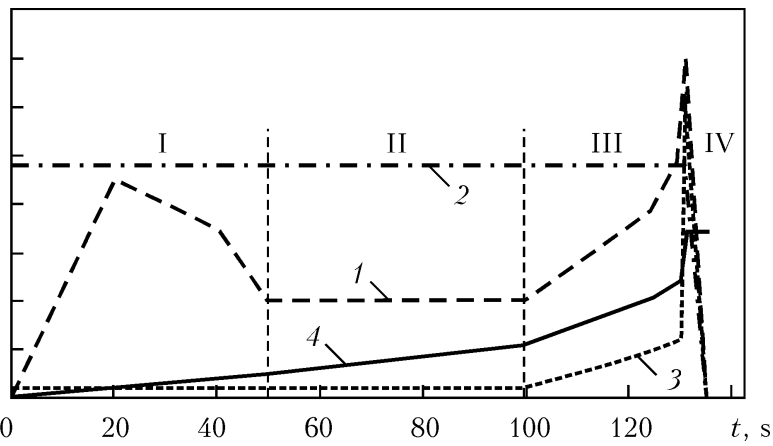

Figure 1. Typical program of change of main parameters in welding of pipes with $25 \mathrm{~mm}$ wall thickness: I - fusion of edges bevel (flashing excitement); II - heating; III accelerated flashing; IV - upsetting; 1 - current; 2 voltage; 3 - speed; 4 - movement (cyclograms are identical for DC and AC) the periods of possible unstable flashing was preset strictly according to the program without its automatic correcting.

As the basis of accepted methods for conductance of experiments the similarity of technology, equipment and accompanied processes in welding of batches of specimens at alternating and direct current was taken. The welding in both cases was performed in universal machine K724 of design of the E.O. Paton Electric Welding Institute with the transformer of $150 \mathrm{kV} \cdot \mathrm{A}$ capacity. After welding of batches of specimens in it at the frequency of $50 \mathrm{~Hz}$, welding transformer was removed and three-phase rectifier of «RoMan» company of $180 \mathrm{kV} \cdot \mathrm{A}$ capacity was connected to the welding circuit. The impedance of machine after its re-equipping using rectifier was preserved $Z_{\text {sh.c }}=240 \mu \mathrm{Ohm}$ (measured at the frequency of $50 \mathrm{~Hz}$ ), effective resistance of $96 \mu \mathrm{Ohm}$.

During flashing of specimens the control of temperature in HAZ was carried out.

All the welded specimens were tested according to the API International standards. The parameters of welding process were recorded and calculated using computer system and software designed by the authors of the article. The frequency of inquiry of each channel of measurement of current and voltage was $10 \mathrm{kHz}$. The results of experiments are given in the Table.

In both cases the average power consumption $Q_{j}$ used for heating does not exceed $5 \%$, which evidences of high stability of processes of metal heating. The intensity of heating sources is also featured by stability, which is confirmed by measurements of temperature fields in welding of specimens of test batches (Figure 2). In DC welding the temperature of both welded test specimens was measured. The temperature fields of zones of heating of the parts, being cathode and anode in flashing, were not much different, which can be predetermined by additional influence of arc discharges generated after fracture (explosion) of local contacts. However, these differ- 


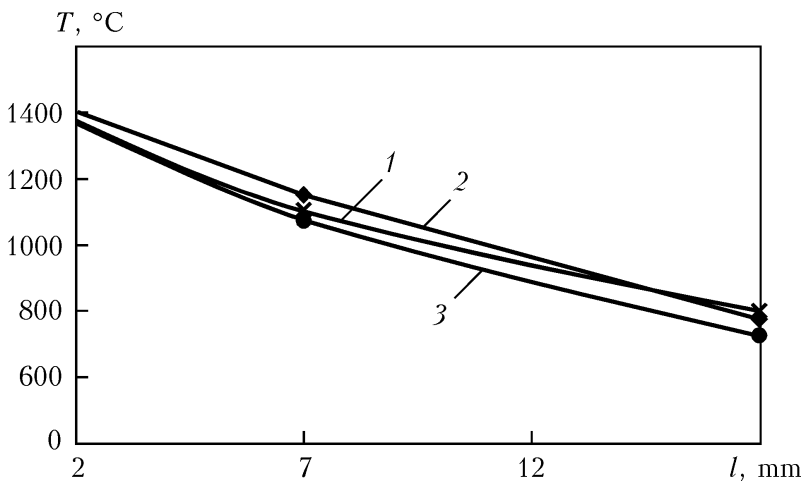

Figure 2. Distribution of temperature in welding zone during flashing before upsetting: 1 - heating using alternating current; 2, 3- heating anode and cathode using rectified current, respectively

ences can not considerably influence the quality of welding because of their small value.

The general power consumption $Q_{1}$, consumed in welding from mains is by $15 \%$ higher in flashing at direct current, and efficiency factor is relatively lower than in flashing at alternating current. Relatively low efficiency factor at direct current is predetermined by sufficiently high resistance of diodes in welding circuit, which leads to additional power losses.

It should be noted that use of high power rectifiers for FBW is not very rational from the economic point of view as compared with the resistance welding. Figure 3 shows the typical characteristic of modern rectifies for the resistance welding. The admitted values of current depend greatly on relative duty cycle and duration of welding current $t$. Such rectifiers are the most power-saving in using at strictly limited duty cycle, being not more than 10-15\%. At duty cycle equal to $20 \%$ the admissible currents are 1.7-2 times reduced. Most machines for spot and projection welding are operating almost in the same mode. During their use for resistance welding when duty cycle reaches $30-50 \%$, the admissible currents are 2.2-2.8 times decreased. Respectively, it becomes necessary to increase the capacity of rectifiers and create cooling systems for them, thus complicating the equipment and increasing the power losses.

According to the procedures of works after welding of two batches of specimens on the base mode it was supposed to perform the separate DC welding at lower voltage $U_{2 \text { op.c }}=6.5 \mathrm{~V}$ to reveal the influence of resistance $Z_{\text {sh.c }}$ in DC welding. However, at decrease of voltage by less than $6.8 \mathrm{~V}$ the stable flashing process was not managed to be obtained, as a result of short circuiting of edges the flashing interrupted. The dependencies, characterizing the changes of voltage on clamps of current conducting jaws and

$$
I_{\mathrm{w}}, \mathrm{kA}
$$

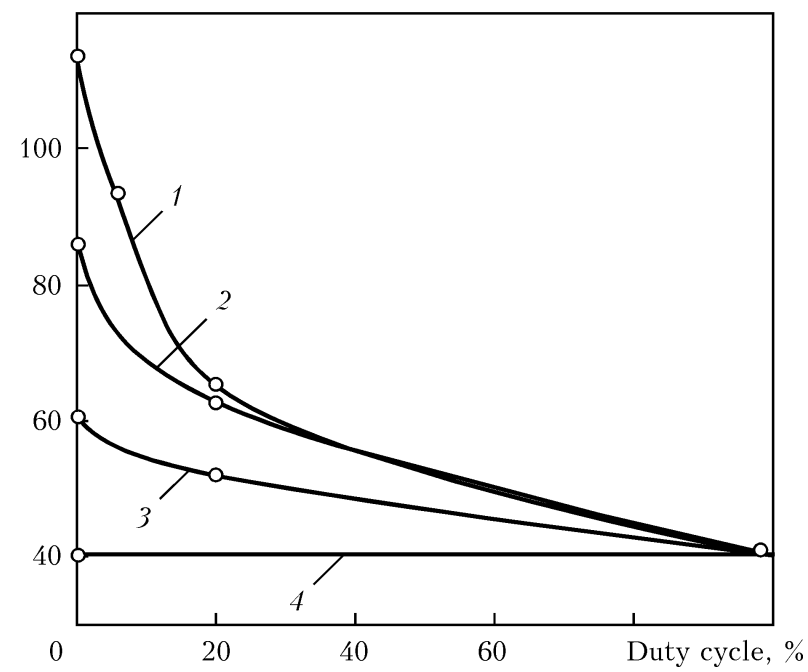

Figure 3. Dependence of current of loading on duty cycle at $t=0.06$ (1), 0.1 (2), 1 (3) and more than 2 (4) $\mathrm{s}$

efficient power, which is generated in contact between the parts [3], are given in Figure 4. From their comparison it is seen that maximum efficient power generated in the contact is approximately the same in both cases and the drops of voltages at the loads close to $15 \mathrm{kA}$ have also the close values. Therefore, the limits of possible admissible increase of conductivity are close. The margin of increase of stability of flashing process at direct current is exhausted by drop of voltage by $2 \mathrm{~V}$ even at the initial period of load current increase. Actually, the flashing process is proceeding at the lower drop of voltage at spark gap than at alternating current. At this area the dynamics of increment of power with increase in conductivity of spark gap is also lower than at

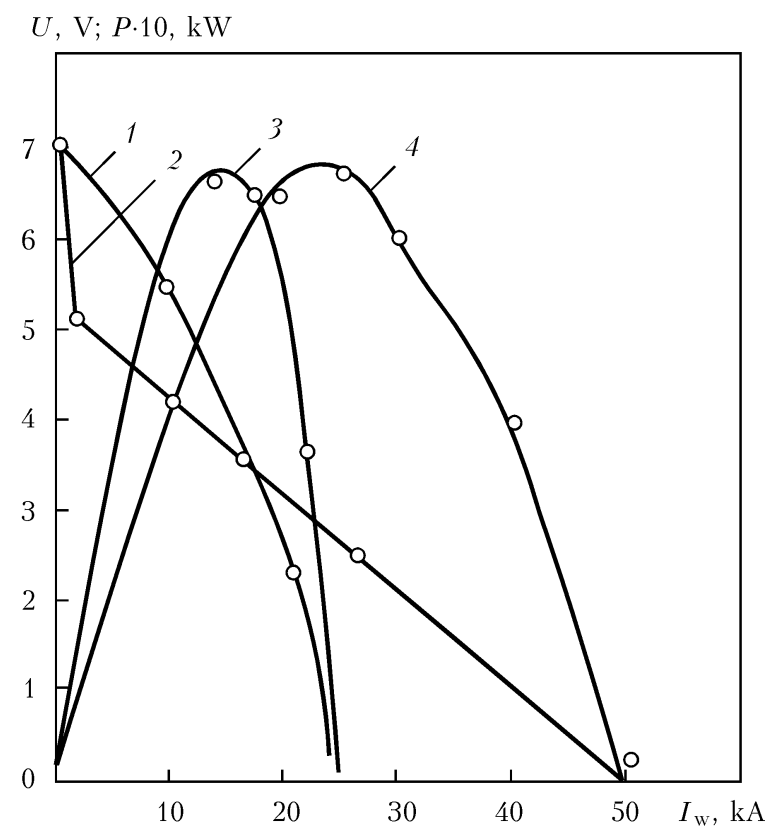

Figure 4. Dependences of voltage $(1,2)$ and power $(3,4)$ on current in welding circuit respectively at alternating (1, $3)$ and direct $(2,4)$ current $\left(U_{\text {op.c }}=7 \mathrm{~V}\right)$ 

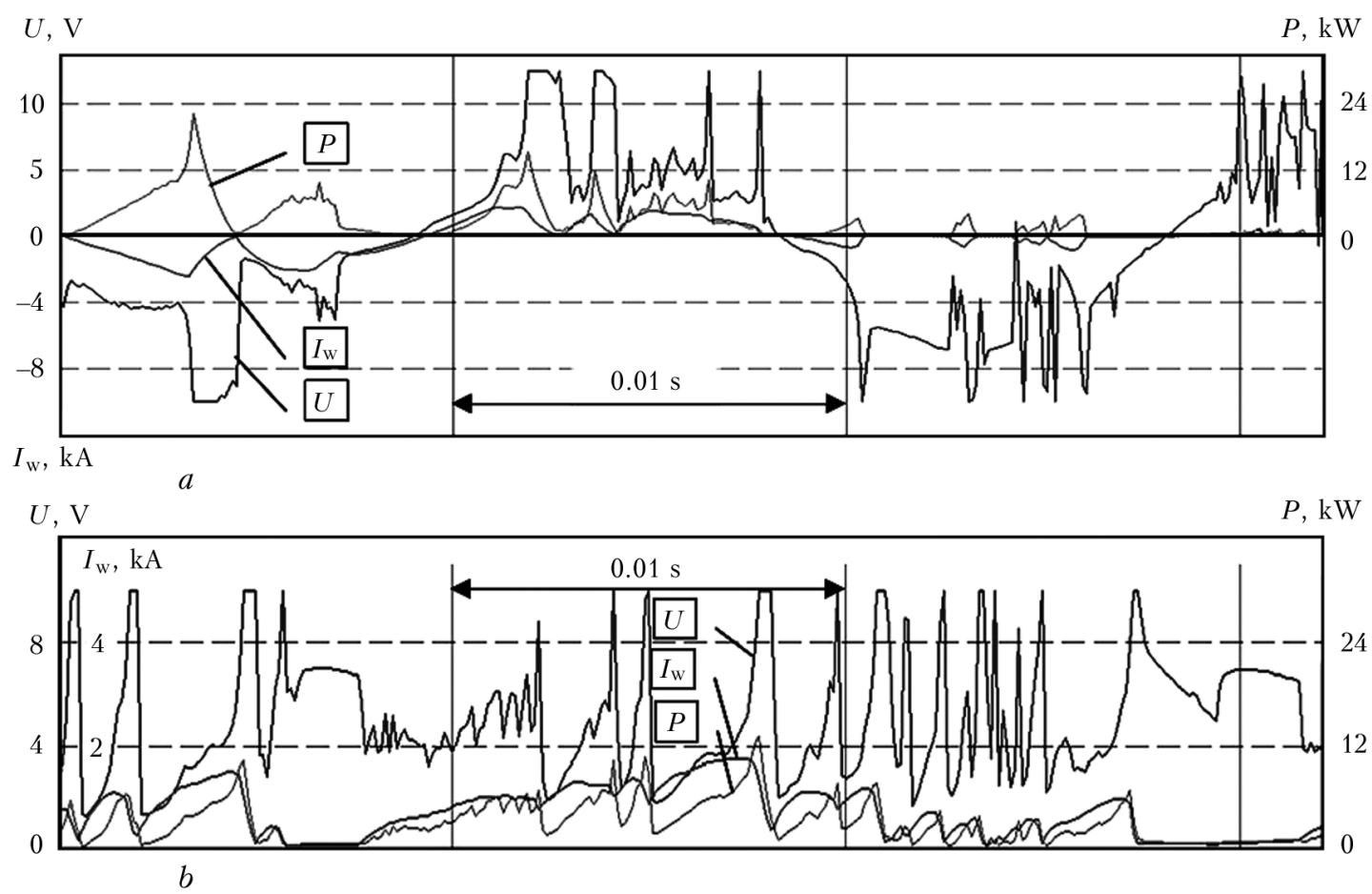

Figure 5. Oscilogram of welding current, voltage and power generated for heating in flashing in the period II at alternating (a) and direct (b) current

alternating current, which does not facilitate the increase of stability of flashing process. The mentioned drop of voltage on diodes is characteristic and inseparable feature of change in their conductivity under load.

The recording of flashing process of specimens at direct and alternating current in the flashing period II is given in Figure 5. Such flashing process is considered to be stable, where there is no long break ups in passing of current and short circuits, at which the current is several times increased in relation to the average values of current in flashing. Such evaluation is quite conditional as far as the process of continuous flashing is interruptive as to its nature. Small interruptions $(0.02-0.03 \mathrm{~s})$ and short-period increase of current, classified as short circuits of $0.01-0.02 \mathrm{~s}$ duration, does not considerably influence the stability of heating and process stability. In this case these data can be used in comparative quality evaluation of process at different stages of its realization according to the program.

The most critical from the point of view of probable violations of process are periods I and III of the program. In the period I the probability of short circuits, when the process of flashing is interrupted, is the highest. Therefore, most often in welding using flashing, including pipes using the program given in Figure 1, the controllers are used, which automatically decrease the speed of flashing and eliminate short circuits. In the process of welding of test batches of specimens such controllers were not used, which allowed revealing the potential possibilities of DC and $\mathrm{AC}$ sources to the greater extent. The most critical from the point of view of influence of stability of flashing on the quality of joint is the period III of the program. Even negligible interruptions and short circuits, not exceeding the fraction of a second, in the period preceding upsetting can result in formation of non-quality joints.

The results of analysis of recording of flashing process at all the stages of the program are given in Figure 6. In the period II of flashing the duration of pauses in passing of current is almost $10 \%$ higher at alternating current as compared to direct one. With increase of flashing speed in the period III at direct current the 1.5-1.8 times higher increase of duration of periods of short circuits is observed than that occurring at alternating one, which evidences of decrease of margin of stability of flashing process before upsetting.

The characteristic feature of oscillograms in FBW is the presence of pulses of high frequency at voltage and current curves (see Figure 5). It is assumed that they are formed at explosions of elementary contacts and can serve as a criterion for evaluation of their number. In work [2] it is shown that pulsations occur during melting of single contacts of large area when their overheating is observed accompanied with boiling and explosion-like evolutions of metal vapors. Their duration is considerably shorter than the real time of heating of contacts of sufficiently large 


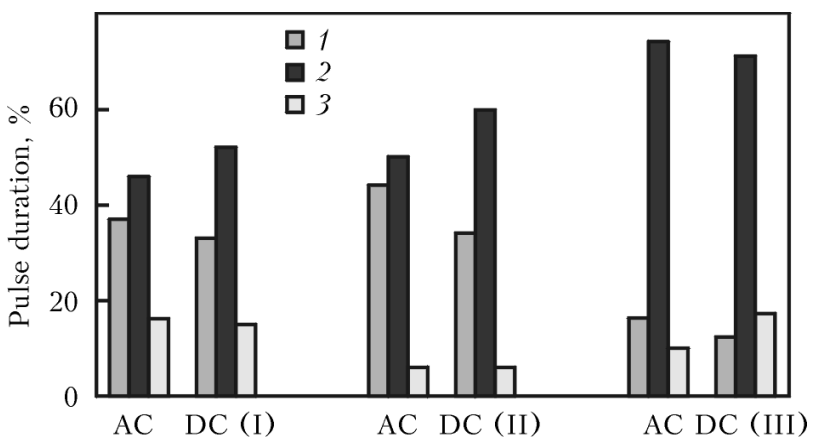

Figure 6. Diagram of relations of duration of interruptions in passing of current (1), short circuits (2) and pulses of current in flashing (3)

area, forming the relief of flashing surface. Pulses of high frequency are differed by amplitude values, duration and depend on the flashing period. The average frequency of pulsations is growing with heating of parts in flashing process, and also in the final period of flashing before upsetting. At the comparable frequency of pulses of welding voltage the number of pulses at direct current almost 2 times higher than at alternating one. It is connected with the fact that flashing and spark formation are excited at instant values of voltage at the clamps after reaching the level of more than 3-4 V. If more than a little of a half of sinusoid corresponds to this condition at alternating current (see Figure 5, $a$ ), then at direct current it is always fulfilled (see Figure 5, b).

As is seen from the records of welding voltages made using digital oscillograph (Figure 7) the amplitude of pulses for direct current is by minimum $25 \%$ higher than that for alternating one, and their duration is relatively shorter. To explain this phenomenon of overvoltages and evaluation of electric parameters of pulses on the oscillogram of voltage on the jaws of FBW machine, let us study the electric diagram of model of welding process at direct current given in $\mathrm{Fi}$ gure 8. Let us neglect the effective resistance of secondary contour and then consider the source $e$ as a DC source.

At the absence of diode $D$ and short circuit of key $K$ we will have a transition from the mode of open circuit to the mode of flashing, then the total voltage $U$ on the resistors and duration of transition process $\tau$ :

$$
U \approx e(1-0.99 \exp (-t R / L)), \quad \tau=L / R .
$$

At disconnection of key $K$ we will have a transition from the mode of flashing to the open circuit mode:

$$
U \approx e(1+100 \exp (-t 101 R / L)), \quad \tau=L / 101 R .
$$

Thus, the jump of voltage at jaws of welding machine at interruption of contact and transition

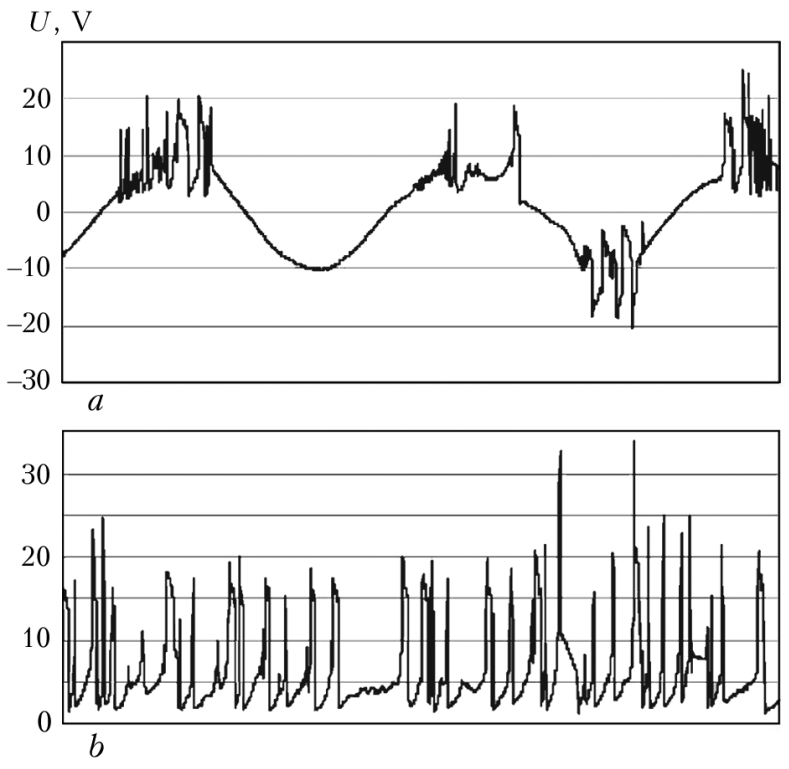

Figure 7. Voltage at jaws of FBW machine with AC (a) and DC (b) source at $t=50(a)$ and $25(b) \mathrm{ms}$

to the open circuit is considerably higher than at appearance of contact (in our example the correlation is $100 / 0.01$ ); the duration of pulses or time of transition process is much shorter than in reverse transition (in our case 1/100).

Due to a very short duration of transition process $\tau$ one can assume also that the spectrum of these pulses is composed of high-frequency harmonics, at which the rectifying diodes lose their properties on rectifying and resistance of diode is significantly increased. It results in great values of amplitude of pulses at direct current as compared to alternating current.

As a result of high-frequency pulsations of voltages the influence of reactivity of welding circuit in DC welding is obvious.

It follows from the given data that a part of pulses of high frequency, observed on oscillograms in DC welding, is not directly connected with melting of single contacts and is a consequence of influence of reactance of welding circuit in DC welding. Alongside, during the comparative analysis of shape of curve of voltage and

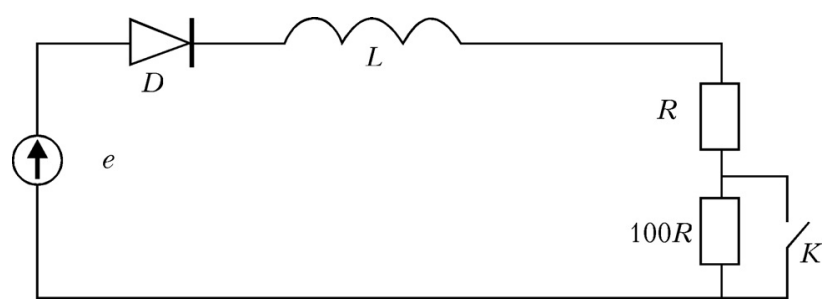

Figure 8. Electric circuit of model of flashing process at direct current: $e$ - voltage at the input of secondary circuit of welding machine (output of power transformer); $D-$ rectifying diode in the DC source; $L$ - inductance of secondary circuit; $R$ - conditional resistance of parts in flashing; $100 R-$ conditional transition resistance of flashing parts at transition from the mode of flashing to the open circuit mode 

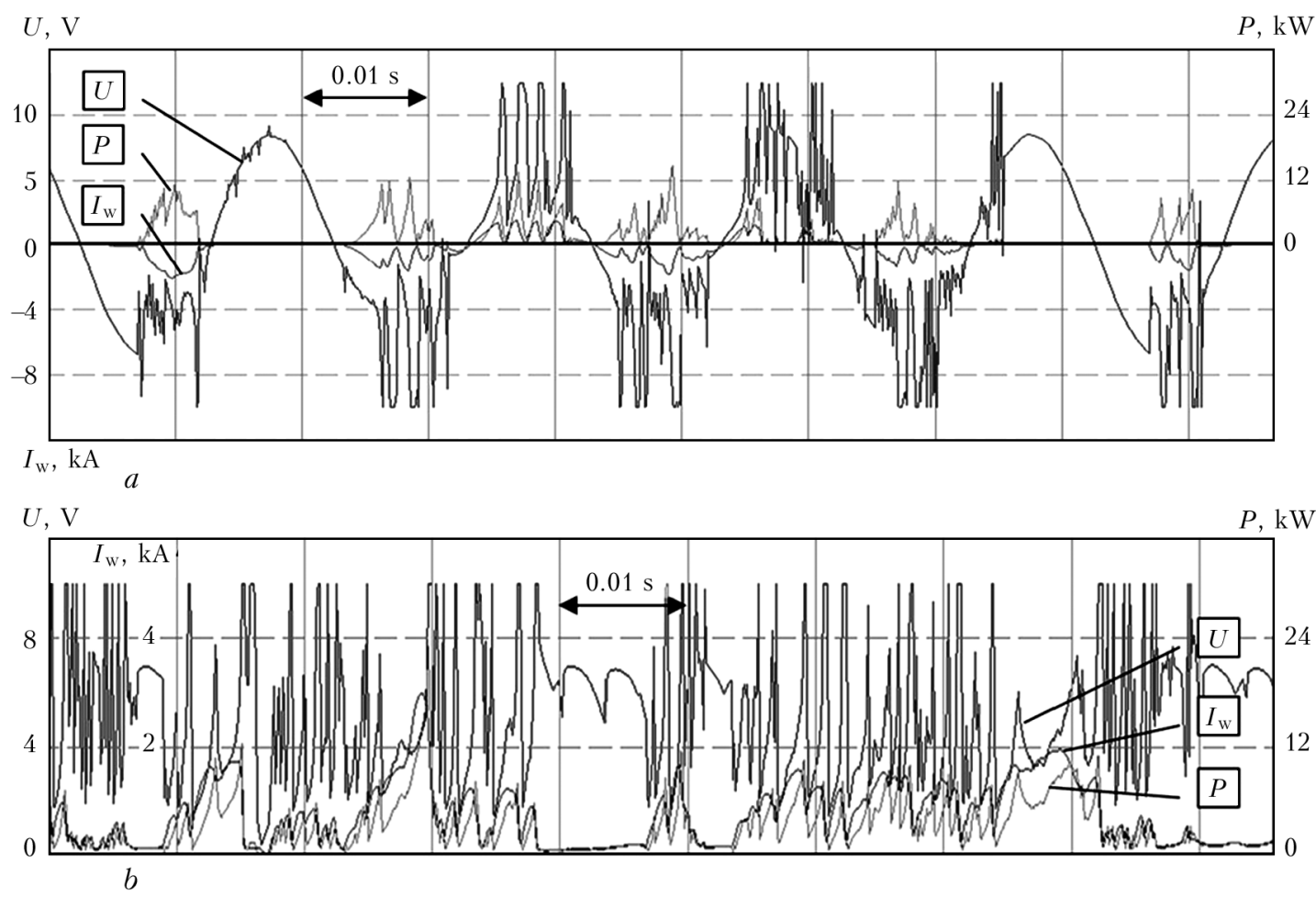

Figure 9. Oscilogramm of welding current, voltage and power at alternating $(a)$ and direct $(b)$ current at flashing before upsetting

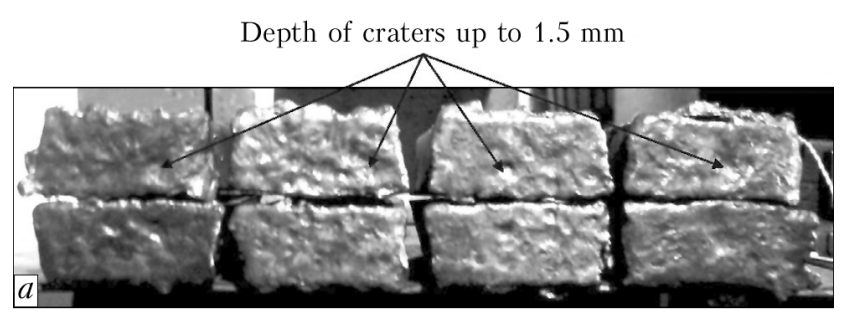

Depth of craters up to $1.0 \mathrm{~mm}$

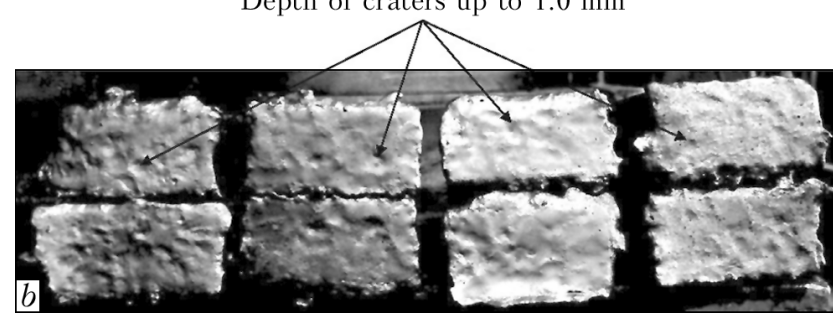

Figure 10. Surface of flashing of specimens after interruption of the process before upsetting at alternating $(a)$ and direct $(b)$ current

current at direct current the attention should be paid to pulsations of voltage and current of sufficiently long duration accompanied by increase of efficient consumed power. The similar pulsations are observed in AC flashing. As is seen from oscillograms taken in the period preceding the upsetting (Figure 9), it is possible to distinguish the separate pulses of a higher duration (more than $2 \mathrm{~ms}$ ) from the pulses of current of increased frequency, at which increase of efficient power is observed. There is bigger number of such pulses in flashing at alternating current. The interruption of flashing process in these periods allowed establishing that the maximum depth of craters, formed at the surface of flashing at direct current, amounts to 1.0 and at alternating one is $1.5 \mathrm{~mm}$ (Figure 10).

The mentioned distinctions in formation of flashing surface did not have influence on quality of joints, which is proved also by other investigations [4] obtained during flashing of thinwalled products. Thus, during flashing at direct current more flat surface of flashing is formed and the probability of formation of different defects in plane of a joint is lower. The mentioned distinctions in formation of flashing surface did not have influence on quality of joints of specimens produced at alternating current according to the similar mode.

The carried out comprehensive mechanical tests of batches of specimens, welded at the given mode at alternating and direct current, proved their complete correspondence to the requirements of the standard.

\section{Conclusions}

1. Application of direct current in FBW using continuous flashing of thick-walled parts of lowalloyed steels does not give essential advantages, which could be expected in connection with decrease of resistance of welding circuit, in particular, to obtain stable flashing at lower open-circuit voltages. 
2. To the number of characteristic features of DC flashing process the reduction of duration of interruptions in passing of current in flashing and also increase of frequency and amplitude of pulsations of voltage and current, resulted by boiling of metal, should be referred. It is shown that this feature of the process is predetermined by change in conductivity of diodes of rectifier in the specified spectrum of high-frequency harmonics of welding current.

3. In DC flashing some decrease of depth of craters at the surface of flashing is observed. In welding of test batches of specimens at the same modes at direct and alternating current the stable quality of joints was obtained corresponding to the standard requirements, which evidences of negligible influence of this process parameter on quality of joints of the mentioned thickness. Obviously, its positive influence on formation of joints can be expected in welding of parts of large thickness (50 $\mathrm{mm}$ and more).

4. In welding at direct current the total power consumption is by $15 \%$ higher than at alternating current, and the efficiency factor is relatively lower ( 0.7 at $\mathrm{DC}$ and 0.8 at $\mathrm{AC})$, which is predetermined by additional losses of power in rectifiers.
5. The intensity of heating sources at direct and alternating current is almost the same. In welding at the same modes the similar heating of metal in HAZ is provided necessary for formation of the quality joints.

6. During re-equipping of $\mathrm{FBW}$ machines from alternating to direct current the necessity of repeated increase of number of modules of DC rectifier as compared to the similar re-equipping of machines for spot and projection welding should be taken into account. This considerably increases its cost and operation costs, in particular, connected with cooling of diodes.

1. Kuchuk-Yatsenko, S.I., Nejlo, Yu.S., Gavrish, V.S. et al. (2010) Prospects of increasing energy characteristics of flash butt welding (Review). The Paton Welding J., 2, 23-27.

2. Kuchuk-Yatsenko, S.I. (1992) Flash butt welding. Kiev: Naukova Dumka.

3. Kuchuk-Yatsenko, S.I., Rudenko, P.M., Gavrish, V.S. et al. (2010) Energy characteristics of the processes of flash-butt welding at alternating at direct currents. The Paton Welding J., 12, 22-26.

4. Sidyakin, V.A., Orlov, B.D. (1969) Flash-butt welding of thin-walled parts at direct current. Svarochn. Proizvodstvo, 9, 22-24. 


\title{
EVALUATION OF OPERABILITY OF THE MAIN PIPELINE WITH LOCAL WALL THINNING AT REPAIR BY ARC SURFACING
}

\author{
E.A. VELIKOIVANENKO, G.F. ROZYNKA, A.S. MILENIN and N.I. PIVTORAK \\ E.O. Paton Electric Welding Institute, NASU \\ 11 Bozhenko Str., 03680, Kiev, Ukraine. E-mail: office@paton.kiev.ua
}

\begin{abstract}
Welding surfacing is one of the most rational methods of repairing the main pipelines without taking them out of service, particularly in the case of the need to eliminate typical defects of local metal loss through corrosion. Here welding application on a pipeline, which is at high internal pressure, envisages a thorough optimization of technological parameters of this process in terms of safety and effectiveness of repair-andrenewal operations, in particular, on the base of the results of modeling the occurring physico-mechanical processes kinetics. In this study a package of tools was developed for mathematical modeling of the process of multipass welding surfacing of thinning defects of the main pipeline elements to predict their technological strength and post-repair residual life. For this purpose an integrated approach of numerical analysis of the kinetics of temperatures, stress-strain state and processes of tough fracture of pipeline material has been implemented. A numerical criterion has been proposed, which allows, with a slight conservatism, prediction of formation of structure state, close to the limiting one, as well as guaranteeing the required load-carrying capacity of the pipeline, after repair of the detected defect of discontinuity type. The case of multipass surfacing repair of an inadmissible defect of the main pipeline wall thinning was used to study the characteristic peculiarities of the influence of the main technological parameters on the structure technological strength and its residual life. 17 Ref., 1 Table, 6 Figures.
\end{abstract}

$\boldsymbol{K} \boldsymbol{e} \boldsymbol{y} \boldsymbol{w} \boldsymbol{o} \boldsymbol{r} \boldsymbol{d} \boldsymbol{s}:$ arc surfacing, main pipeline, defect, local wall thinning, repair under pressure, safety of repairand-renewal operations, plastic instability, tough fracture

Maintaining the operability of main pipelines (MP) involves a package of measures on non-destructive testing of their actual state, evaluation of residual life, allowing for the detected service damage, as well as repair-and-renewal operations in the sections with inadmissibly low static strength. MP common defects are external surface local metal losses of corrosion origin, caused by the impact of aggressive media in the region of violation of insulating coating integrity. In view of considerable extent of MP systems, elimination of such defects by capital repair is labourconsuming and requires long downtime in MP operation. One of the techniques, allowing elimination of defects detected by technical diagnostics with minimum reduction of product throughput volumes, is repair by welding, in particular, welding surfacing [1, 2]. Application of local welding heating here involves temporary weakening of pipeline wall that makes the question of the structure technological strength at surfacing urgent in terms of guaranteeing the required level of repair safety.
A number of foreign and national studies [3-5 etc.] are devoted to this problem. In them the questions of technological strength in repair welding of pipelines without shutting them down, are usually divided into two conditional classes: evaluation of development of structural transformations, mechanical stresses and diffusion processes in the structure metal in terms of minimizing the risk of appearance of welding defects (first of all, cold cracks); and analysis of the kinetics of temperature and strain field, in order to determine conservative modes of local welding heating, allowing prevention of burnsthrough or excess distortion in the repair section.

Influence of welding process on steel susceptibility to cold cracking, has been studied well enough, and a well-established practice of guaranteeing absence of such defects in the surfacing area is preheating up to $100-150{ }^{\circ} \mathrm{C}$ that was reflected in currently valid standards and norms $[6,7]$. The second problem class is more complicated, as it includes multidimensional analysis of interrelated processes of kinetics of temperature, stress and strain fields in welding, as well as prediction of possible initiation and propagation of micro- and macrofracture of the structural element. At present, two main criteria of tech- 
nological parameters optimization in defect surfacing in operating MP can be singled out.

1. Battelle criterion [8]

$$
T_{\text {in.max }}<T_{\text {in.c r }}=720 \div 980{ }^{\circ} \mathrm{C} \text {, }
$$

where $T_{\text {in. max }}$ is the maximum temperature on pipeline inner surface during surfacing; $T_{\text {in.cr }}$ is the critical temperature, dependent on the used electrode type.

2. Criterion based on model 46345 [9]

$$
d r<d r_{\mathrm{cr}} \sim 1 \mathrm{~mm},
$$

where $d r$ is the maximum radial distortion of the wall in the heating area as a result of internal pressure impact; $d r_{\text {cr }}$ is the critical strain value.

There also exist a number of alternative criteria, in particular, the approach earlier proposed by PWI specialists, which consists in tracing the evolution of isothermal surface $T_{\text {def }}=1000{ }^{\circ} \mathrm{C}$, and evaluation of admissibility of such an area as a thinning defect [5], similar to CRC / CSIRO model [10]. All the above-mentioned procedures allow realization of simple in practical application, but maximum conservative engineering criteria, not allowing for a number of important aspects of welding surfacing, for instance, pipeline internal pressure and geometry for condition (1), degree of melting and temperature dependencies of mechanical properties of a specific steel for (2). This is related, in particular, to the problem of selection of criterial parameters $\left(T_{\text {in.cr }}\right.$, $\left.d r_{\text {cr }}, T_{\text {def }}\right)$, which are not fracture resistance characteristics of structure material and require either experimental precising for each specific case of service damage, or significant conservatism for sufficiently wide applicability.

Within the bounds of this study, with the purpose of further development of methodological fundamentals of analysis of the safety and effectiveness of multipass surfacing in operating $\mathrm{MP}$, a package of kinetic models of interrelated physico-mechanical processes characteristic for this technology have been developed, and respective criteria of structure integrity preservation have been proposed. Peculiarities of pipeline condition, determining both its technological strength during repair welding, and its performance in subsequent operation, have been analyzed in the case of multipass surfacing of an external defect of MP wall thinning under internal pressure.

Numerical analysis was based on calculated kinetics of the temperature field, determined by solving the equation of heat conductivity with temperature-dependent thermophysical characteristics of the material [11]. Subsequent tracing of elasto-plastic strains within the bounds of finite-element solution of boundary problem of nonstationary thermoplasticity was used to calculate the kinetics of the structure stress-strain state [12]. At each tracing step the relationship between the components of tensors of stresses $\sigma_{i j}$ and strains $\varepsilon_{i j}$ was defined by generalized Hooke's law and associated plastic flow rule, proceeding from the following relationships:

$$
\begin{gathered}
\Delta \varepsilon_{i j}=\psi\left(\sigma_{i j}-\delta_{i j} \sigma_{m}\right)+ \\
+\delta_{i j}\left(K \sigma_{m}+\Delta \varepsilon_{m}+\Delta f / 3\right)- \\
-\frac{1}{2 G}\left(\sigma_{i j}-\delta_{i j} \sigma_{m}\right)^{*}+\left(K \sigma_{m}\right)^{*},
\end{gathered}
$$

where $K=(1-2 v) / E^{*} ; G=E /(2(1+v)) ; E$ is the Young's modulus; $v$ is the Poisson's ratio; $\delta_{i j}$ is the Kronecker symbol; $\psi$ is the material state function, determined by iteration to satisfy the plastic flow condition; $f$ is the volume concentration of microdiscontinuity, initiating during material fracture; $\sigma_{m}=\sigma_{i j} / 3$ is the membrane stress; $i, j=\{r, \beta, z\}$ according to Figure 1 ; here summation is performed by repeated symbols.

Optimization of repair technological parameters is based on the ability of MP defective section to take complex load from internal hydrostatic pressure $P_{r}$ at the moment of performance of repair-and-renewal operations, alongside temporary welding stresses in the surfacing area. Therefore, an important step is selection of rational criteria, which guarantee the integrity of pipeline wall for the considered case. As violation of material continuity in arc surfacing repair of local thinning of pipeline wall occurs at high temperatures in the absence of sharp-angled geometrical raisers, the prevailing fracture mechanism is the tough fracture, which consists in initiation and propagation of material micropores at intensive plastic deformation [13]. This, eventually, leads to formation of macrodefects and violation of structure integrity. As demonstrated by the authors in [14], change of load-carrying net-section of the material after it has reached limit loads, should be additionally taken into account

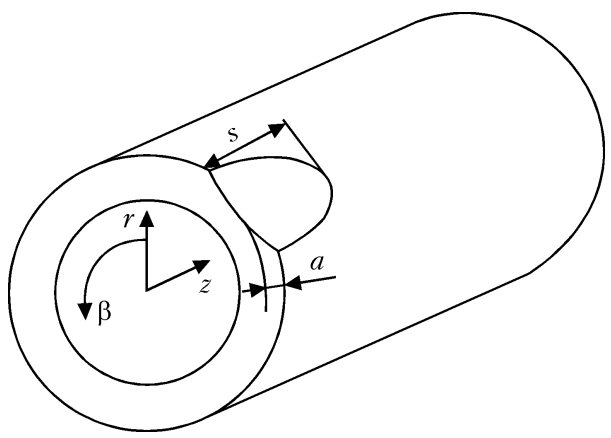

Figure 1. Schematic of pipeline section with local wall thinning (in cylindrical system of coordinates) 
at definition of the problem of nonstationary thermoplasticity for correct evaluation of the structure limiting state. One of the recognized approaches is use of material yield surface, allowing for uniformly distributed discontinuity within the bounds of Gurson-Tvergaard-Needleman model [15]:

$$
\left\{\begin{array}{l}
\psi=\frac{1}{2 G,} \text { if } \sigma_{i}<\sigma_{s}=\sigma_{\mathrm{y}} \times \\
\times \sqrt{1+\left(q_{3} f\right)^{2}-2 q_{i} f \cosh \left(q_{2} \frac{3 \sigma_{m}}{2 \sigma_{\mathrm{y}}}\right)}, \\
\psi>\frac{1}{2 G}, \text { if } \sigma_{i}=\sigma_{s},
\end{array}\right.
$$

where $q_{1}=1.5, q_{2}=1, q_{3}=1.5$ are the constants; $\sigma_{i}=\sqrt{\sigma_{i j} \sigma_{i j} / 2}$ is the stress intensity.

Thus, the criterion of pipeline wall integrity preservation at surfacing is absence of plastic instability of porous material that is mathematically expressed by the following condition:

$$
\psi<\frac{1}{2 G}+\frac{\varepsilon f-\kappa^{*}}{1.5 \sigma_{i}(\kappa, T)(1-2 f / 3)},
$$

where $\kappa^{*}$ is the Odqvist parameter, referred to the previous step of tracing the elastoplastic strains; $\varepsilon_{f}$ is the ultimate strain of metal dependent on the stressed state rigidity, according to [12].

Moreover, considerable development of material porosity by the tough mechanism causes an essential increase of true stresses in the structure metal, and its fracture as a result of it. Therefore, a further condition can be added to (5) with the purpose of definition of a criterion of MP integrity preservation, which is correct and convenient for numerical analysis, as follows:

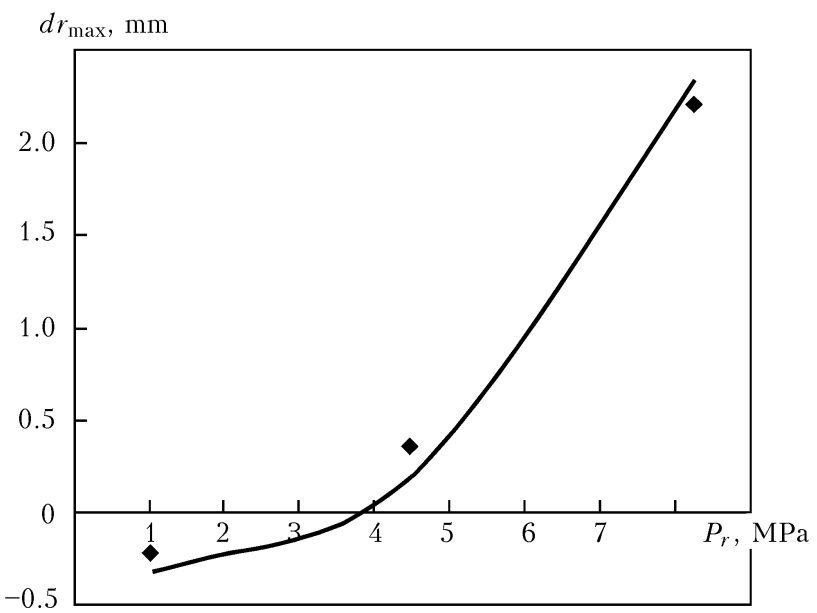

Figure 2. Comparison of calculated values of pipeline wall residual radial distortions after surfacing with experimental data [11]

$$
\left(q_{3} f\right)^{2}-2 q_{1} f \cosh \left(q_{2} \frac{3 \sigma_{m}}{2 \sigma_{\mathrm{y}}}\right) \rightarrow 0 .
$$

Models of pore initiation and propagation right up to fracture in pipeline elements with geometrical anomalies, are given, in particular, in [14].

An important factor of effectiveness of the considered repair procedure, which is not allowed for in its optimization criteria (1) and (2), is residual postweld deformed state of the structure. During local heating, the defect area acquires excess radial displacement $d r_{\text {res }}$ under the impact of internal pressure. In fact, the detected defect of pipe wall local thinning is transformed into a shape defect after surfacing under pressure, the admissibility of which is determined by pipeline analysis for static strength. Here, the position of shape defect coincides with the deposited beads that makes higher requirements to the quality of welding operation performance and to subsequent nondestructive testing in terms of guarantee of welding defect absence.

Admissibility of shape defect is determined, in particular, by national standard [16], according to the requirements of which the safety factor of a pipe with defect $n$ should be not smaller than the admissible value of $k$ [17]:

$$
n \geq k=\frac{0.9 k_{1} k_{\mathrm{p}}}{m},
$$

where $k_{1}, k_{\mathrm{p}}$ are the safety factors by material and purpose, respectively; $m$ is the coefficient of pipeline operation conditions.

Thus, simultaneous fulfillment of conditions (5)-(7) is a complex numerical criterion of optimization of welding surfacing technological parameters. Proposed complex models were verified proceeding from the data on stress-strain state of model pipeline samples (diameter $D=219 \mathrm{~mm}$, wall thickness $t=3.2 \mathrm{~mm}$, material - API 5L steel) at different values of internal pressure $\left(P_{r}=1.03-8.47 \mathrm{MPa}\right)$ at deposition of two circumferential beads on them [9]. Figure 2 gives comparison of calculation results with experimental data. It should be also noted that in keeping with the developed procedure of evaluation of pipeline limiting state at surfacing, plastic instability for the considered case is found at the pressure of about 8.6 MPa. Studying the microstructure of an experimental sample deposited at the pressure of $8.47 \mathrm{MPa}$, revealed initiation of material discontinuities in the region of maximum deformation that corresponds to the ingress of its limiting state. The above-said leads to the conclusion that the results of numerical studies 
within the bounds of the proposed numerical analysis procedure, describe with sufficient accuracy the behaviour of pipeline elements in welding surfacing.

Characteristic features of the limiting state and the effectiveness of this approach, in particular, its conservatism, compared to criteria (1) and (2) were studied in the case of welding surfacing repair of thinning defect of length $2 s=$ $=140 \mathrm{~mm}$ and depth $a=10 \mathrm{~mm}$ on external surface of pipeline of $D=1420 \mathrm{~mm}$ with wall thickness $t=20 \mathrm{~mm}$ from steel 17G1S $\left(\sigma_{\mathrm{y}}=\right.$ $\left.=490 \mathrm{MPa}, \sigma_{\mathrm{t}}=560 \mathrm{MPa}\right)$ with maximum operating pressure $P=7.4 \mathrm{MPa}$. An isolated defect of local thinning of MP wall was considered as a semi-elliptical surface geometrical anomaly, which was surfaced in two layers by the following schematic, given in Figure 3. It was assumed that pipeline section with the detected defect was preheated up to temperature $T_{\mathrm{pr}}$ to avoid cold cracking. Accordingly, repair parameters are welding current $I$, internal pressure in the pipeline at surfacing $P_{r}$, as well as the time between deposition of each of the beads, ensuring maintenance of maximum metal temperature, not lower than the required $T_{\min } \geq T_{\mathrm{pr}}$.

To illustrate the relationship of conservatism of criteria (1) and (2) and numerical criterion (5) $-(7)$, Figure 4 gives the result of calculation of the dependence between value of pipeline wall maximum radial distortion $d r$ in the area of welding heating and maximum temperature of the inner surface for deposition of one bead (in the defect center) at repair parameters, recommended by the currently valid standards: $I=$ $=80 \mathrm{~A}, P_{r}=4 \mathrm{MPa}, T_{\mathrm{pr}}=100{ }^{\circ} \mathrm{C}$. As is seen from this dependence, maximum compliance of the wall to internal pressure $\left(d r_{\max }=1.17 \mathrm{~mm}\right)$ is observed not at maximum temperatures of heating the pipeline metal or its inner surface, but at certain heat propagation to the periphery of surfacing area. Therefore, monitoring the extent of wall distortion during welding according to (2) is not rational, as the process of heated area cooling is difficult to monitor after deposition of a specific bead. Moreover, the balance between the increasing strength of cooling metal and growing stresses in the area of local bending of the pipe wall, determining the pipeline limiting state, is difficult to predict without the respective multidimensional analysis of thermomechanical processes. This confirms the rationality of the proposed approach to evaluation of the limiting state in terms of minimizing its conservatism. Moreover, bead deposition in the center of a rather deep defect causes local overheating, ex-

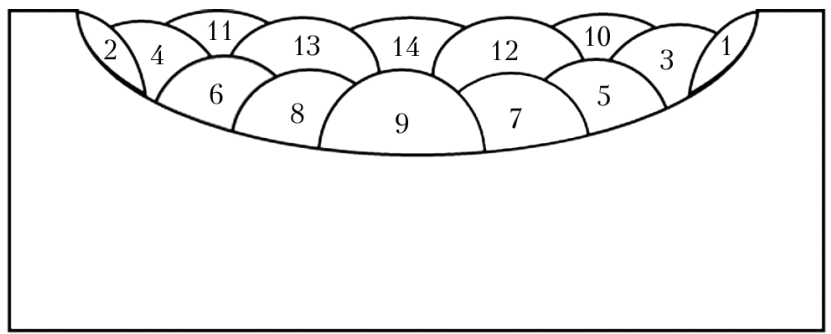

Figure 3. Schematic of surfacing repair of thinning defect on pipeline external surface

cess distortion of the wall and non-fulfillment of criterion (2), whereas criteria (1) and (5)-(7) confirm the pipe integrity at such repair parameters that leads to the conclusion about their lower conservatism.

Change of the stress-strain state during multipass surfacing is of a complex nature, determined both by different bead location relative to the thinning defect, and by the change of profile of the pipeline damaged part as the deposited metal solidifies (Figure 5). This, in its turn, predetermines the essentially nonlinear dependencies between surfacing parameters in terms of ensuring repair safety and pipeline operability after repair of thinning defect. As an example, the Table gives the results of evaluation of admissibility of some modes of surfacing repair of the above MP defect. Admissibility of residual deformed state according to [16] is based on the distribution of residual radial displacement $d r_{\text {res }}$, derived through mathematical simulation by numerical tracing of the structure state. In particular, the specific value of maximum radial buckling $d r_{\max }$ is determined by the degree of development of pipeline metal plastic strains under the joint impact of welding heating and internal pressure: surfaced defect area becomes more compliant to external force impact that intensifies

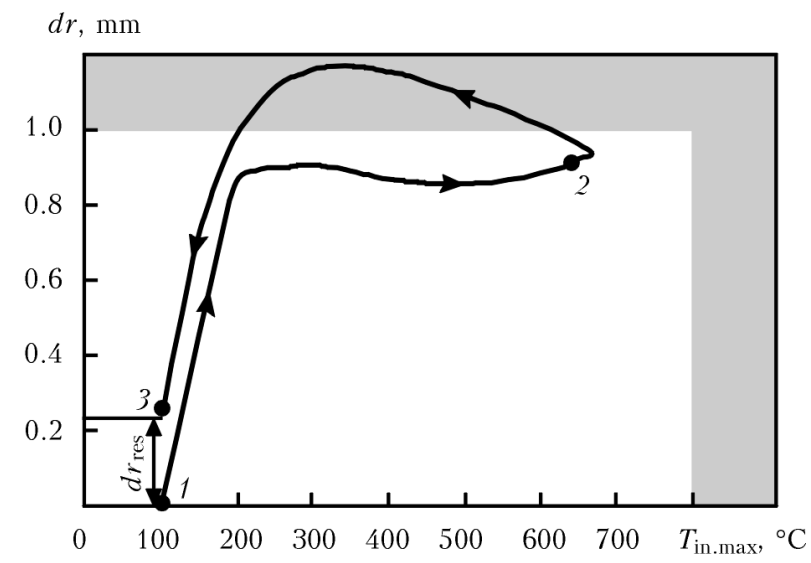

Figure 4. Dependence of excess radial displacement of pipeline external wall on maximum temperature on inner surface at bead deposition on thinning defect (gray colour marks the region of inadmissible states by criteria (1) and (2): 1 - start of defect surfacing; 2 - end of heat source action; 3 - complete cooling of repair area) 


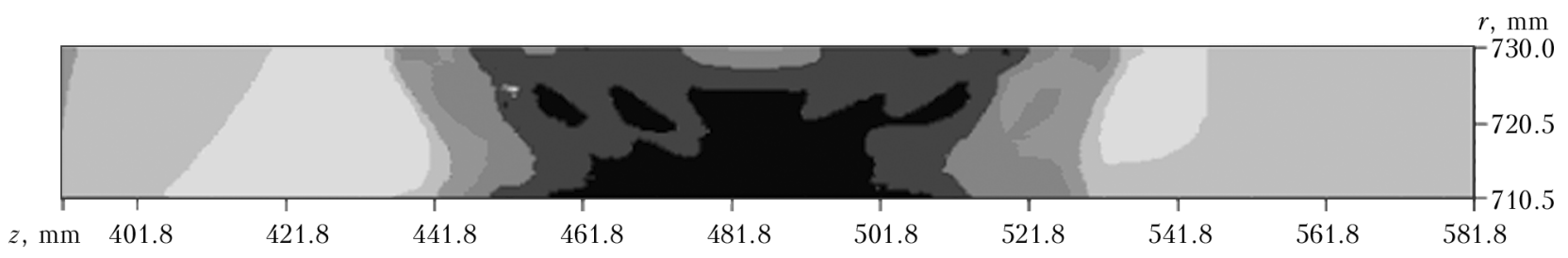

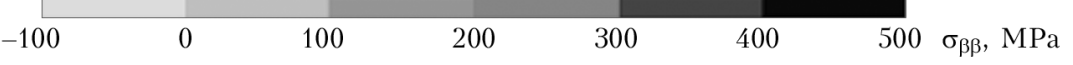

Figure 5. Distribution of residual circumferential stresses in the area of pipeline wall thinning defect after its repair by mutlipass welding surfacing
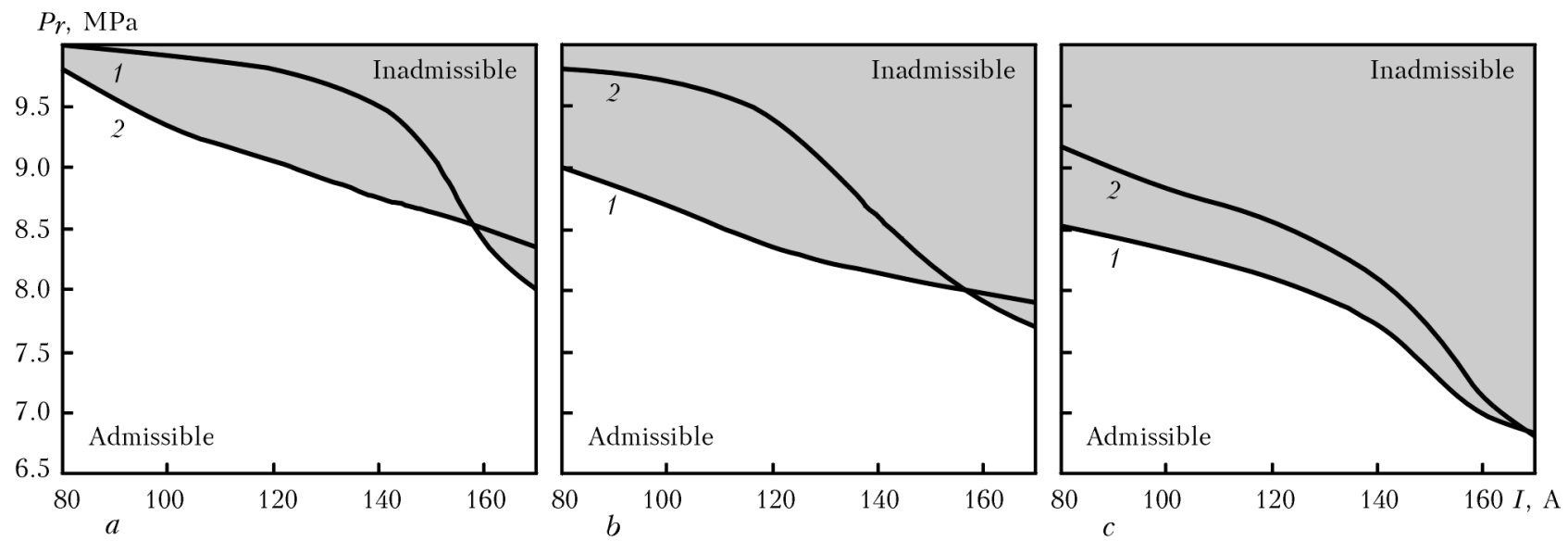

Figure 6. $I-P$ diagram of applicability of multipass surfacing modes allowing for admissibility of residual shape defect 1 and plastic instability criteria $2: a-T_{\mathrm{pr}}=100 ; b-300 ; c-500{ }^{\circ} \mathrm{C}$

Influence of some technological parameters of surfacing on pipeline limiting and residual states

\begin{tabular}{|c|c|c|l||}
\hline$P_{r}, \mathrm{MPa}$ & $I, \mathrm{~A}$ & $T_{\min },{ }^{\circ} \mathrm{C}$ & \multicolumn{1}{|c|}{ Conclusion on admissibility } \\
\hline 4.0 & 100 & 300 & Surfacing is allowed \\
\hline 4.0 & 100 & 500 & \multicolumn{1}{c|}{ Same } \\
\hline 7.5 & 150 & 500 & $\begin{array}{l}\text { Shape defect, formed as a result of } \\
\text { surfacing, is medium according to } \\
{[16], 1.593=n<k=1.617}\end{array}$ \\
\hline 7.5 & 170 & 500 & Plastic instability $\psi \sim 1$ \\
\hline
\end{tabular}

the local accumulation of irreversible plastic strains.

These data can be presented more completely in the form of 2D diagrams, in particular, in the repair pressure-welding current coordinates, an example of which for the considered case (pipeline properties and geometry, extent and nature of damage) is given in Figure 6. These data lead to the conclusion that at significant heat input the prevailing mechanism limiting the application of surfacing, is the risk of plastic instability, whereas at relatively low powers of local heating and high pressures excess residual distortion of the structure becomes dangerous. Curves in the given diagrams mark the boundary separating the regions of pipeline admissible and inadmissible states in multipass surfacing and subsequent operation: parameter region, located below curves
1, corresponds to fulfillment of criterion (7), whereas the region under curve 2 corresponds to parameters, guaranteeing fulfillment of criteria (5), (6), according to the results of numerical calculations of MP state kinetics in surfacing.

It should be also noted that at practical application, the engineering recommendations on welding surfacing, in keeping with the described numerical analysis procedures, should further allow for safety factors by individual kinds of input data that can quantitatively change the evaluation of technological parameters admissibility, proceeding from the actual condition of MP specific section with the detected damage.

\section{Conclusions}

1. Mathematical models of the kinetics of physico-mechanical processes in multipass arc surfacing of a detected defect of pipeline wall local thinning were developed proceeding from currently available models of stress-strain and limiting states of pipeline elements at complex force and thermal impact. A complex numerical criterion of MP integrity at surfacing was proposed, allowing both for pipeline technological strength and its operability after performance of repair-and-renewal operations.

2. Lower conservatism of the developed numerical criteria of integrity of pipeline element with an external defect of local metal loss, is 
shown, compared to the currently available approaches, namely Battelle criterion and 46345 model. Lowering of conservatism of numerical evaluation within the bounds of the proposed methodology is based on additional allowing for the processes of tough fracture, which determine formation of pipeline limiting state at simultaneous impact of internal pressure and local welding heating at surfacing.

3. Characteristic features of the main technological parameters influence on structure technological strength were studied in the case of multipass arc surfacing of an inadmissible defect of MP wall thinning. It is shown, in particular, that at considerable heat input the prevailing mechanism limiting the application of surfacing, is the risk of plastic instability, whereas at relatively low powers of local heating and high pressures the most hazardous is the residual deformation of the structure.

1. Amend, B., Bruce, W.A. (2013) Welding on in-service pipelines: Dispelling popular myths and misconceptions. Welding Assoc. J., 2, 30-39.

2. LaMorte, C.R., Boring, M., Porter, N. (2007) Advanced welding repair and remediation methods for in-service pipelines: Final Report. Columbus: EWI.

3. Sabapathy, P.N., Wahab, M.A., Painter, M.J. (2000) The prediction of burn-through during inservice welding of gas pipelines. Int. J. Press. Vess. Piping, 11, 669-677.

4. Makhnenko, V.I., Milenin, A.S. (2009) To problem of repair of land main in-service pipelines. In: Proc. of Sci.-Techn. Seminar on Service Reliability Control of Pipeline Transport Systems (10-11 June, 2009, Kiev, Ukraine), 12-18. Kiev: PWI.

5. Makhnenko, V.I., But, V.S., Velikoivanenko, E.A. et al. (2001) Mathematical modeling of pitting defects in active oil and gas pipelines and development of a numerical method for estimation of permissible parameters of arc welding repair of defects. The Paton Welding J., 11, 2-9.

6. $V B N$ V.3.1-00013471-07:2007: Main pipelines. Methods of repair of defective zones. Kyiv: Ministry of Fuel and Energy of Ukraine.

7. STO Gazprom 2-2.2-136-2007: Instruction on welding technologies in construction and repair of industrial and main pipelines. Pt2. Moscow: VNIIGAZ.

8. Kiefner, J.F., Bruce, W.A., Stephens, D.R. (1994) Pipeline repair manual. Houston: Technical Toolboxes.

9. Boring, M.A., Zhang, W., Bruce, W.A. (2008) Improved burn-through prediction model for in-service welding application. In: Proc. of 7th Int. Pipeline Conf. (Sept. 29-Oct.3, 2008, Calgary, Alberta, Canada), Vol. 3, 249-259. New York: ASME.

10. Painter, M., Sabapathy, P. (2000) In-service welding on gas pipelines: Program Report. Clayton: CSIRO Manufac. Sci. \& Techn.

11. Makhnenko, V.I. (1976) Calculation methods for investigation of welding stress and strain kinetics. Kiev: Naukova Dumka.

12. Makhnenko, V.I. (2006) Safety service resource of welded joints and assembly units of modern structures. Kiev: Naukova Dumka.

13. Karzov, G.P., Margolin, B.Z., Shvetsova, V.A. (1993) Physical-mechanical modeling of fracture processes. St.-Petersburg: Politekhnika.

14. Velikoivanenko, E.A., Rozynka, G.F., Milenin, A.S. et al. (2013) Modelling of processes of nucleation and development of ductile fracture pores in welded structures. The Paton Welding J., 9, 24-29.

15. Tvergaard, V. (1990) Material failure by void growth to coalescence. Adv. in Appl. Mech., 27, 83-151.

16. DSTU-N B V.2.3-21:2008: Directive. Determination of residual strength of main pipelines with defects. Kyiv: Minregionbud.

17. SNiP 2.05.06-858: Main pipelines. Building norms and acts. Moscow: VNIIST Minneftegazstroya.

Received 03.07.2014 


\title{
PREDICTION OF THERMODYNAMIC PROPERTIES OF $\mathrm{Al}_{2} \mathrm{O}_{3}-\mathrm{SiO}_{2}$ SYSTEM MELTS
}

\author{
I.A. GONCHAROV ${ }^{1}$, V.I. GALINICH ${ }^{1}$, D.D. MISHCHENKO ${ }^{1}$ and V.S. SUDAVTSOVA ${ }^{2}$ \\ ${ }^{1}$ E.O. Paton Electric Welding Institute, NASU \\ 11 Bozhenko Str., 03680, Kiev, Ukraine. E-mail: office@paton.kiev.ua \\ ${ }^{2}$ I.M. Frantsevich Institute of Problems of Materials Science, NASU \\ 3 Krzhizhanovsky Str., 03680, Kiev, Ukraine
}

\begin{abstract}
Aluminium and silicon oxides are included into the composition of fluxes for welding, electroslag remelting and metallurgical slags. Knowledge of thermodynamic properties of aluminium oxide-silicon oxide system mixtures will allow evaluation of the nature of their interaction in the melt that will provide an insight into the metallurgical properties of the respective materials for welding and related technologies developed on their base. Analysis of published data on phase equilibria of constitutional diagrams of aluminium oxide-silicon oxide system and thermodynamic properties of this system was performed. It is established that the constitutional diagram data are correct, and experimental values of activities of these melt components are characterized by large scatter. The coordinates of liquidus line of the constitutional diagram of aluminium oxide-silicon oxide system were used to calculate the thermodynamic activities of aluminium oxide at its concentration in the range of $0.7-1.0$. It is established that they start manifesting small negative deviations from ideal solutions in the eutectic melt (0.74). Integration of Gibbs-Dugem equation was performed to assess the activities of silicon oxide. It was determined that they demonstrate slight negative deviations from ideal solutions. It is shown that the influence of aluminium oxide-silicon oxide system melts on the nature of interaction in complex multicomponent solutions can be significant. It is found that addition of thermodynamically stable chemical compounds (for instance, sillimanite) to multicomponent slag melts leads to lowering of their oxidizing ability. Replacement of quartz sand and alumina by disthensillimanite concentrate in agglomerated flux charge leads to lowering of thermodynamic activity of oxygen in the slag melt, slows down running of silicon-reduction process and reduces manganese losses in welding. 25 Ref., 6 Figures.
\end{abstract}

$\boldsymbol{K} \boldsymbol{e} \boldsymbol{y} \boldsymbol{w} \boldsymbol{o} \boldsymbol{r} \boldsymbol{d} \boldsymbol{s}:$ aluminium and silicon oxides, constitutional diagrams, thermodynamic activity of components, slag melts, fluxes for welding and electroslag remelting

Aluminium and silicon oxides are included into the fluxes for welding, electroslag remelting and metallurgical slags [1]. In multicomponent slag melts on their base, complex alumosiliconoxygen anions of different degrees of polymerization form, which determine the melt physico-chemical properties, and technological and metallurgical properties of the respective materials, accordingly. Knowledge of thermodynamic properties of $\mathrm{Al}_{2} \mathrm{O}_{3}-\mathrm{SiO}_{2}$ system melts is required to predict the thermodynamic properties of the respective ternary and quaternary slag systems, which include binary $\mathrm{Al}_{2} \mathrm{O}_{3}-\mathrm{SiO}_{2}$ system, and improvement of currently available welding fluxes and metallurgical slags.

In this connection, the objective of this work was analysis of the available published data on phase equilibria and thermodynamic properties of $\mathrm{Al}_{2} \mathrm{O}_{3}-\mathrm{SiO}_{2}$ system mixtures, as well as calculation of activity of components of liquid so- lutions, proceeding from the coordinates of liquidus line in a broad concentration range.

The first publication of phase diagram [2] is in agreement with the data on liquidus line coordinates [3]. The authors showed that $3 \mathrm{Al}_{2} \mathrm{O}_{3} \cdot 2 \mathrm{SiO}_{2}$ compound called mullite [4] is more stable in air at atmospheric pressure than sillimanite $\left(\mathrm{Al}_{2} \mathrm{SiO}_{5}\right)$. Experimental data on phase equilibria in this system were determined more precisely and were analyzed, for instance, in [5-15].

In $[5,6]$ different factors influencing mullite melting were also considered, and in [12] the invariant compositions and their temperatures were summed up. All these data and some of the more recent ones are given in Figure 1, from which it is easy to visualize the modern constitutional diagram of $\mathrm{Al}_{2} \mathrm{O}_{3}-\mathrm{SiO}_{2}$ system.

$\mathrm{SiO}_{2}$ eutectic - mullite, according to the data of [13], has the following coordinates: $1545^{\circ} \mathrm{C}$; 3.3 mol.\% $\mathrm{Al}_{2} \mathrm{O}_{3}$, that is confirmed by thermal data [14], according to which the average eutectic temperature is $1546{ }^{\circ} \mathrm{C}$. 


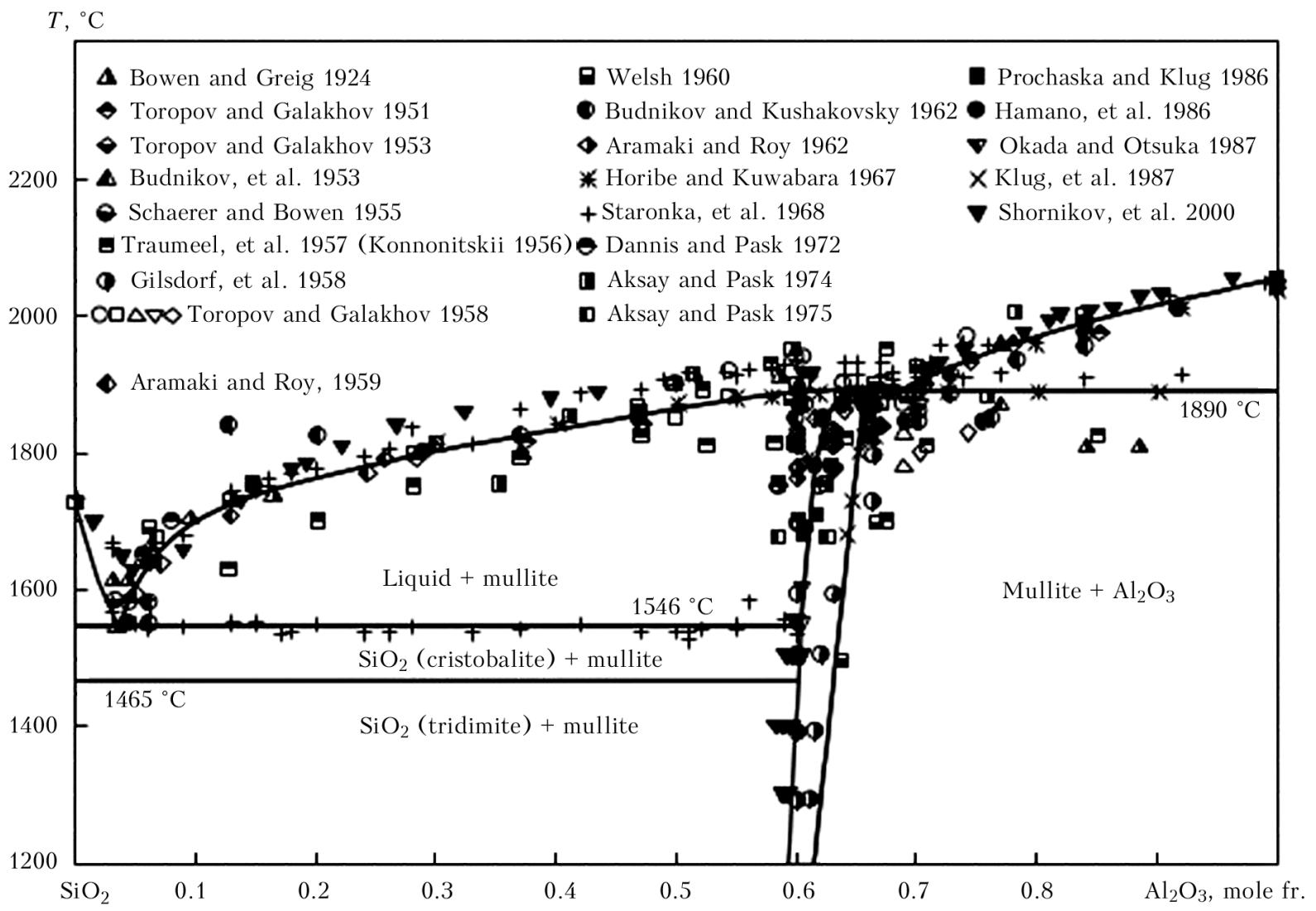

Figure 1. Constitutional diagram of $\mathrm{Al}_{2} \mathrm{O}_{3}-\mathrm{SiO}_{2}$ system by the data of different authors

Considering the data given in Figure 1, we can come to the conclusion that mullite (65.3 mol.\% $\left.\mathrm{Al}_{2} \mathrm{O}_{3}\right)$ melts in a congruent manner at $1891.5{ }^{\circ} \mathrm{C}$, and mullite $-\mathrm{Al}_{2} \mathrm{O}_{3}$ eutectic contains $68.5 \mathrm{~mol} . \% \mathrm{Al}_{2} \mathrm{O}_{3}$ and melts at $1890{ }^{\circ} \mathrm{C}$. It is also found that mullite decomposes at $T<$ $<434{ }^{\circ} \mathrm{C}$.

A. Zajtsev with co-authors [16] studied the activities of silicon oxide in mullite $-\mathrm{Al}_{2} \mathrm{O}_{3}$ twophase region at 1200 and $1480{ }^{\circ} \mathrm{C}$ by the method of Knudsen effusion mass-spectrometry (KEMS), using pure $\mathrm{SiO}_{2}$ as a standard condition. Ignoring the temperature impact, it was found that activity $a_{\mathrm{Al}_{2} \mathrm{O}_{3}}=0.56$.

S. Shornikov with co-authors [17] applied the same method to study partial pressures of different particles over the mullite solution and obtained $a_{\mathrm{Al}_{2} \mathrm{O}_{3}}=0.37$ at 1550 and 0.18 between 1660 and $1760{ }^{\circ} \mathrm{C}$.

In [18] differential KEMS method was used to determine $a_{\mathrm{Al}_{2} \mathrm{O}_{3}}$ in melts of $\mathrm{Al}_{2} \mathrm{O}_{3}-\mathrm{SiO}_{2}$ system at 1600 and $1700,1800{ }^{\circ} \mathrm{C}$ with $\pm 20 \%$ error. Considering that the initial samples were nonequilibrium, and had high viscosity, this prevented establishment of equilibrium during the experiments. In view of the above, these results cannot be regarded as valid. Moreover, the determined $a_{\mathrm{Al}_{2} \mathrm{O}_{3}}$ demonstrate very large negative deviations from the Raoult law that is unchar- acteristic for systems with weak interparticle interaction, to which the considered system belongs.

KEMS method was used to study the activities of silicon dioxide in this system melts at 1927, 2027 and $2127{ }^{\circ} \mathrm{C}$ [19]. From Figure 2 it is seen that $a_{\mathrm{Al}_{2} \mathrm{O}_{3}}$ values derived in [19] have alternating deviations from ideal solutions and slight temperature dependence.

The same method was used in [20] to determine $a_{\mathrm{Al}_{2} \mathrm{O}_{3}}$ at 1748 and $1877^{\circ} \mathrm{C}$ in melts of $\mathrm{Al}_{2} \mathrm{O}_{3}$ with $\mathrm{SiO}_{2}$ up to aluminium oxide concentration $\leq 0.6$. These data demonstrate the smallest negative deviations from Raoult law.

In [21] KEMS method was used to determine $a_{\mathrm{Al}_{2} \mathrm{O}_{2}}$ in a broader compositional range at 1577 and $1677{ }^{\circ} \mathrm{C}$. It is found that in the region of $\mathrm{SiO}_{2}$-enriched liquid solutions, $a_{\mathrm{Al}_{2} \mathrm{O}_{3}}$ activity demonstrates slight negative, and at $a_{\mathrm{Al}_{2} \mathrm{O}_{3}}>$ $>0.3$ - positive deviations from Raoult law. At penetration into the heterogeneous region at $a_{\mathrm{Al}_{2} \mathrm{O}_{3}}>0.6, \mathrm{SiO}_{2}$ activities, as was anticipated, acquire constant values.

Modelling $a_{\mathrm{Al}_{2} \mathrm{O}_{3}}$ of the system mixtures in the entire compositional range was performed in works [22, 23] using a package of applied software Thermocalc and Factsage, respectively. $\mathrm{SiO}_{2}$ activities determined in these works, are given in Figure 2. It is clear that they correlate 


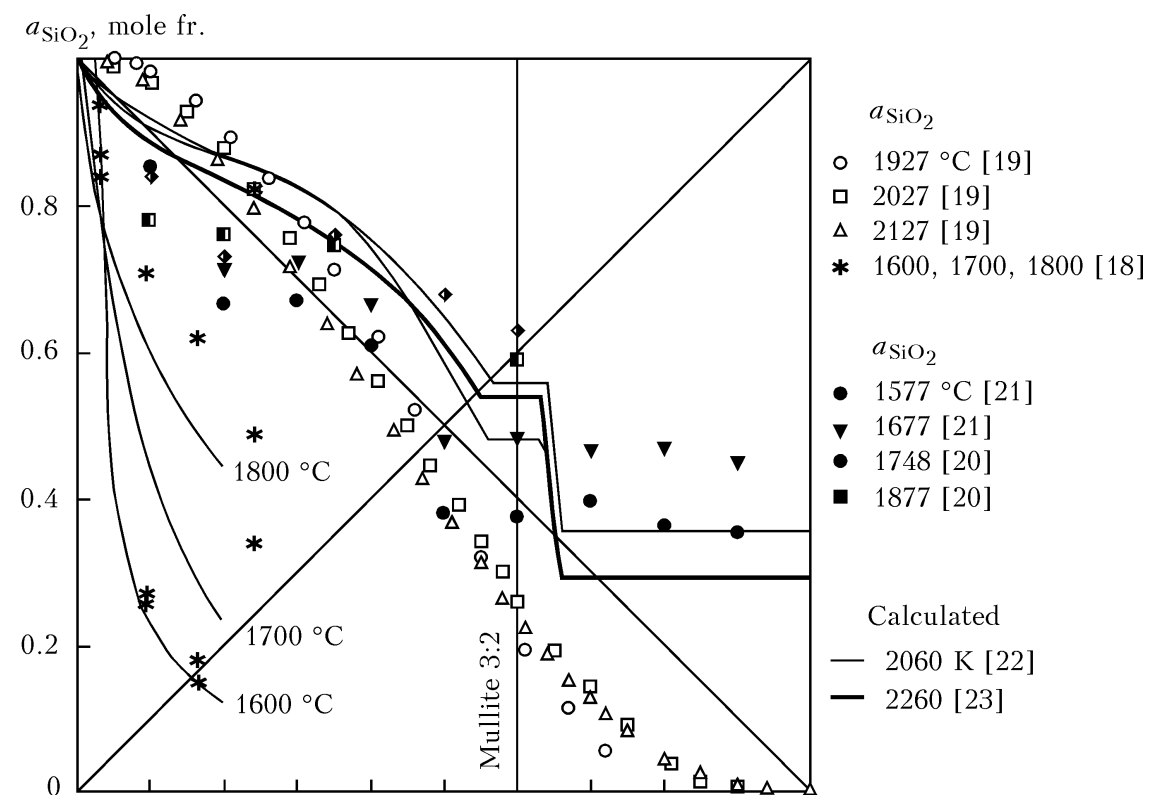

Figure 2. Activities of $\mathrm{Al}_{2} \mathrm{O}_{3}-\mathrm{SiO}_{2}$ system melt components

with the data from one of the more recent studies [21].

Considering the great scatter of data in experimentally established $a_{\mathrm{Al}_{2} \mathrm{O}_{3}}$ (see Figure 2), we calculated $a_{\mathrm{Al}_{2} \mathrm{O}_{3}}$ from the liquidus line coordinates in composition region of $0.7<x_{\mathrm{Al}_{2} \mathrm{O}_{3}}<$ $<1$ by the procedure developed by us [24]. It turned out that $a_{\mathrm{Al}_{2} \mathrm{O}}$ demonstrate values, close to ideal solutions. This is not surprising, as the properties of $\mathrm{Al}_{2} \mathrm{O}_{3}$ and $\mathrm{SiO}_{2}$ are similar and, therefore, the energies of their interaction, either in solid, or in liquid state, cannot be strong. Moreover, we find that in eutectic melt $a_{\mathrm{Al}_{2} \mathrm{O}_{3}}$ activity starts manifesting slight negative deviations from ideal solutions. Considering that they will remain just as small with increase of $\mathrm{SiO}_{2}$ content, we have extrapolated them to the entire composition region (Figure 3 ).

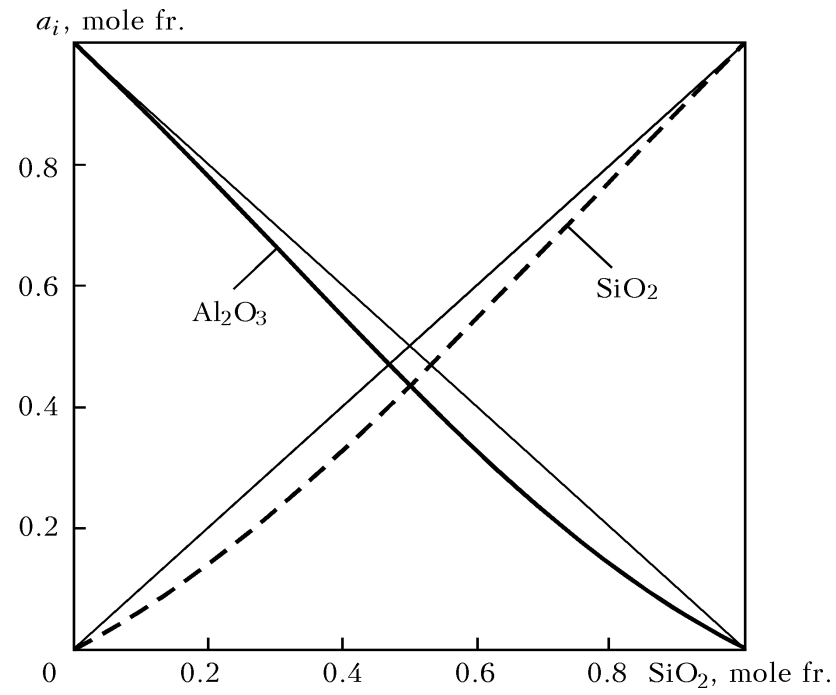

Figure 3. Activities of $\mathrm{Al}_{2} \mathrm{O}_{3}-\mathrm{SiO}_{2}$ system melt components calculated from liquidus line coordinates at $2160 \mathrm{~K}$
From the thus obtained $a_{\mathrm{Al}_{2} \mathrm{O}_{3}}$, the $a_{\mathrm{Al}_{2} \mathrm{O}_{3}}$ values were calculated by integration of $\mathrm{Gibbs}^{-}$ Dugem equation (Figure 3). As was anticipated, $a_{\mathrm{Al}_{2} \mathrm{O}_{3}}$ also demonstrate slight negative deviations from ideal solutions, i.e. reveal a similar dependence.

All the known experimental results on activities of $\mathrm{Al}_{2} \mathrm{O}_{3}-\mathrm{SiO}_{2}$ system melt components are characterized by large errors, which due to that, first, the studied alloys often were non-equilibrium, secondly, all of them are had very high viscosity, because of which the alloy composition can change during high-temperature investigations, in connection with predominant evaporation of one of the components. Therefore, the experiments should be followed by chemical analysis of the samples, and then the obtained results would be more adequate.

Alloys of this system cannot demonstrate large negative deviations from ideal solutions, as it was obtained in [18]. Results of [17] are not

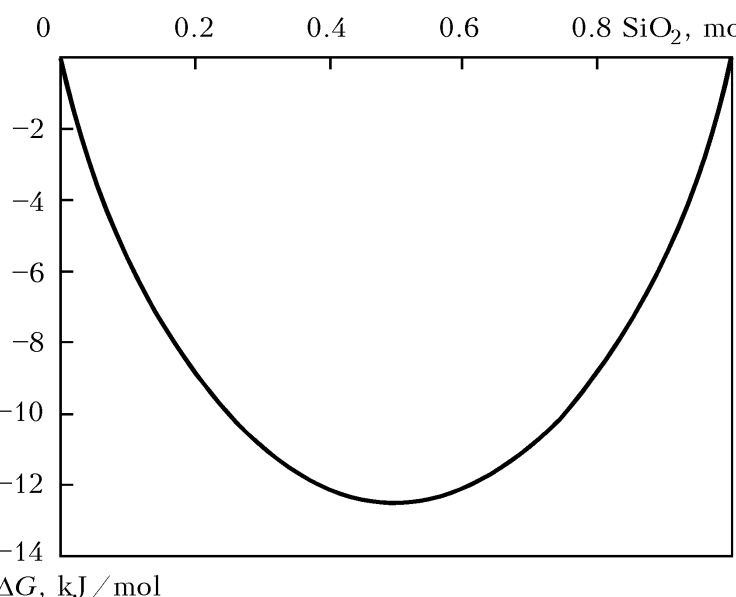

Figure 4. Gibbs mixing energy of $\mathrm{Al}_{2} \mathrm{O}_{3}-\mathrm{SiO}_{2}$ system melts at $2160 \mathrm{~K}$ 
quite valid, either, as they demonstrate considerable temperature dependencies in a narrow temperature range. Therefore, we believe that the data obtained by us provide the most adequate insight into the actual nature of liquid state interaction (at small overheating above the liquidus line). The advantage of our method consists in that with the availability of our reliable experimental data on phase equilibria, it always allows obtaining component activities, close to those found by accurate experimental methods.

We calculated Gibbs mixing energy from the obtained component activities (Figure 4).

As one would expect, it is characterized by small absolute values. Nonetheless, at addition of alkali-earth metal oxides and fluorides, a strong interaction of the latter both with $\mathrm{SiO}_{2}$ and with $\mathrm{Al}_{2} \mathrm{O}_{3}$ can be observed, that follows from the data for melts of $\mathrm{CaO}-\mathrm{SiO}_{2}\left(\mathrm{Al}_{2} \mathrm{O}_{3}\right)$ binary systems [25]. Therefore, the influence of the considered system on the nature of interaction in complex multicomponent fluxes can be significant.

Thus, presence of strong interaction due to these factors should be taken into account at investigation and application of the actual oxide-fluoride melts.

Performed analysis of thermodynamic properties of $\mathrm{Al}_{2} \mathrm{O}_{3}-\mathrm{SiO}_{2}$ system melts led to the assumption that addition of thermodynamically stable chemical compounds based on silicon and aluminium oxides to multicomponent slag melts, will allow lowering the oxidizing ability of the slag melt relative to molten metal, reducing the alloying element losses in welding and ESR and preventing the occurrence of silicon-reduction process in the metal of weld and ingot, which is undesirable in terms of metallurgy, welding and ESR of high-strength steels.

To check this assumption, EDS method was used to study oxygen activities in melts of agglomerated fluxes of $\mathrm{MgO}-\mathrm{Al}_{2} \mathrm{O}_{3}-\mathrm{SiO}_{2}-\mathrm{CaF}_{3}-$

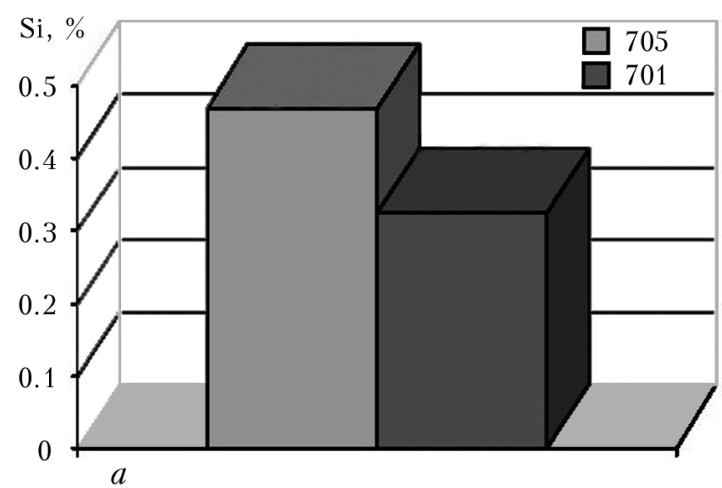

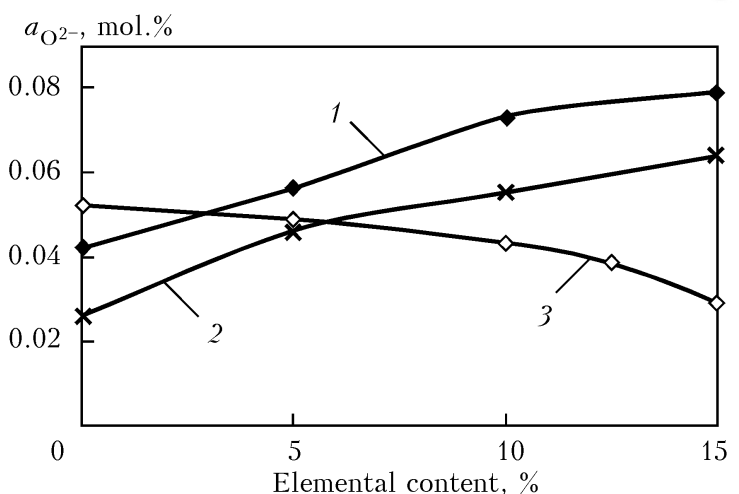

Figure 5. Dependence of oxygen activity in slag melt of $\mathrm{MgO}-\mathrm{Al}_{2} \mathrm{O}_{3}-\mathrm{SiO}_{2}-\mathrm{TiO}_{2}$ system on the content of quartz sand (1), alumina (2) and disthen-sillimanite concentrate $\mathrm{Al}_{2} \mathrm{SiO}_{5}$ (3) in agglomerated flux charge

$\mathrm{TiO}_{2}$ system. Slags had approximately the same composition and differed just by the method of addition of silicon and aluminium oxides to agglomerated flux charge. In one case alumina and quartz sand were added, and in the second case this was disthen-sillimanite concentrate, in which these oxides are bound in $\mathrm{Al}_{2} \mathrm{SiO}_{5}$ complex compound.

Figure 5 shows the dependence of oxygen activity in slag melts on these components content in slag melt charge. It is established that addition of alumina and quartz sand leads to increase of oxygen activity in the slag melt. At their replacement by disthen-sillimanite concentrate oxygen activity in the slag melt drops noticeably. This is attributable to high thermal stability and insignificant dissociation of $\mathrm{Al}_{2} \mathrm{SiO}_{5}$ compound and to melt dilution by an inert substance.

We also determined [Si], [Mn] content in the deposited metal in submerged-arc welding with fluxes based on disthen-sillimanite concentrate (701), as well as those based on quartz sand and alumina (705) (Figure 6).

Figure 6 shows that replacement of quartz sand and alumina by thermodynamically stable disthen-sillimanite concentrate leads to lowering of manganese losses in the weld metal, and es-

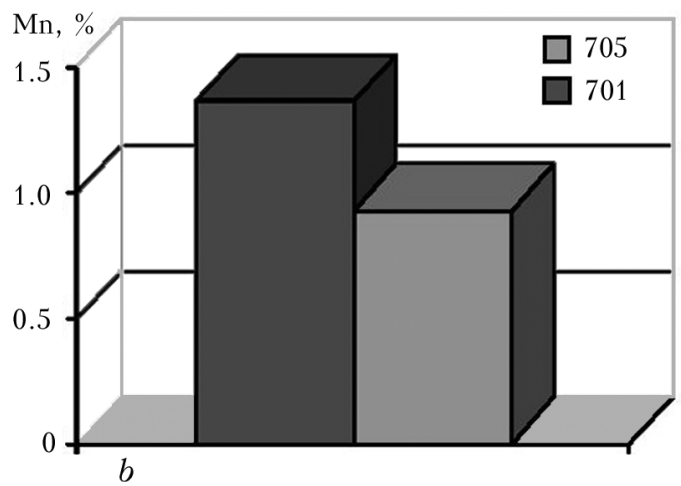

Figure 6. Content of silicon $(a)$ and manganese $(b)$ in the deposited metal in submerged-arc welding using fluxes based on disthen-sillimanite concentrate (701), as well as those based on quartz sand and alumina (705), with application of Sv-08G1NMA wire 
sential prevention of running of silicon-reduction process.

Thus, the attractiveness of disthen-sillimanite concentrate application in manufacture of agglomerated welding fluxes is obvious.

\section{Conclusions}

1. Performed analysis of published data on phase equilibria and thermodynamic properties of $\mathrm{Al}_{2} \mathrm{O}_{3}-\mathrm{SiO}_{2}$ system alloys revealed that the constitutional diagram is correct, and component activities of these alloys are characterized by large scatter.

2. Coordinates of liquidus line of $\mathrm{Al}_{2} \mathrm{O}_{3}-\mathrm{SiO}_{2}$ system constitutional diagram, determined by different authors, were used to calculate $a_{\mathrm{Al}_{2} \mathrm{O}}$ activities at $0.7<x_{\mathrm{Al}_{3} \mathrm{O}_{3}}<1$. It is established that they start manifesting small negative deviations from ideal solutions in eutectic melt $\left(x_{\mathrm{Al}_{2} \mathrm{O}_{3}}=0.74\right)$.

3. Proceeding from $a_{\mathrm{Al}_{2} \mathrm{O}_{3}}$ values, calculated by us, integration of Gibbs-Dugem equation was used to evaluate silicon oxide activities. It is established that they demonstrate slight negative deviations from ideal solutions.

4. Influence of $\mathrm{Al}_{2} \mathrm{O}_{3}-\mathrm{SiO}_{2}$ system melts on the nature of interaction in multicomponent solutions can be significant.

5. Addition of thermally-stable chemical compounds (for instance, sillimanite) to multicomponent slag melts leads to lowering of their oxidizing ability. Replacement of quartz sand and alumina by disthen-sillimanite concentrate in agglomerated flux charge leads to lowering of thermodynamic activity of oxygen in the slag melt, slows down the silicon-reduction process and reduces manganese losses in welding.

1. Zajtsev, A.I., Mogutnov, B.M., Shakhpazov, E.Kh (2008) Physical chemistry of metallurgical slags. Moscow: Interkontakt Nauka.

2. Shepherd, E.S., Rankin, G.A., Wright, F.E. (1909) The binary systems of alumina with silica, lime and magnesia. Am. J. Sci., 28, 293-298.

3. Bowen, N.L., Greig, J.W. (1924) The system alumina-silica. J. Am. Ceram. Soc., 7, 238-254.

4. Bowen, N.L., Greig, J.W., Zies, E.G. (1924) Mullite, a silicate of alumina. J. of the Washington Academy of Sci., 14, 183-191.

5. Chaudhuri, S.P. (1987) Melting/decomposition of mullite: Incongruent or congruent? $\mathrm{Pt} \mathrm{I}$ : Phase equilibria of the system aluma-silica. Ceram. Int., 13(3), 167-175.

6. Chaudhuri, S.P. (1987) Melting/decomposition of mullite: Incongruent or congruent? Pt II: Responsible factors for dual nature of mullite. Ibid., 13(3) 177-181.
7. Gao, Z. (1981) Review of studies and controversy on the phase diagram of the alumina-silica system. Ibid., 9(2), 197-217

8. Mueller-Hesse, H. (1963) The development of investigations and present-day knowledge of the system $\mathrm{Al}_{2} \mathrm{O}_{3}-\mathrm{SiO}_{2}$. Ber. Deut. Keram. Ges, 40(5), 281-285.

9. Pask, J.A. (1990) Critical review of phase equilibria in the alumina-silica system. Ceram. Transact., 6, 1-13.

10. Roy, R. (1990) The alumina-silica phase diagram: Metastability and order-disorder. Ibid., 45-50, 1132 .

11. Jantzen, C.M., Schwahn, D., Schelten, J. et al. (1981) The silica alumina system. Pt 1: Later stage spinodal decomposition and metastable immiscibility. Phys. Chem. Glasses, 22(5), 122-137.

12. Shornikov, S.I., Archakov, I.Yu. (2000) Mass-spectrometric study of processes of evaporation and phase equilibria in $\mathrm{Al}_{2} \mathrm{O}_{3}-\mathrm{SiO}_{2}$ system. Zhurnal Phys. Khimii, 74(5), 775-782.

13. Aksay, I.A., Pask, J.A. (1975) Stable and metastable equilibriums in the system silica-alumina. J. Am. Ceram. Soc., 58(11/12), 507-512.

14. Staronka, A., Pham, H., Rolin, M. (1968) Cooling curve study on the silica-alumina system. Revue Int. des Hautes Temp. et des Refractaires, 5(2), 111-115.

15. Aramaki, S., Roy, R. (1962) Revised phase diagram for the system $\mathrm{Al}_{2} \mathrm{O}_{3}-\mathrm{SiO}_{2}$. Ibid., 45, 229-242.

16. Zajtsev, A.I., Litvina, A.D., Mogutnov, B.M. (1995) Thermodynamical properties of mullite $3 \mathrm{Al}_{2} \mathrm{O}_{3} \cdot 2 \mathrm{SiO}_{2}$. Neorgan. Materialy, 31(6), 768-772.

17. Shornikov, S.I., Stolyarova, V.L., Shultz, M.M. (1994) High temperature mass spectrometric study of $3 \mathrm{Al}_{2} \mathrm{O}_{3} \cdot 2 \mathrm{SiO}_{2}$. Rapid Commun. Mass Spectrom., $8(6), 478-480$

18. Dhima, A., Stafa, B., Allibert, M. (1986) Activity measurements in steelmaking-related oxide melts by differential mass spectrometry. High Temperature Sci., 21(3), 143-159

19. Shornikov, S.I., Archakov, I.Yu., Chemekova, T.Yu. (2000) Mass spectrometric study of thermodynamical properties of $\mathrm{Al}_{2} \mathrm{O}_{3}-\mathrm{SiO}_{2}$ melts. Zhurnal Phys. Khimii, 74(5), 783-788.

20. Bjorkvall, J., Stolyarova, V.L. (2001) A mass spectrometric study of $\mathrm{Al}_{2} \mathrm{O}_{3}-\mathrm{SiO}_{2}$ melts using a Knudsen cell. Rapid Commun. Mass Spectrom., 15(10), 836-842.

21. Bondar, V.V., Lopatin, S.I., Stolyarova, V.L. (2005) Thermodynamical properties of $\mathrm{Al}_{2} \mathrm{O}_{3}-\mathrm{SiO}_{2}$ system at high temperatures. Neorgan. Materialy, 41(4), 362-369.

22. Mao, H., Seleby, M., Sundman, B. (2005) Phase equilibria and thermodynamics in the $\mathrm{Al}_{2} \mathrm{O}_{3}-\mathrm{SiO}_{2}$ system modeling of mullite and liquid. J. Am. Ceram. Soc., 88(9), 2544-2551.

23. Jak, E., Hayes, P.C., Pelton, A.D. et al. (2009) Thermodynamic modeling of the $\mathrm{Al}_{2} \mathrm{O}_{3}-\mathrm{CaO}-\mathrm{FeO}-$ $\mathrm{Fe}_{2} \mathrm{O}_{3}-\mathrm{PbO}-\mathrm{SiO}_{2}-\mathrm{ZnO}$ system with addition of $\mathrm{K}$ and $\mathrm{Na}$ with metallurgical applications. In: Proc. of 8th Int. Conf. on Molten Slags, Fluxes and Salts, 473-490. Santiago: Geramin.

24. Sudavtsova, V.S., Makara, V.A., Kudin, V.G. (2005) Thermodynamics of metallurgical and welding melts. Pt 3: Alloys based on nickel and tin, methods of modeling and prediction of thermodynamic properties. Kiev: Logos.

25. Goncharov, I.A., Galinich, V.I., Mishchenko, D.D. et al. (2014) Prediction of thermodynamic properties of melts of $\mathrm{Al}_{2} \mathrm{O}_{3}-\mathrm{SiO}_{2}$ system. The Paton Welding J., 4, 26-29.

Received 30.10.2014 


\title{
PECULIARITIES IN MANUFACTURE OF THIN-WALLED WELDED TRANSFORMABLE-VOLUME STRUCTURES FOR SPACE APPLICATION
}

\author{
L.M. LOBANOV and V.S. VOLKOV \\ E.O. Paton Electric Welding Institute, NASU \\ 11 Bozhenko Str., 03680, Kiev, Ukraine. E-mail: office@paton.kiev.ua
}

\begin{abstract}
The need in carrying out the presented investigations was predetermined by the actual problem of optimizing the process of manufacture of welded structures of a transformable-volume for long-time service under the extreme space conditions. The comparative investigations of elastic-plastic properties, and also the microstructural analysis and micromechanical investigations of welded joints of transformable-volume structures of foil materials, produced at different combinations of parameters of pulse modes of microplama welding were carried out. Feasibility of manufacture of multi-section transformable-volume structure, capable to retain the stability of service characteristics under the conditions of space factors at long-time service was shown. Optimum conditions of formation of permanent joints of thin transformable shells of steel of austenite class, combination of physical-mechanical properties and structural peculiarities of which are maximum close to similar properties of base metal were determined and confirmed experimentally. The result of the presented work demonstrates the feasibility of manufacture of transformable-volume structure with preset properties of welded joints, optimized for long-time service under the action of earlier investigated combinations of service and external factors. 7 Ref., 6 Figures.
\end{abstract}

Key words: transformable-volume structures, thin walled load-carrying shells, microplasma welding

Transformable-volume structures (TVS), developed at the E.O. Paton Electric Welding Institute (PWI), represent the load-carrying structures on base of convex closed shells of a zero Gaussian curvature, capable to change one of their dimensions many times and within the wide ranges, however, preserving a spatial rigidity, stability and integrity of the surface material. These properties of the load-carrying shells make it possible to apply them in the space industry, where the launch of structure to the near-earth orbit in a compact form can become the solution of problem of optimizing its mass-dimensional characteristics.

As a structural material of the shell the metals of a definite range of elastic-plastic properties, in particular, at ratio of yield strength $\sigma_{\mathrm{y}}$ to tensile strength $\sigma_{\mathrm{t}}$ in the range of $\sigma_{\mathrm{y}} / \sigma_{\mathrm{t}}=0.3-0.8$ are used. These are aluminium alloys, high-alloy austenitic steels, titanium, etc. It is evident that welding is, in principle, the only method of manufacture of metal vacuum-tight shell structures. One of the main problems in manufacture of TVS shells is the attaining of combination of high physicalmechanical characteristics with a simultaneous vacuum-tightness of welds, which are subjected to a complex of effects of mechanical loads and specific

(C) L.M. LOBANOV and V.S. VOLKOV, 2015 aggressive external factors. The carried out investigations were aimed at determination of optimum conditions of formation of permanent joints of thin transformable steel shells of TVS, capable to provide the service characteristics of structures under the extreme service conditions.

Figure 1 presents the stages of manufacture of structure element of conical-type TVS, including welding of straight-linear welds of semi-product (Figure 1, $a$ ) and its subsequent transformation into flat corrugated disc (Figure $1, b$ ) by using the technology of cold volume deforming, developed at the PWI. As a material, steel strip AISI 321 of thickness $\delta=0.15-0.17 \mathrm{~mm}$ was used, the largest diameter of shell was $400 \mathrm{~mm}$. The similarity of this transformation to the isometric one allows the disc to be returned to the initial conical shape (Figure 1,c), thus creating an excessive pressure in its inner cavity after the contour pressurization. In this case small residual plastic deformations in apexes of circumferential stiffeners form corrugations, which greatly increasing the rigidity of structural conical elements and load-carrying capacity of the structure as a whole.

Scheme of isometric transformation of the shell, described by a family of continuous images of its neutral surface, assumes an isotropy of structural material of the latter, therefore, the welds should have physical-mechanical properties, equivalent to the structure base metal. The technology of volume deforming of the PWI de- 


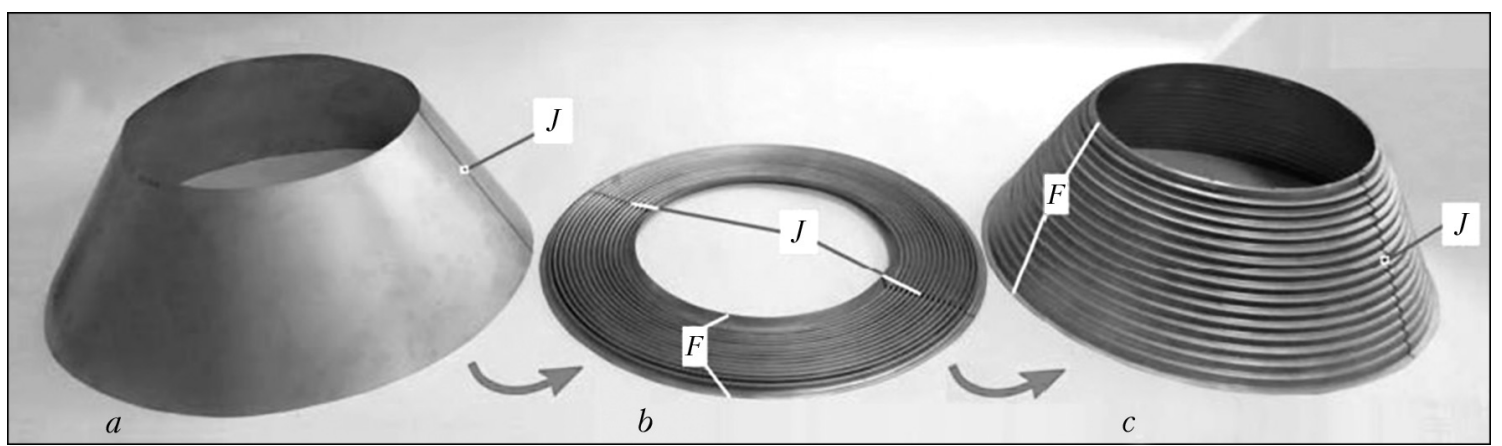

Figure 1. Stages of manufacture of transformable conical shell of TVS illustrating the nature of technological deforming of its welded joints $J$ ( $F-$ flanging for subsequent welding of shells into a single structure)

velopment assumes a continuous movement of forming tool (punch) over the shell surface, to which forming force is applied. Nevertheless, the weld geometry (reinforcement) is not decisive, as the punch during shell rotation contacts the weld root and main technological task consists in providing the quality welded joint with preset characteristics of ductility and strength.

When manufacturing the space-purpose TVS, to reduce the mass the minimum thicknesses of shell structural materials are used, at which the required strength of structure without loss of its functional properties can be provided. In selection of method for welding of butt joints of stainless steel and titanium of thicknesses $\delta=0.1-$ $0.2 \mathrm{~mm}$, microplasma welding was preferable. It allowed simplifying greatly the preparation of edges of conical semi-product for welding, thus increasing the efficiency of the TVS manufacture and decreasing the thermal deformations of weld in applying the preliminary flanging of edges being welded.

In welding of semi-products of stainless steel of $0.15-0.17 \mathrm{~mm}$ thickness the flanging of edges for value equal to two thicknesses of material was used. In addition, the microplasma welding could provide almost full repeatability of preset welding result, that can be explained by less strict requirements to accuracy of the mechanism of welding heat source movement, as compared with those specified for laser welding.

To manufacture a series of volume-transformable conical shells, the welding stand was designed (Figure 2), in which the problems of providing the precision assembly and welding of foil materials were solved at the designing level with maximum use of unified high-cost parts and units realized in advanced systems of the similar application [1]. In particular, assembly of movement mechanism with ball-screw transmission by rolling was made from separate completing parts, united into a single unit at $\pm 10 \mu \mathrm{m}$ accuracy of mutual fixation. Here, adjustments were provided, which could correct the position of the entire system of movement 1 with plasmatron 2 with respect to the plane of assembly-welding rig 3 at $\pm 25 \mu \mathrm{m}$ accuracy along each of three coordinates. Floating fixation of torch unit with respect to movement mechanism carrier 4 prevents the undesirable vibrations of plasmatron

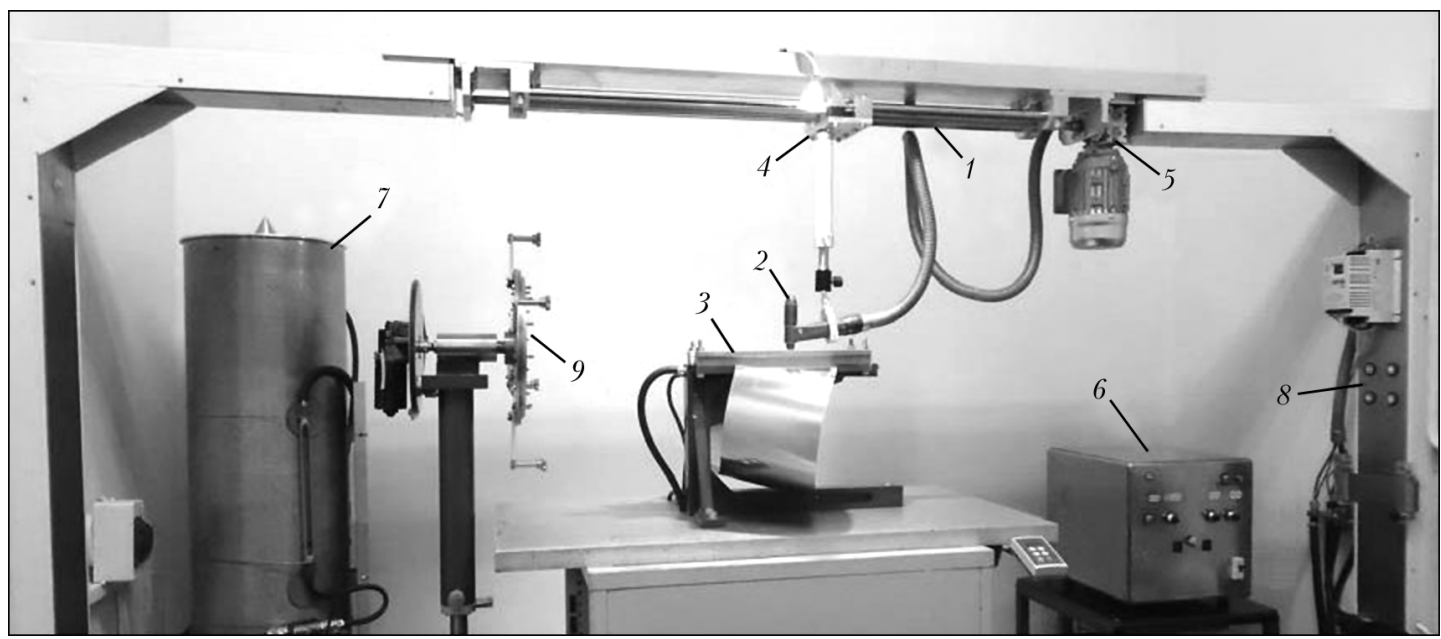

Figure 2. Experimental stand for welding of semi-products of transformable shells of foil materials: 1 - mechanism of movement; 2 - plasmatron; 3 - assembly-welding rig with conical semi-product of TVS shell; 4 - carrier of movement mechanism; 5 - motor with reducer; 6 - microplasma welding power source; 7 - heat-exchange module of plasmatron; 8 - automatic system of position adjustment of welding process parameters; 9 - device for welding of TVS circumferential welds 
during welding, and the combination of characteristics of motor, reducer with hollow shaft 5 and frequency transducer allowed avoiding the deviations in welding speed in the range of 1$25 \mathrm{~mm} / \mathrm{s}$, connected with kinematical error of the involute gearing. The equipment includes power source 6 for microplasma welding of the PWI design, providing the high stability of characteristics at welding currents of $1 \mathrm{~A}$ and higher.

The unique PWI developments were used also for designing the subassemblies of plasmatron, its cooling system and assembly-welding rig, which provides the deformation-free welding and effective protection of permanent joints of foil class metals.

Determination of range of energy inputs, at which the stable formation of quality straight-linear permanent joints of the foil class metal is possible in use of microplasma welding, does not encounter difficulties and described in works [2-4]. At the same time the conformity to the above-mentioned range can be attained at different welding conditions (at direct current or in pulsed mode) and in different combinations of parameters of pulsed mode (Figure 3), determining the different degree of the microstructure heterogeneity and distribution of alloying elements in weld metal and near-weld zone, as well as deviations of microhardness in weld section. At other equal conditions the optimality of mentioned characteristics, and also their combination with the best elastic-plastic and strength properties of permanent joints was the main criterion of selection between different groups of welding process parameters.

Determination of optimum parameters of welding process and next manufacture of thinwalled elements (sections) of the TVS were carried out in the specially designed assembly-welding rig, providing the rigid fixation of edges of foil conical semi-products at the length of some tens of centimeter at the absence of welding warping, effective removal of heat from the weld zone and maximum simplicity of assembly operation (see Figures 2 and 3). Protection of weld root with its simultaneous forced-convective cooling was attained by the inert gas pumping through a series of successive holes of alternate section in the protection channel, mated with collector. The depth, section and configuration of holes, as well as the cleanness of treatment of their edges allow reaching at the entire length of weld root almost the laminar flowing with full opening of the jet and at equal flow rates for shielding gases of different density at their consumption in the range of $5-10 \mathrm{dm}^{3} / \mathrm{min}$. At preset current value $I_{\mathrm{sp}}$ and filling coefficient $D$ the correction of energy input $Q_{1}$ at different frequencies $f_{\mathrm{pc}}$ was provided

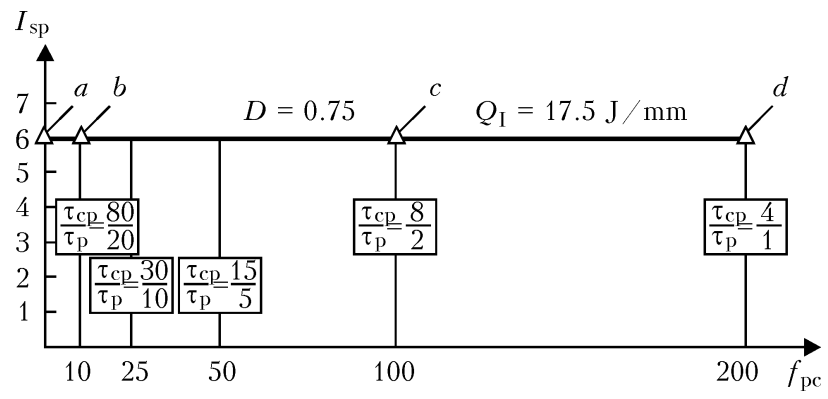

Figure 3. Combinations of parameters of pulsed conditions in microplasma welding of transformable conical shell of AISI 321 steel strip $0.17 \mathrm{~mm}$ thick: $I_{\mathrm{sp}}$ - current of straight polarity, $\mathrm{A} ; f_{\mathrm{pc}}-$ frequency of pulsed current, $\mathrm{Hz} ; \tau_{\mathrm{cp}}-$ duration of current pulse, ms; $\tau_{\mathrm{p}}-$ duration of pause, ms; $Q_{1}-$ energy input of welding; $D=\tau_{\mathrm{cp}} /\left(\tau_{\mathrm{cp}}+\tau_{\mathrm{p}}\right)-$ coefficient of filling; $a, b, c, d-$ basic combinations of parameters

by the change of volume consumptions of plasma and shielding gases at their unchanged optimum ratio, obtained empirically for selected parameters of the plasmatron and equal to about 0.32 at argon applying. Limitation of frequency of pulsed current by value $f_{\mathrm{pc}}=200 \mathrm{~Hz}$ was a need in search for optimum criteria of the quality of joints in the range of source parameters, not causing the quick wear of electrode and chamber of plasmatron plasma formation and, as a consequence, the violation of the stationary mode of welding.

Results of metallographic examinations of typical specimens from the series of welded joints produced at combinations of parameters, corresponding to Figure 3, are presented in Figure 4. Determined were the nature of heterogeneities of weld metal, near-weld zone and base metal of shell at variations of ratio $\tau_{\mathrm{cp}} / \tau_{\mathrm{p}}$, corresponding to different frequency of pulsed current, and also in case of welding with direct current of straight polarity at the preset value of energy input in all the combinations being examined.

Metallographic examinations, carried out in microscope «Neophot-32», illustrate the highest structural heterogeneity of series of specimens, made at SPDC (Figure 4, $a$ ). Weld microstructure over its section is characterized by non-uniformity and non-coaxility of crystallites with scattering of their sizes in width near the fusion line from 5 up to $7.5 \mu \mathrm{m}$ and from $4-5 \mu \mathrm{m}$ in the weld center up to $25 \mu \mathrm{m}$ near the weld root. Deviations of microhardness of weld and transition zone, measured by Vickers in LECO microhardness meter M-400 in DC welding are the highest: from 1920 up to $2570 \mathrm{MPa}$ at value of parameter of $2210 \mathrm{MPa}$ for the shell base metal (see Figure 4).

Microstructure of specimens, made at pulsed current with coefficient of filling $D=0.75$ at frequency 10 (Figure 4, b), 100 (Figure 4,c) and $200 \mathrm{~Hz}$ (Figure 4, $d$ ) is characterized by 

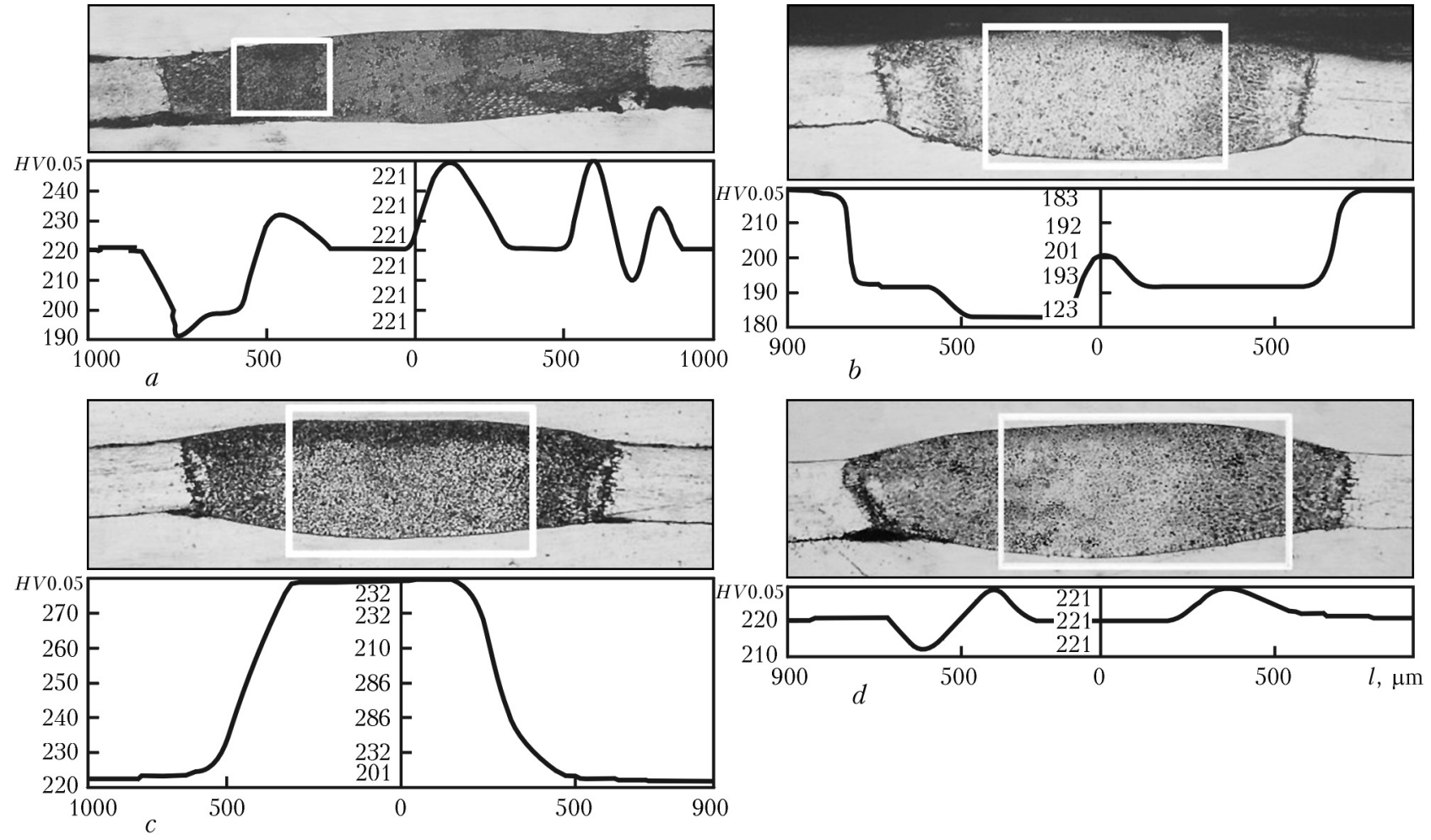

Figure 4. Results of metallographic examinations of series of welded joint specimens of AISI 321 foil $0.17 \mathrm{~mm}$ thick made at equal values of energy input using microplasma welding at SPDC $(a)$ and at pulsed current with $f_{\mathrm{pc}}=10(b)$, $100(c)$ and $200(d) \mathrm{Hz}$ (in zero point of diagram (weld middle) the values of microhardness $H V$ in vertical axis of welds are marked)

significantly higher homogeneity and co-axiality of cells at simultaneous decrease of deviations of microhardness in weld horizontal axis. In particular, the best combinations of parameters being examined were noted in series of specimens at $200 \mathrm{~Hz}$, i.e. the size of equi-axial cells corresponds to the range of 5-7 $\mu \mathrm{m}$ over all the weld section, the deviation of measured value of microhardness in any of directions of section does not exceed $5 \%$ of its value for the base metal.

In comparison of presented results with the results of testing of series of specimens, similar to groups of Figure 4, $a-d$, for static tension and bending tests, modeling the real service conditions, the closeness of elastic-plastic properties for base metal and welded joints with increase of pulsed current frequency was noted. Thus,

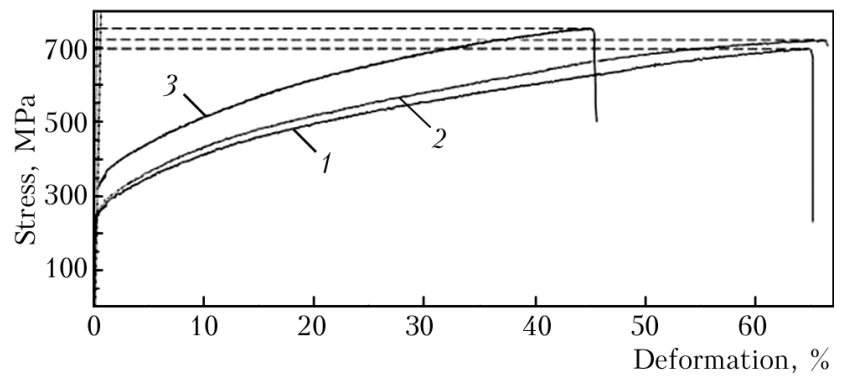

Figure 5. Diagrams of tension of specimen of $17 \mathrm{~mm}$ thick foil of steel AISI 321 without weld (1) and similar specimens made at pulsed current with $f_{\mathrm{pc}}=200 \mathrm{~Hz}(2)$ and at SPDC (3) ultimate tensile strength $\sigma_{\mathrm{t}}=724.5 \mathrm{MPa}$ and the conventional yield strength $\sigma_{0.2}=256.5 \mathrm{MPa}$ are typical of specimen of AISI 321 strip $0.17 \mathrm{~mm}$ thick with weld, made at pulsed current with $f_{\mathrm{pc}}=200 \mathrm{~Hz}$ (Figure 5, curve 2); for similar specimen without weld $\sigma_{\mathrm{t}}=699.7 \mathrm{MPa}, \sigma_{0.2}=$ $=259.2 \mathrm{MPa}$ (Figure 5, 1). Difference in the given characteristics does not exceed the errors of measurement of test system MTS ${ }^{\varpi} 318.25$, used for obtaining of experimental data. Typical diagram of tension for specimens made at SPDC is given in Figure 5, $3\left(\sigma_{t}=753.4 \mathrm{MPa}\right.$ and $\left.\sigma_{0.2}=289.3 \mathrm{MPa}\right)$.

The above-mentioned unique combination of technological and external factors in TVS service does not allow limiting by standard methods of testing in evaluating the quality of its welded structures. Vacuum of space causing desorption of shell material elements in combination with effect of radiation can be only considered conditionally as the chemically neutral environment; in transition of light-shadow boundaries at the structure surface the formation of condensates is possible with inclusions of active substances, present in natural external atmosphere of basic spacecraft for TVS. The appearance of intercrystalline corrosion, pores and microcracks, inadmissible by this reason, can be revealed by capabilities of optic microscopy at different stages of TVS manufacture by using capillary, eddy-current analysis and helium sampling. Nevertheless, the duration of action of external factors (up to 
several years), cyclic deformations caused by temperature fluctuations in the range up to $275^{\circ} \mathrm{C}$, and also natural effect of high and low temperatures require prediction of stability of properties of welded joints by their thorough study at all the structural levels. In evaluating the quality of welded joints, an integrated methodological approach to investigations of welded joints at macro- and micro level, passed a successful testing at the PWI, was realized.

In parallel with metallographic examinations, the assessment of distribution of alloying elements in weld metal was made by the method of $\mathrm{X}$-ray spectral microanalysis; the microanalyzer Camebax SX-50 (Cameca ${ }^{\circledR}$ ) with probe diameter of about $1 \mu \mathrm{m}$ at accelerating voltage $20 \mathrm{kV}$ and probe current $20 \mathrm{nA}$ was used. Curves of distribution of alloying elements were recorded in weld height and over its neutral surface. The analysis of obtained results proves that amount of alloying elements (in wt.\%) in weld metal and transition zones of specimens of Figure 4, b-d) (pulsed current) corresponds almost to similar parameters of the base metal.

The final stage of evaluation of welded joints of foil materials was the investigation of their fine structure, based on assumption about decisive effect of structural-phase state of the joint material on its physical-mechanical properties [5-7]. During investigations of dislocation structures, dislocation density and uniformity of its distribution, including structural conditions, causing the occurrence of local internal stresses in weld metal, the method of transmission microdiffraction electron microscopy (JEOL JEM200CX) was applied. Results of investigations allow making conclusion about reduction of localized deformations and structural stresses in specimens, made in use of the pulsed HF current. On the basis of the experimental-calculation estimations of contribution of structural and phase formations of the near-weld zone to the characteristics of ductility and strength the parameters of the technological process of welding were corrected. Results of work can make the conclusion about possibility of combination of the quality criteria of examined permanent joints in the range of welding process parameters, corresponding to frequencies of welding pulsed current $f_{\mathrm{pc}}=$ $=100-200 \mathrm{~Hz}$.

Optimum algorithm of conical type TVS transformation corresponds to proportions of determinative sizes, at which the ratio of conical section in unfolded position to its diameter does not exceed 0.5 value. Hence, the need in creation of structure of larger length or volume requires the uniting of many sections into single structure by their welding along their mating contours. The solution of the problem of stability of the multi-section TVS of space application and estimation of its deformability allow specifying the requirements to configuration and rigidity of welded joining elements of conical sections, in particular, the elements of smaller diameter, subjecting to the highest specific loads. The functional application of circumferential welded joints is not limited by maintaining the integrity, mechanical strength and vacuum-tightness of the multi-section long structure; the required damping properties of the latter can be provided by the peculiarities of profile of the conical surfaces of TVS in combination with rigidity of circumferential joining elements. Welding of the conical sections around the perimeters of basements unites their abutted flanges (see Figure 1,F) into single element of rigidity, i.e. ring frame, the efficiency of which depends greatly on ring width, but not on its total thickness, and also the nature of the welded joint. In particular, when welding the considered TVS flanges of smaller diameter with calculated width of $6 \mathrm{~mm}$ in the designed rotary device (see Figure 2, 9), the required result is attained by application of the combined weld, i.e. slot weld with fixation of plasmatron axis in normal to the flange plane, and then edge weld in orientation of plasmatron axis along the line of flat corrugated disc radius.

The multi-section conical TVS in compact and unfolded position at test stand of unfolding is presented in Figure 6 . The presented models of segments $(1,2)$ illustrate the scheme of making of welded joints, allowing binding the parameters of conical section into rigid ring type element of the structure. Vacuum-tight joint of edge conical section with closing element (bottom) ( $\mathrm{Fi}^{-}$ gure 6,3$)$, having material thickness $\Delta=(6-8) \delta$, where $\delta$ is the thickness of structure shell material, is performed by a preliminary welding of perimeter of section with ring of intermediate thickness $\delta_{1}=(\Delta+\delta) / 2$. Circumferential welded joints of conical TVS, unlike the straight-linear welds of the structure, are not subjected to high technological and service deformations and undergo negligible loads from internal excessive pressure of unfolding, not exceeding the value of $50 \mathrm{kPa}$. The joints can be made by the microplasma method in pulsed mode at the condition of correction of scheme of shielding gas supply for the edge welds (see Figure $6, J$ ).

The on-land cycle of tests of structure is oriented, first of all, to study of kinetics of unfolding process during the preset interval of time and under conditions, close with possible validity to the zero gravity conditions of the orbital flight. Design of vacuum-tight contour (see Figure 6, 5) will allow carrying out tests of unfolding of long TVS in different spatial positions, realizing its mass reduction simultaneously with modeling 


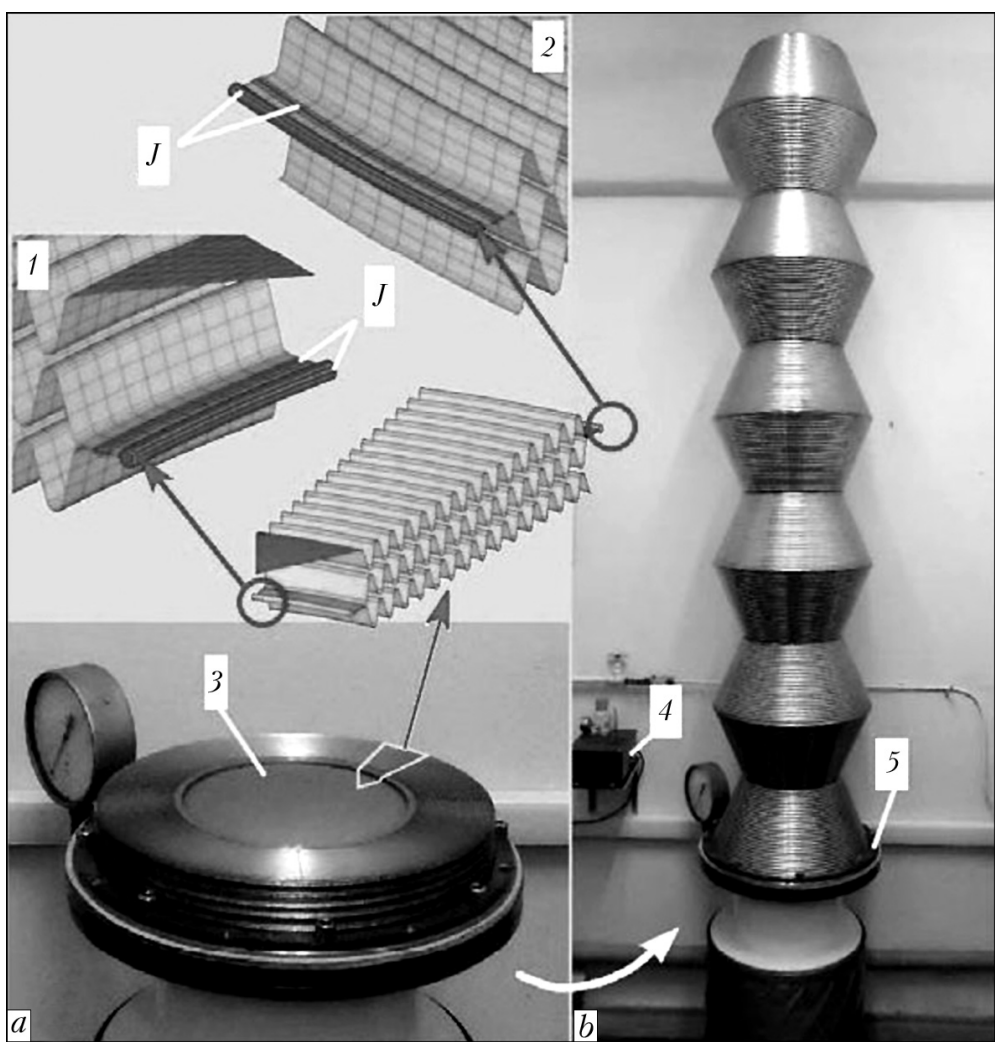

Figure 6. Conical TVS of 11 shells in the compact $(a)$ and unfolded $(b)$ positions: on the left at the top - models of segments of structure with internal (1) and external (2) circumferential welded joints $J$; 3 - closing element; 4 compact compressor with manovacuummeter; 5 - rigid vacuum-tight contour of unfolding stand

of regulated vibration actions and making the modal analysis. The scheduled vacuum tests with simulation of heat loads under the space conditions will allow evaluating the thermooptical properties of TVS surfaces and boundary temperatures, which are attained on them, thus making it possible to specify values of stresses occurred in the shell and, when necessary, to correct the configuration of ring joining elements of standard structure. In this case, the air-tightness (vacuum tightness) of the compact multi-section shell can be effectively confirmed by the advanced NDT methods.

Results of the presented work demonstrate the feasibility of TVS manufacture with preset properties of welded joints, optimized for longtime service under the action of combination of factors, not investigated earlier. By this reason, the scheduled testing of structure under the conditions of the orbital flight, which can be predicted, but cannot be reproduced at the on-land tests represents the greatest interest.

\section{Conclusions}

1. The optimum conditions of formation of permanent joints of transformable shells of foil of AISI 321 grade, the combination of physical-mechanical properties and structural peculiarities of which are maximum close to similar properties of the base metal and should provide the oper- ating characteristics of structure under extreme conditions of service, were determined and confirmed experimentally.

2. Complex of technological equipment was developed, providing the defect-free technology of microplasma welding of vacuum-tight permanent joints of foil materials under conditions of the pilot production.

3. Approaches are described for the design of multi-section TVS, capable to guarantee the serviceability of structures of this class at long-time exposure under extreme service conditions.

1. Mikrofuegetechnik GmbH. Automation + Application Technology. http: / media.mig-o-mat.com

2. Paton, B.E., Gvozdetsky, V.S., Dudko, D.A. et al. (1979) Microplasma welding. Kiev: Naukova Dumka.

3. (2008) Microjoining and nanojoining. Cambridge: Woodhead Publ.

4. Lobanov, L.M., Volkov, V.S. (2012) Development of the technology of manufacturing double-wall welded transformable-shell structure. The Paton Welding J., 10, 34-39.

5. (1997) Welding and surfacing reviews. Pt 1: Welded structures. Ed. by B. Paton, L. Lobanov. London: Taylor \& Francis.

6. Evans, G.M., Bailey, N. (1997) Metallurgy of basic weld metal. Cambridge: Woodhead Publ.

7. Nikitina, Ye.V., Frolov, V.A., Stepanov, V.V. et al. (2014) Investigation of the structural and chemical heterogeneity in welding of different groups of metallic materials. Welding Int., 28(10), 793-798.

Received 18.11.2014 


\title{
APPLICATION OF WELDED STUDS FOR FASTENING OF RAILWAY BRIDGE DECK
}

\author{
V.V. KNYSH ${ }^{1}$, S.A. SOLOVEJ ${ }^{1}$, A.A. GRISHANOV ${ }^{1}$, G.O. LINNIK $^{2}$ and M.G. MALGIN ${ }^{3}$ \\ ${ }^{1}$ E.O. Paton Electric Welding Institute, NASU \\ 11 Bozhenko Str., 03680, Kiev, Ukraine. E-mail: office@paton.kiev.ua \\ ${ }^{2}$ Ukrzaliznytsya \\ 5 Tverskaya Str., 03680, Kiev, Ukraine. E-mail: cpi@lotus.uz.gov.ua \\ ${ }^{3}$ MIDAS Information Technology Co., Seul, Korea. E-mail: malgin@midasit.com
}

\begin{abstract}
Proposed is a new structure of fastening of slabs of ballast-free bridge deck to T-girders of railway bridges, which provides for change of thread studs to welded ones. Arc-contact welding allows for stud positioning directly over vertical wall of T-girder that does not result to angular deformation of girder upper flange typical in application of thread studs. Aim of present work was evaluation of possibility of application of welded studs for fastening of slabs of ballast-free bridge deck in construction and repair of railway bridges. For that, fatigue tests of welded joints of stud to upper flange of girder from the most wide-spread steels St3sp (killed) and 09G2S were carried out at different ranges of loading, which are realized in stud preliminary tightened with 6 tf force during rolling stock movement. It is determined that cyclic life of such joints exceeds $5 \cdot 10^{6}$ cycles of stress alternation at loading range $\Delta P \leq 3 \mathrm{tf}$. Numerical simulation showed that application of oak board and rubber band as spacing layer between slab of ballast-free bridge deck provides for cyclic life of welded stud not less than $5 \cdot 10^{6}$ cycles of stress alternation, since loading range exceeds $\Delta P=3 \mathrm{tf}$. However, application of fast hardening nonshrinking mixtures (cast-in-place concrete) as spacing layer allows reducing range of loading to $\Delta P=1 \mathrm{tf}$, that guarantees welded stud life not less than $5 \cdot 10^{6}$ cycles of stress alternation. 13 Ref., 2 Tables, 16 Figures.
\end{abstract}

Keywords: welded joint, welded stud, slab of balast-free bridge deck, fatigue resistance, fatigue test

Nucleation and propagation of fatigue cracks in welded assemblies and structure elements of spans of railway bridges can be prevented with the help of technological methods (measures), directed on increase of welded joint fatigue resistance as well as by improvement of existing structural solutions, including structure of bridge deck, which has significant effect on life of railway bridge span [1-4]. Perspective direction for improvement of technical characteristics of spans under operation is progressive replace- ment of timber-based bridge deck by reinforced concrete slab-based bridge deck. The latter has the following advantages, namely high stability of element positioning and long-term operation; protection from corrosion and contamination of upper flange of girders and connections between them; being economic as for total cost of manufacture, laying and operation during bridge service life.

However, structure of bridge deck based on reinforced concrete slabs (Figure 1) has some disadvantages. Applied structure of fastening of slab to main or longitudinal T-girders of span

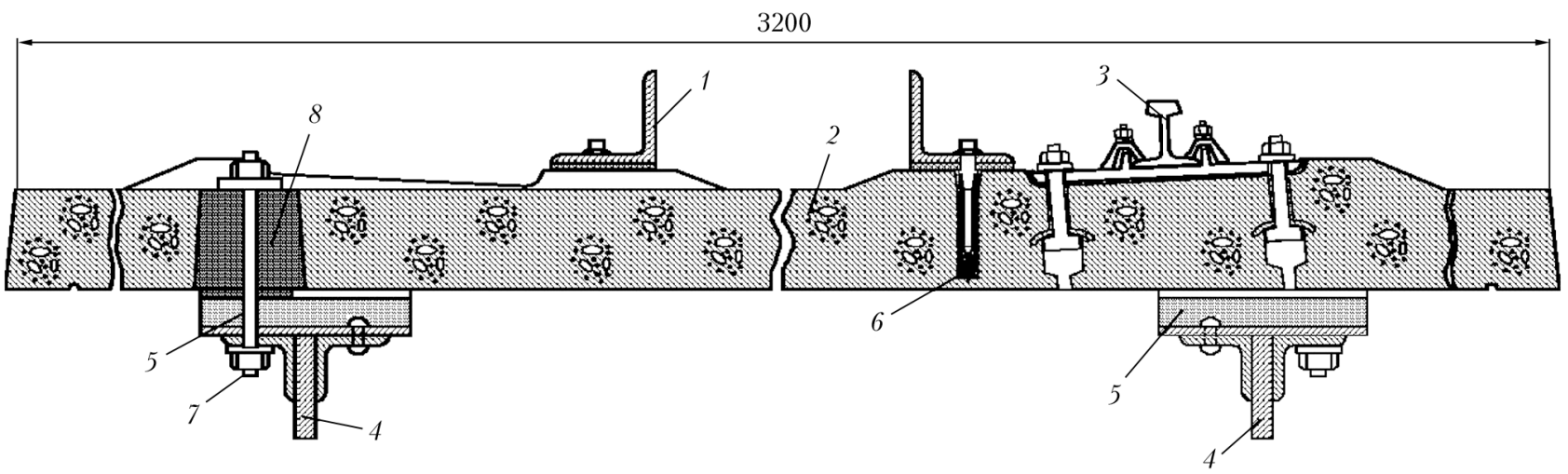

Figure 1. Structure of bridge deck based on BFBD slabs: 1 - contrangle; 2 - reinforced concrete slab of bridge deck; 3 - rail; 4 - main or longitudinal beam; 5 - spacing layer; 6 - polymer dowel with screw spike; 7 - high-strength stud; 8 - hole for stud 


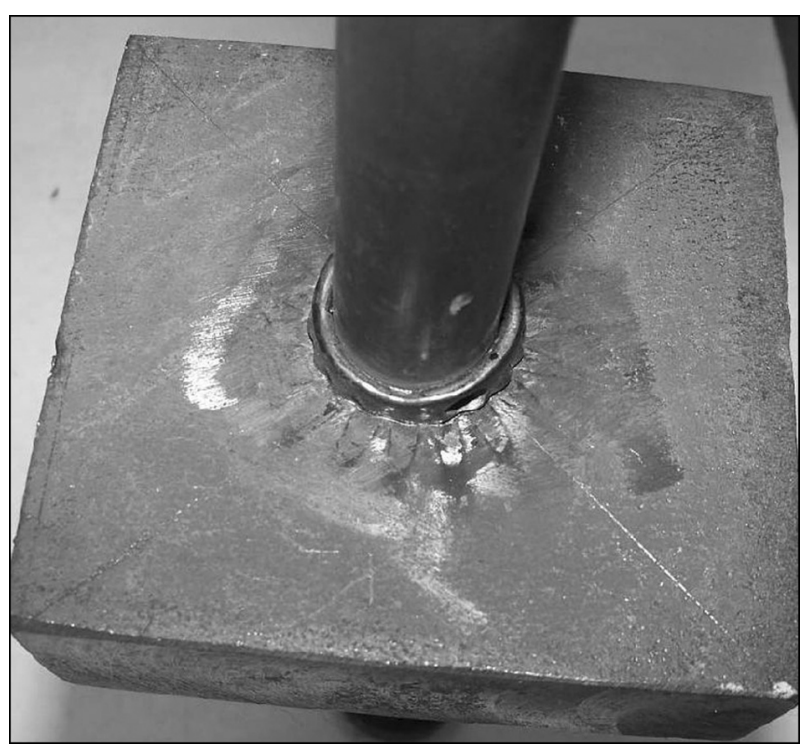

Figure 2. Stud to plate welded joint

can be referred to such disadvantages. Existing technology of fastening of slabs of balast-free bridge deck (BFBD) by removable high-strength thread studs provides for their positioning with eccentricity in relation to vertical wall of longitudinal girder that provokes for appearance of additional loading on upper flange of girder in rolling stock movement, that results in preliminary nucleation of fatigue cracks of $T_{4}$ and $T_{9}$ types [5].

It is obvious that elimination of indicated eccentricity requires positioning of fastening studs of BFBD slabs in the plane of vertical wall of T-girder. Such structural solution is possible only under condition of application of welding processes. Considering restricted normative limits on organizing of works on replacement of bridge deck as well as possibility of application of stand-

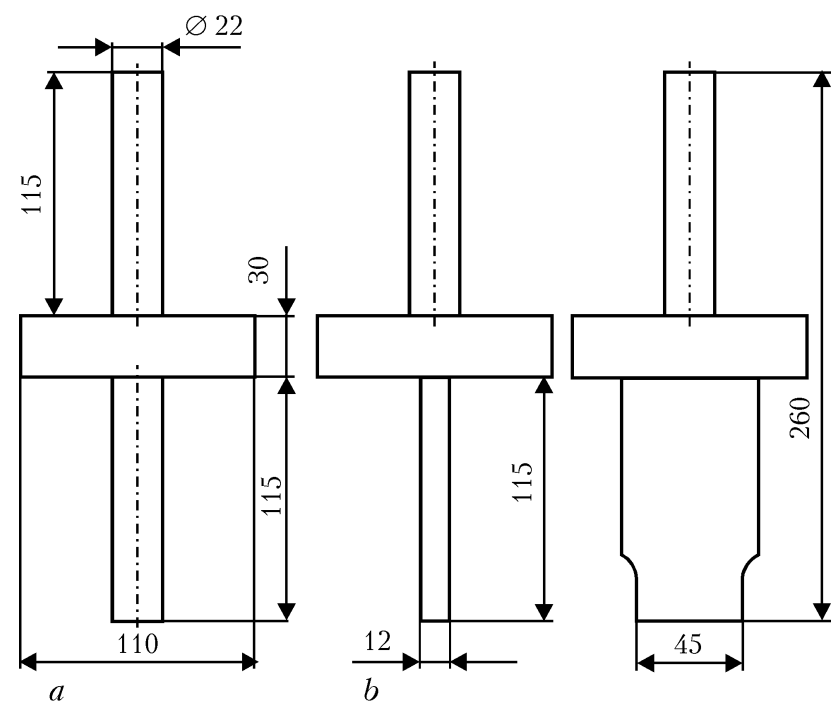

Figure 3. Drawing of mock-up welded joint of stud for fastening of BFBD slabs to upper flange of T-girder with cylindrical $(a)$ and prismatic (b) gripping parts (first series of specimens) ard fasteners, stud welding is relevant to be carried out with the help of arc-contact technology. However, given welded element (welded stud operating under alternating tension) is absent in domestic and foreign reference documents on fatigue calculation [6-9].

Therefore, aim of present work lies in estimation of possibility of application of welded studs for fastening of BFBD slabs in construction and repair of railway bridges.

Materials and investigation procedure. Experimental investigations on fatigue resistance of welded joint of stud to upper flange of solid (not composite) T-girder was carried out on mock-up specimens. The latter consist of the following parts: stud, plate simulating solid upper flange of T-girder; and gripping part. Stud from lowalloy steel $09 \mathrm{G} 2 \mathrm{~S}$ was welded using arc-contact method on center of the plate (Figure 2), and electric-arc welding by stick electrodes UONI$13 / 55$ was used for gripping part. Dimensions of the gripping part are stipulated by gripping devices of test machine ZDM-10pu, which allows for carrying out test of the specimens at alternating stresses of repeated or reversed cycles in $\pm 10 \mathrm{tf}$ loading range. Testing of mock-up specimens was carried out at uniaxial cyclic tension with $5 \mathrm{~Hz}$ frequency. Such loading scheme corresponded to scheme of loading of high-strength studs in fastening of BFBD slabs in railway bridge spans. Complete fracture of the specimen or exceeding of testing base of $5 \cdot 10^{6}$ cycles of stress alternations were taken as criterion of test completion.

The first series of specimens for fatigue tests consisted of four mock-up specimens, where $22 \mathrm{~mm}$ diameter stud was welded to 09G2S steel $\left(\sigma_{\mathrm{y}}=375 \mathrm{MPa}, \sigma_{\mathrm{t}}=510 \mathrm{MPa}\right)$ plate of $30 \mathrm{~mm}$ thickness: two specimens each with cylindrical and prismatic gripping parts (Figures 3 and 4). The tests were carried out at zero-to-tension cycle with maximum force $6 \mathrm{tf}$. Such stud loading was determined on full-scale structures (see $\mathrm{Fi}^{-}$ gure 1), spacing layer of which consists from $200 \times 40 \mathrm{~mm}$ size oak board and $200 \times 8 \mathrm{~mm}$ rubber band. It should be noted that today given

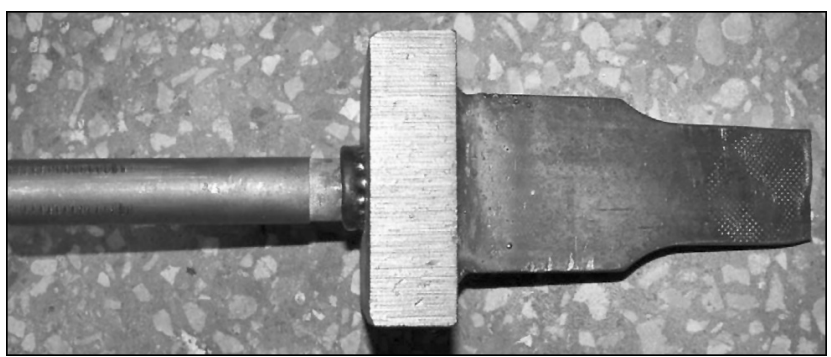

Figure 4. View of welded mock-up specimen for fatigue testing with prismatic gripping part 

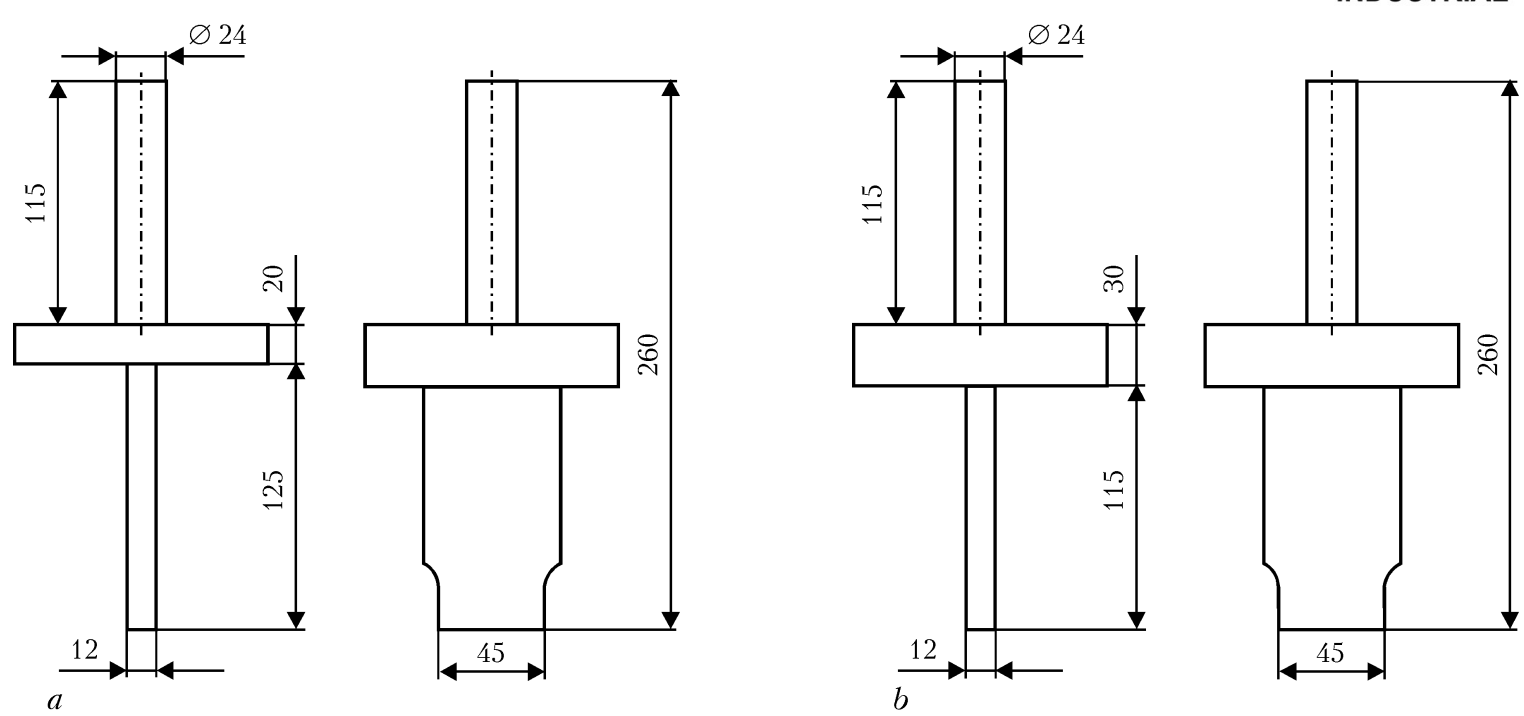

Figure 5. Drawing of mock-up specimen of welded joint of fastening stud of BFBD slabs to upper flange of T-girder from St3sp $(a)$ and 09G2S (b) steels (second and third series of specimens, respectively)

structure of the spacing layer is a basic one in construction and repair of railway bridges in Ukraine.

Test procedure was improved and corrected based on results of testing of first series of specimens. Diameter of welded stud was increased to $24 \mathrm{~mm}$. Taking into account that most of T-girder of railway bridge spans are manufactured from St3sp (killed) low-carbon steel and low-alloy steel $09 \mathrm{G} 2 \mathrm{~S}$, therefore, $24 \mathrm{~mm}$ diameter stud in mock-up specimens of second series was welded to St3sp steel $\left(\sigma_{\mathrm{y}}=235 \mathrm{MPa}, \sigma_{\mathrm{t}}=420 \mathrm{MPa}\right)$ plate of $20 \mathrm{~mm}$ thickness, and $24 \mathrm{~mm}$ diameter stud in specimens of third series was welded to 09G2S steel $\left(\sigma_{\mathrm{y}}=375 \mathrm{MPa}, \sigma_{\mathrm{t}}=510 \mathrm{MPa}\right)$ plate of $30 \mathrm{~mm}$ thickness (Figure 5). Each series consisted of eight specimens. The gripping part of specimens was made prismatic.

The tests were carried out on following procedure. Cyclic life of stud welded joints was de-

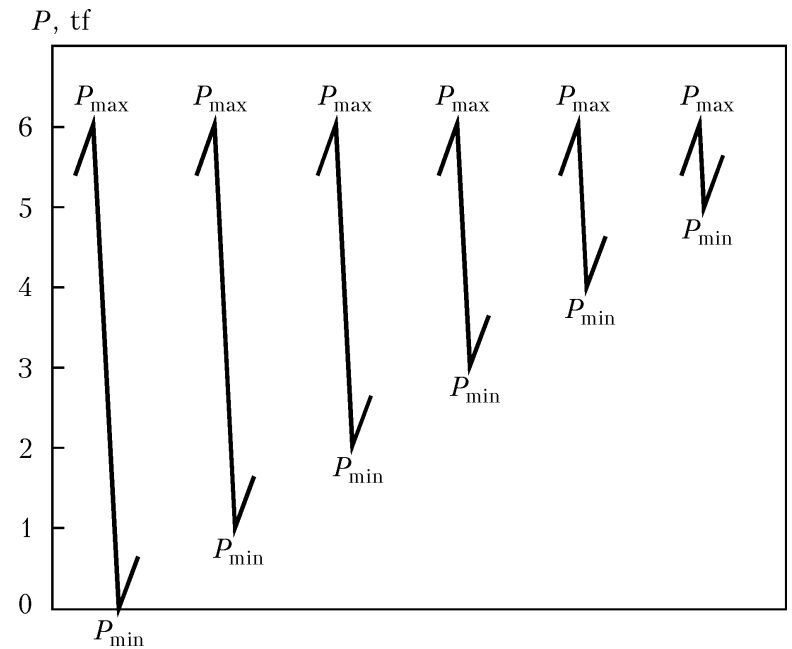

Figure 6. Schematic representation of loading range in fatigue testing of mock-up welded specimens of second and third series termined at different loading ranges. Maximum applied loading was not changed and made $6 \mathrm{tf}$, that corresponded to stud tightening force at mounting of BFBD slab. Initial minimum applied loading made $0 \mathrm{tf}$, that corresponded to complete unloading of the stud. If set initial loading range of $6 \mathrm{tf}$ promoted preliminary fracture of two specimens at life not less than $5 \cdot 10^{6}$ stress alternation cycles, then the range was reduced by $1 \mathrm{tf}$ due to increase of minimum loading. Schematic representation of loading ranges in fatigue testing of the second and third series of specimens is given in Figure 6.

Investigation results. Failure of all specimens of first series took place on welded joint of stud to plate, simulating solid horizontal flange of T-girder. Specimen life determined in experimental way lies in the range from 53,500 to 105,600 cycles of stress alternation (at that necessary cyclic life of $\leq 5 \cdot 10^{6}$ cycles of stress alternation are not provided):

$\begin{array}{rcccc}\text { Number of specimen } & 1 & 2 & 3 & 4 \\ \text { Number of cycles be- } & 105,600 & 165,800 & 53,500 & 175,900\end{array}$
fore failure $N$

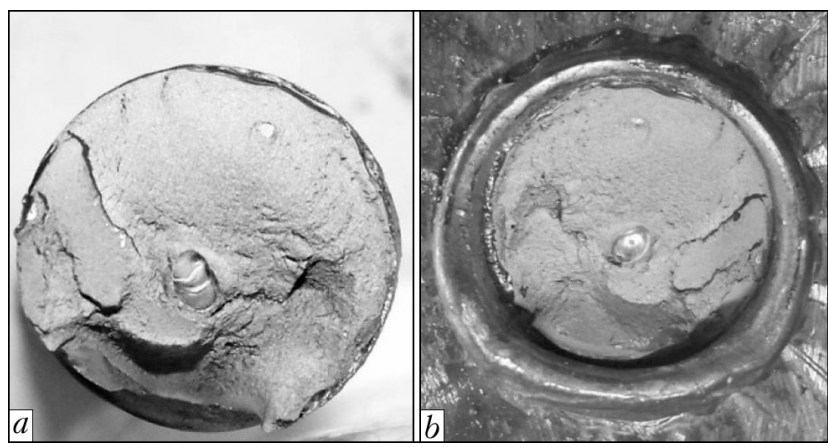

Figure 7. Internal weld defects in specimen 3 of first series: $a$ - pores; $b-$ lack of fusion 


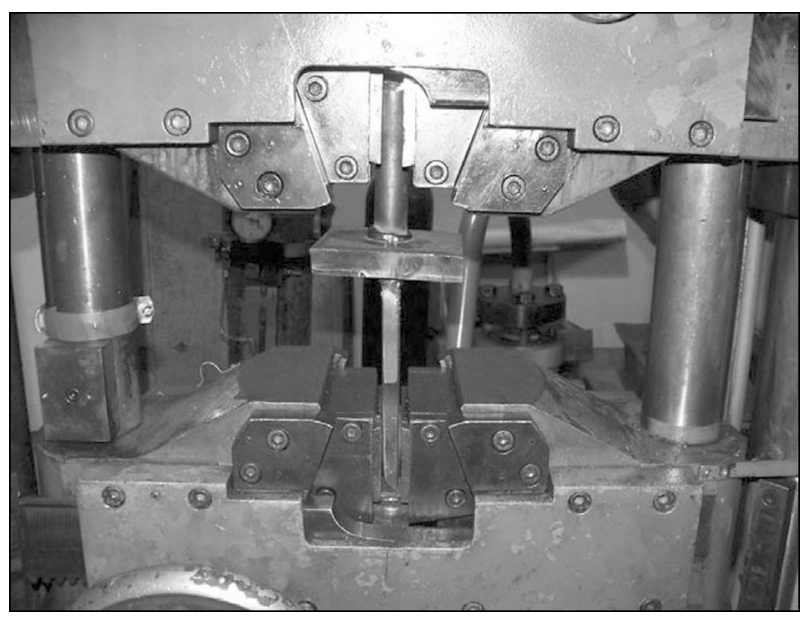

Figure 8. Fatigue tests of specimen of welded joint of second series on ZDM-10pu machine

Performed fractographic analysis of failure places determined presence of such internal defects as pores on welded joint center and lack of fusion on edge (Figure 7). Presence of defects indicates possible deviations of technological parameters of welding process, caused by effect of external factors or insufficient adjustment of welding technology. It should be noted that loading of mock-up specimen with zero-to-tension stress of $6 \mathrm{tf}$ promotes for achievement of $160 \mathrm{MPa}$ maximum stresses in throat area of $22 \mathrm{~mm}$ diameter welded stud. Limited life of defect-free butt welded joints under such stresses is at the level of $2 \cdot 10^{6}$ cycles of stress alternation with $50 \%$ failure possibility [10, 11]. Calculation value of margin of limited durability of butt welded joints on basis of not less than $5 \cdot 10^{6}$ cycles of stress alternation at $95 \%$ failure possibility
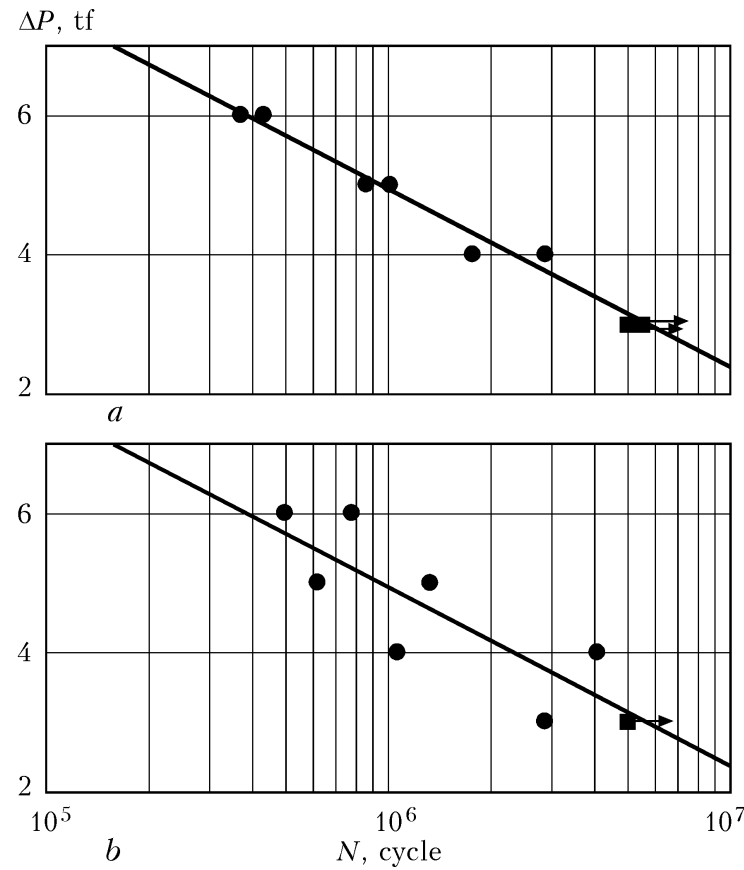

Figure 9. Fatigue curve of welded joints of $24 \mathrm{~mm}$ diameter stud to plate from St3sp $(a)$ and 09G2S $(b)$ steels
Table 1. Results of fatigue tests of mock-up specimens of second and third series

\begin{tabular}{|c|c|c|}
\hline \multirow{2}{*}{$\begin{array}{c}\text { Specimen } \\
\text { No. }\end{array}$} & Second series & Third series \\
\cline { 2 - 3 } & 433,500 & 782,400 \\
\hline 1 & 371,600 & 499,800 \\
\hline 2 & $1,011,900$ & 623,600 \\
\hline 3 & 863,000 & $1,326,100$ \\
\hline 4 & $1,757,600$ & $4,080,800$ \\
\hline 5 & $2,873,300$ & $1,062,500$ \\
\hline 6 & $>5,000,000$ & $2,873,300$ \\
\hline 7 & $>5,000,000$ & $>5,000,000$ \\
\hline 8 & \multicolumn{2}{|c|}{$P_{\max }=6$ tf. 2 . For specimens 1 and 2} \\
\hline $\begin{array}{l}\text { Notes. } 1 . \text { For all specimens } \\
P_{\min }=0 ; 3,4-1 ; 5,6-2 ; 7 \text { and } 8-3 \text { tf. }\end{array}$ \\
\hline
\end{tabular}

according to [6] makes $114 \mathrm{MPa}$. It should be considered that values of stress concentration coefficient for stud to plate joint significantly exceed the values of stress concentration coefficient typical for butt joints $\left(\alpha_{\sigma}=1.1-1.3\right)$.

Thus, it can be concluded using the results of testing of first series of specimens that application of welded studs in railway bridge spans is possible under condition of reduction of stress effect in the throat area of stud due to increase of stud diameter and decrease of loading ranges in use of new structures for spacing layer between BFBD slab and upper flange of T-girder.

Equipment for arc-contact welding «Nelson Nelweld 6000» provides for welding of $24 \mathrm{~mm}$ diameter studs. Increase of stud diameter from

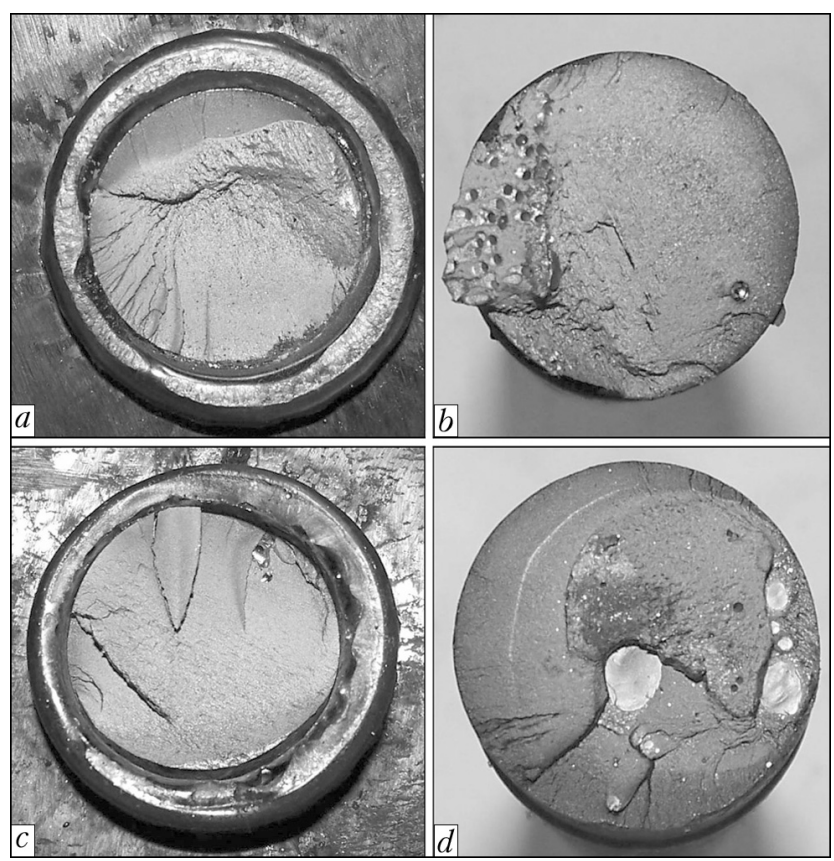

Figure 10. Fracrtures of mock-up specimens 3 and 4 of second $(a, b)$ and 5 and 6 of third $(c, d)$ series 
Table 2. Properties of materials of spacing layer between BFBD slab and upper flange of T-girder

\begin{tabular}{|c|c|c|c|c|}
\hline \multirow{2}{*}{ Material } & \multirow{2}{*}{ Element of bridge deck } & \multicolumn{2}{|c|}{ Modulus of elasticity $E, \mathrm{MPa}$} & \multirow{2}{*}{ Poisson coefficient $v$} \\
\hline & & Range & Calculation & \\
\hline Concrete & BFBD slab & \multicolumn{2}{|c|}{$3 \cdot 10^{4}$} & 0.2 \\
\hline Concrete & Spacing layer & \multicolumn{2}{|c|}{$3 \cdot 10^{4}$} & 0.2 \\
\hline Wood across the grain & Same & $500-1000^{*}$ & 750 & 0.16 \\
\hline Rubber & $\gg$ & $7-14^{* *}$ & 10 & 0.5 \\
\hline Steel & Stud & \multicolumn{2}{|c|}{$2.1 \cdot 10^{5}$} & 0.3 \\
\hline
\end{tabular}

22 to $24 \mathrm{~mm}$ allows for reducing maximum stresses in the throat area from 160 to $130 \mathrm{MPa}$.

Testing of second and third series of mock-up specimens were also carried out on ZDM-10pu machine at $5 \mathrm{~Hz}$ frequency (Figure 8).

Results of fatigue tests of specimens from second series (stud was welded to plate from St3sp steel) and from third one (stud was welded to plate from steel 09G2S) are given in Table 1, and Figure 9 represents corresponding fatigue curves. Failure of specimens of second series took place on welded joint of stud to plate. Cyclic life of tested specimens exceeds the values of $5 \cdot 10^{6}$ cycles of stress alternation at loading range $\Delta P \leq 3$ tf. Fractographic analysis was carried out for place of fracture of mock-up specimens. Presence of such internal defects as pores (Figure 10, b) reduces cyclic life of the specimens by $20 \%$ (life of specimen 4 with pores makes 863,000 cycles of stress alternations and 1,011,900 cycles for specimen 3 without pores).
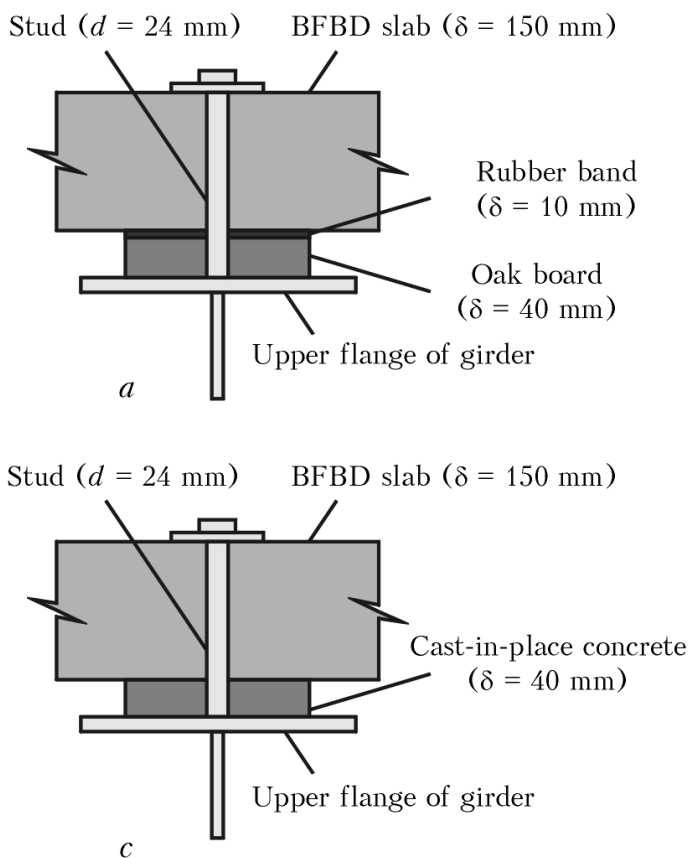

Failure of specimens of third series took place in welded joint of stud to plate. Cyclic life of tested specimens also exceeds the values of $5 \cdot 10^{6}$ cycles of stress alternation at $\Delta P<3 \mathrm{tf}$ loading range. At that, experimental data for specimens of third series have larger spread in comparison with specimens of second series. Presence of pores and lack of fusions (Figure 10, $d$ ) promotes 4 times reduction of cyclic life of specimens (life of specimen 5 makes 4,080,800 cycles of stress alternation and 1,062,500 cycles for specimen 6 without pores).

Considering data received on mock-up specimens of first series, increase of stud diameter from 22 to $24 \mathrm{~mm}$ resulted in 3-6 times increase of life under similar levels of loading range from 0 to $6 \mathrm{tf}$. At that, peculiarities of fracture of studied specimens of all three series indicate the necessity of adjustment of technology of arc-contact welding for fastening studs of BFBD slabs. Reduction of amount of internal defects allows
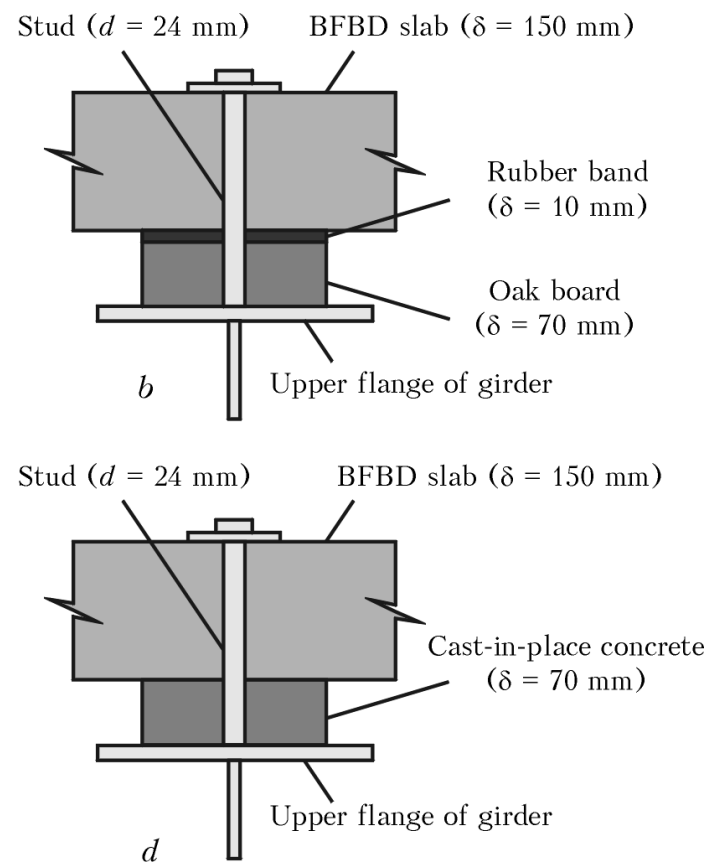

Figure 11. Types of spacing layer of bridge deck from oak board, rubber band $(a, b)$ and cast-in-plate concrete $(c, d)$ of various thickness 

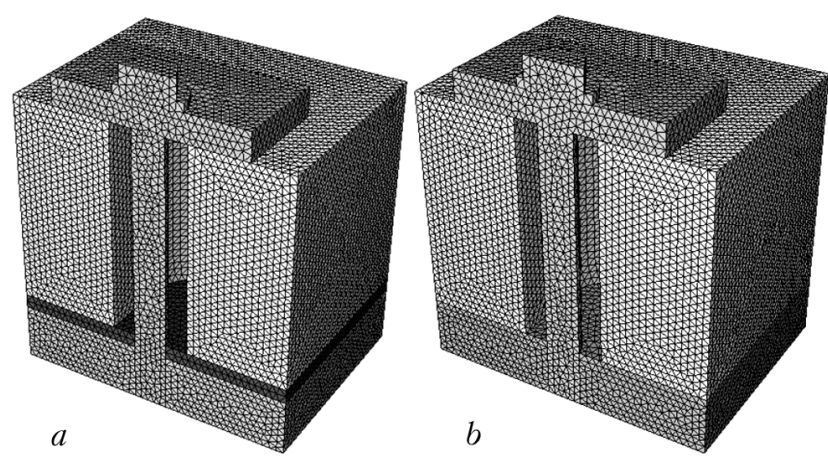

Figure 12. Fragment of calculation models for spacing layer from wood and rubber $(a)$ and cast-in-place concrete $(b)$

for increasing a possibility of nonfailure of welded joints of $24 \mathrm{~mm}$ diameter studs in loading range from 3 to $6 \mathrm{tf}$.

Data of full-scale investigations showed that loading ranges effecting welded stud exceed $3 \mathrm{tf}$ in use of the spacing layer between BFBD slabs and T-girder (oak board and rubber band). Range of stud operating alternating stresses from 3 to $6 \mathrm{tf}$ can be achieved by means of increase of rigidity of the spacing layer, for example, thanks to application of fast hardening nonshrinking mixtures (concretes).

Numerical calculation was applied to change of initial ( $6 \mathrm{tf})$ tightening force of welded stud

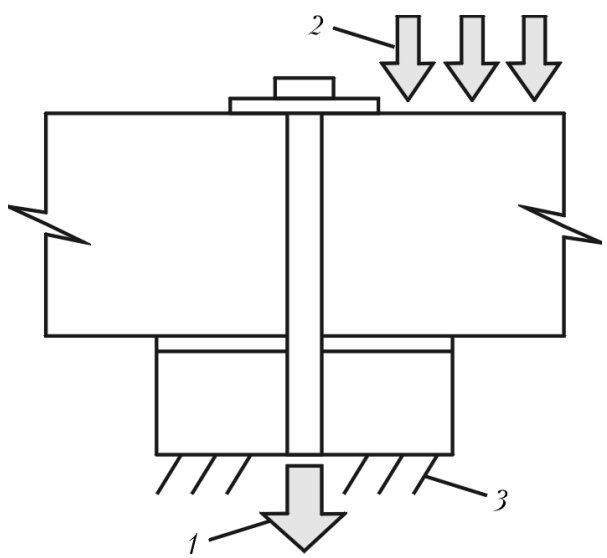

Figure 13. Scheme of calculation model: 1 - set movement of stud basis (tightening); 2 - pressure from transport wheel; 3 - rigid attachment

during passing of rolling stock depending on applied types of the spacing layers since stress-strain state of elements of bridge deck in initial condition and in passing of rolling stock depends on the spacing layer between BFBD slab and Tgirder. All numerical calculations were performed in program complex midas Civil using finite-element method.

The following conditions were used in performance of numerical modelling: reinforced concrete slab of BFBD had typical geometry dimen-
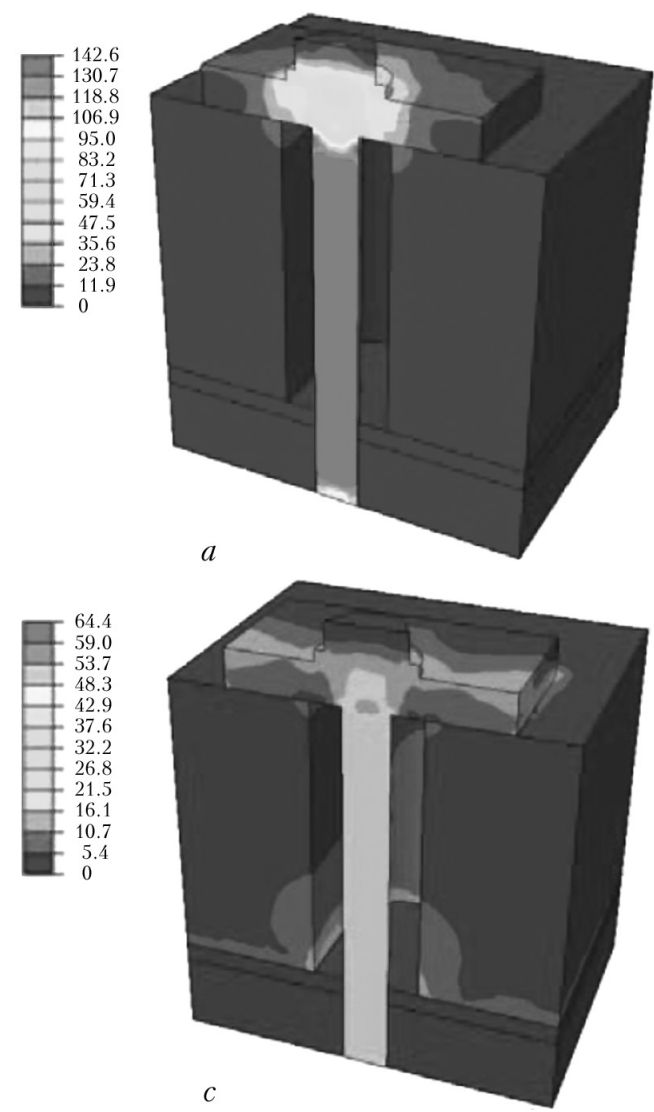
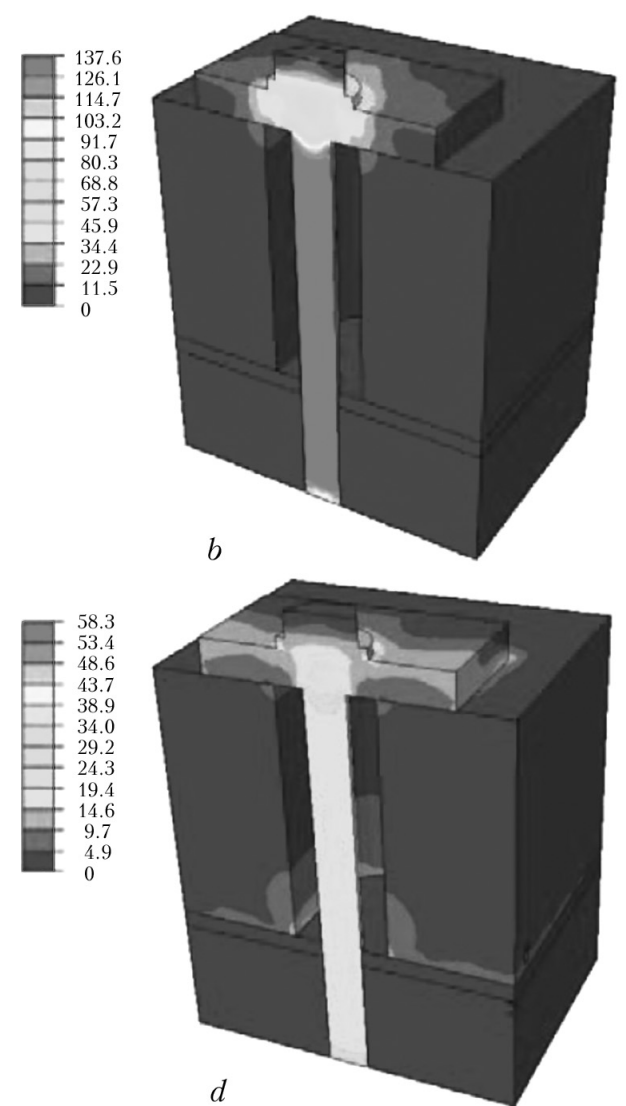

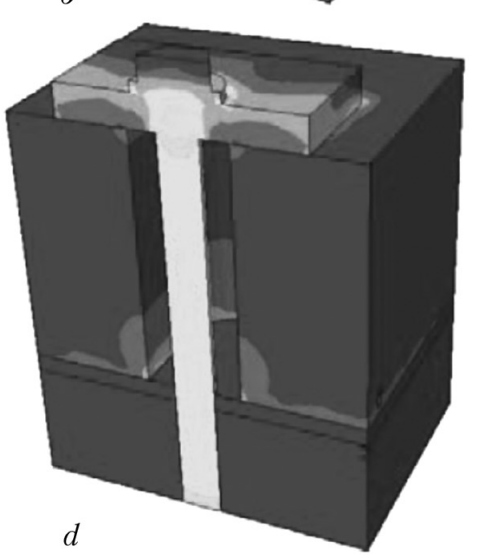

Figure 14. Isofields of stresses in welded stud in initial condition $(a, b)$ and during passing of rolling stock (c, $d)$ : $a$, $c-$ spacing layer from oak board of $\delta=40 \mathrm{~mm}$ and rubber band of $\delta=10 \mathrm{~mm} ; b, d-$ spacing layer from $70 \mathrm{~mm}$ oak board and $10 \mathrm{~mm}$ rubber band 

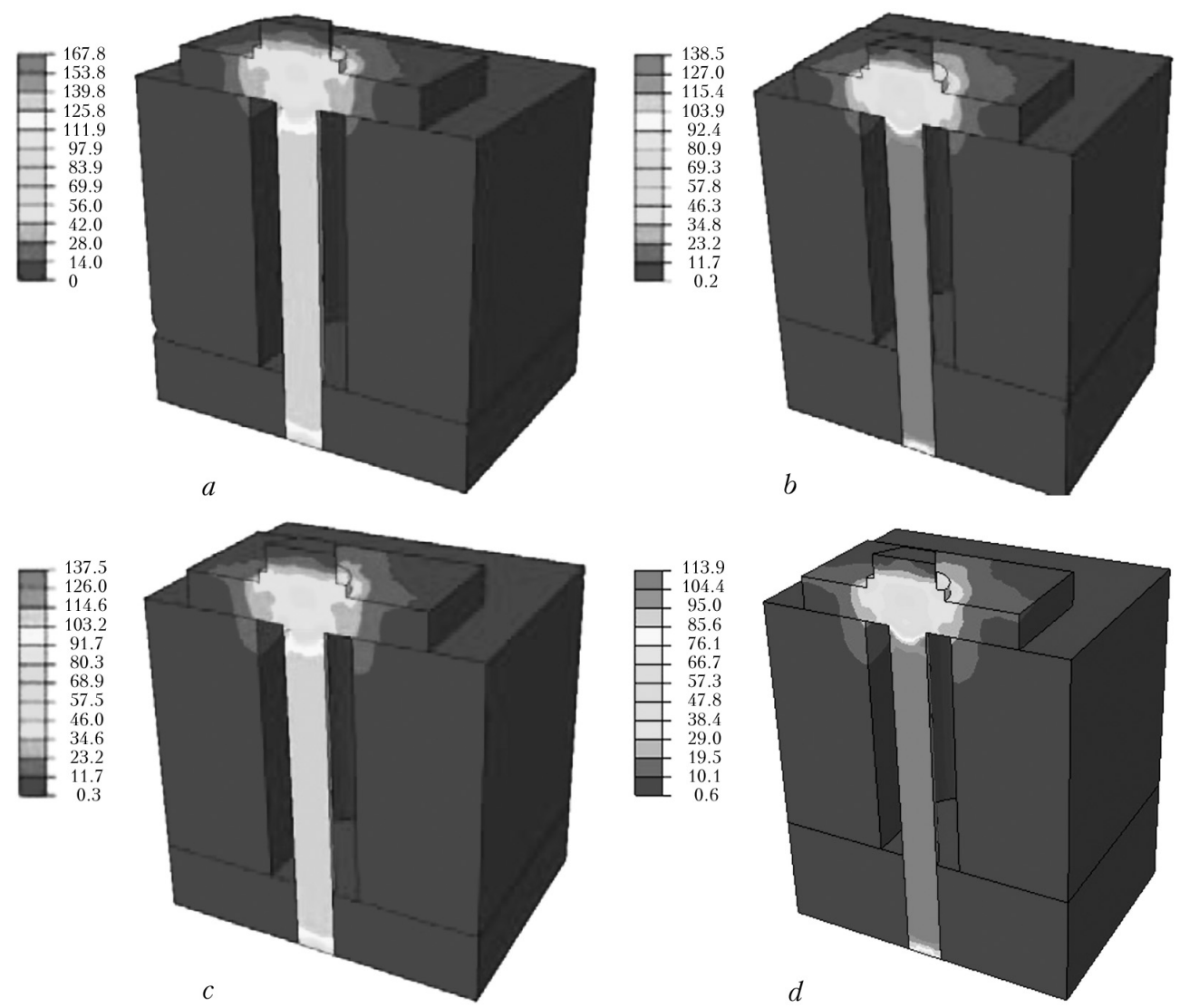

Figure 15. Isofields of stresses in welded stud in initial condition $(a, b)$ and during passing of rolling stock ( $c, d)$ : $a$, $c$ - spacing layer from cast-in-place concrete of $\delta=40 \mathrm{~mm} ; b, d-$ the same, but $\delta=70 \mathrm{~mm}$

sions [12], diameter of welded stud was $24 \mathrm{~mm}$, initial tightening force made $6 \mathrm{tf}$ and axial loading from railway transport was $30 \mathrm{tf}$.

Four spacing layers were investigated between BFBD slab and T-girder, namely oak board of $\delta=40 \mathrm{~mm}$ and rubber band of $\delta=10 \mathrm{~mm}\left(\mathrm{Fi}^{-}\right.$ gure $11, a), \delta=70 \mathrm{~mm}$ oak board and $\delta=$ $=10 \mathrm{~mm}$ rubber band (Figure 11, b), cast-inplace concrete of $\delta=40$ (Figure 11, $c$ ) and $70 \mathrm{~mm}$ (Figure $11, d$ ). In all calculation schemes the width of elements for the spacing layer made $200 \mathrm{~mm}$, calculation models were approximated by finite elements in form of tetrahedrons (Figure 12). Table $2[4,13]$ provides for properties of materials of the spacing layer, assumed in numerical calculation.

Initial $6 \mathrm{tf}$ tightening force of the stud was set by movement of its basis for corresponding value that simulated pressing of reinforced concrete slab to spacing layer. At that, reduction of tightening force (stud unloading) was carried out by applying of distributed loading to BFBD slab surface from pressure of wheel of railway transport. Ban for linear and angular displacements of assemblies on lower surface of the spacing layer (Figure 13) was imposed as boundary conditions in the calculation models.
Calculations of stress-strain state of welded stud for four investigated types of spacing layer between BFBD slab and upper flange of T-girder
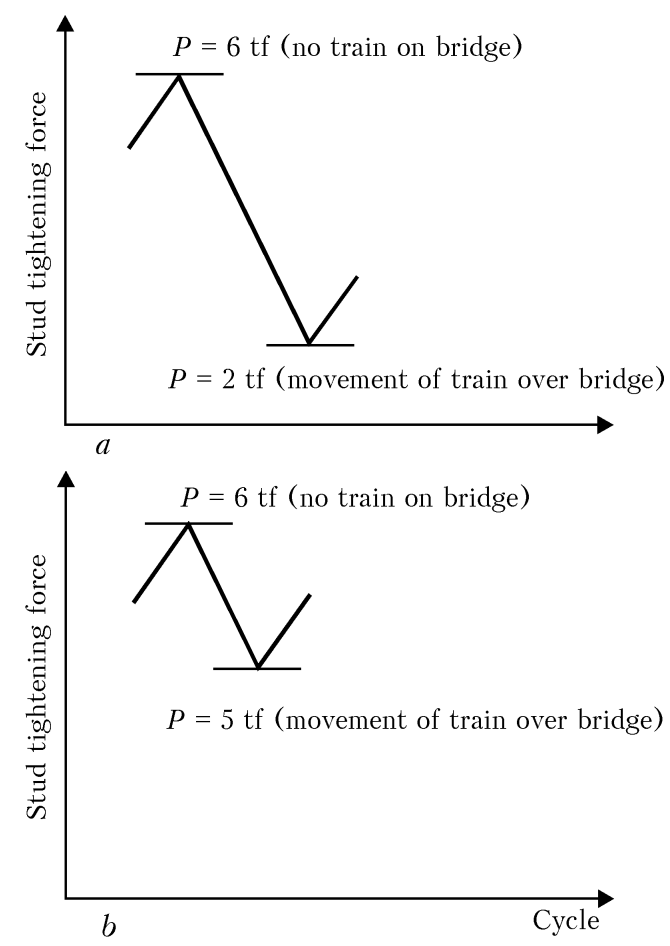

Figure 16. Schematic view of loading range in stud with spacing layer from oak board and rubber band $(a)$ and cast-in-place concrete $(b)$ 
were carried out. Isofields of stresses were received for welded stud in initial condition (at $6 \mathrm{tf}$ tightening force) and during passing of rolling stock for spacing layer from wood and rubber (Figure 14) and cast-in-place concrete (Figure 15). Tensile stresses of around $130 \mathrm{MPa}$ (Figures 14, $a, b$ and 15, $a, b$ ) appear in tightening of the stud with $6 \mathrm{tf}$ independent on spacing layer between BFBD slab and upper flange of T-girder in cross section of the stud.

During passing of rolling stock stresses in the stud reduce to $40 \mathrm{MPa}$ with spacing layer from wood and rubber and to $110 \mathrm{MPa}$ with spacing layer from cast-in-place concrete. Increase of thickness of oak board from 40 to $70 \mathrm{~mm}$ promotes $7 \%$ reduction of stresses in the stud (see $\mathrm{Fi}$ gure $14 c, d$ ) and that decreases by $5 \%$ with rise of thickness of cast-in-place concrete from 40 to $70 \mathrm{~mm}$ (see Figure 15, $c, d$ ). Figure 16 shows view of loading ranges in the stud in use of wood and rubber as well as cast-in-place concrete.

\section{Conclusions}

1. New structure of fastening of reinforced concrete slab of ballast-free railway bridge deck is proposed. It provides for welding of studs over vertical wall of longitudinal $\mathrm{T}$-girders at their fastening that eliminates angular deformation of upper flange.

2. Cyclic life tests of welded joints of stud (steel 09G2S) to upper flange of T-girder (steels St3sp and 09G2S), produced by arc-contact method, were carried out. Cyclic life of such joints at different loading ranges, being realized in preliminary $6 \mathrm{tf}$ tightened stud during passing of rolling stock, was determined. It is shown that life $\left(5 \cdot 10^{6}\right.$ cycles of stress alternation) of stud welded joint is provided in $\Delta P<3 \mathrm{tf}$ operating loading range.

3. Numerical simulation of stress-strain state of elements of bridge deck in initial condition and during passing of rolling stock verifies the data of full-scale investigations about the fact that ranges of operating loads in welded stud significantly depends on the spacing layer between BFBD and girder. Cyclic life of welded stud is not less than $5 \cdot 10^{6}$ cycles of stress alternation in use of oak board and rubber band as spacing material, since loading range makes $\Delta P \approx$ $\approx 4 \mathrm{tf}$. Application of 40 and $70 \mathrm{~mm}$ thick castin-place concrete as spacing layer between BFBD slab and $\mathrm{T}$-girder allows reducing loading range in welded stud to $\Delta P \approx 1 \mathrm{tf}$. This guarantees its cyclic life of not less than $5 \cdot 10^{6}$ cycles of stress alternation.

1. Linnik, G.O., Zakora, O.L., Marochka, V.V. (2010) Experimental investigations of carrying capacity of longitudinal beams depending on type of bridge deck. In: Theory and practice of building industry, 193195. Lviv: NULP.

2. Linnik, G.O. (2010) Studies of local deformations of concrete spacing layer using bridge deck on ballastfree bridge slabs (BFBD). Ibid., 293-296.

3. (2009) Procedural guidelines on spacing layer arrangement of ballast-free bridge deck on concrete slabs of metal spans of railway bridges in different service conditions. St.-Petersburg: NIIM.

4. $R$ 773/11:2004: Polymer composite cushion under slabs of ballast-free bridge deck. Organizing cooperation of the railways. Moscow.

5. (1990) Guidelines on inspection and reinforcement of in-service welded spans. Moscow: NII LIIZHTa.

6. $R D$ 50-694-90: Procedural guidelines. Reliability in technique. Probabilistic method of fatigue design of welded structures. Moscow.

7. $D B N$ V.2.3-26:2010: Bridges and pipes. Steel structures. Design rules. Kyiv: Minregionbud Ukrainy.

8. DSTU-N B EN 1993-1-9:2012: Eurocode 3: Design of steel structures. Pts 1-9: Endurance (EN 1993-19:2005, IDT). Kyiv: Minregionbud Ukrainy.

9. Hobbacher, A. Recommendations for fatigue design of welded joints and components. IIW Doc. 1823-07 ex XIII-2151r4-07/XV-1254r4-07.

10. Trufyakov, V.I. (1973) Fatigue of welded joints. Kiev: Naukova Dumka.

11. (1990) Strength of welded joints under alternating loads. Ed. by V.I. Trufyakov. Kiev: Naukova Dumka.

12. TsP-0137:2006: Instruction on laying and service of ballast-free bridge deck (BBD) on concrete slabs. Kyiv: Shvyd. Rukh.

13. Pisarenko, G.S., Yakovlev, A.P., Matveev, V.V. (1988) Reference book on strength of materials. Ed. by G.S. Pisarenko. 2nd ed. Kiev: Naukova Dumka.

Received 20.11.2014 


\title{
PECULIARITIES OF WELDING AND CONTROL IN MANUFACTURE OF HEAT-EXCHANGE MODULES OF EXHAUST-HEAT BOILER OF STEAM-GAS ELECTRIC PLANT OF 150 MW CAPACITY
}

\author{
A.K. TSARYUK ${ }^{1}$, V.P. ELAGIN ${ }^{1}$, E.A. DAVYDOV ${ }^{1}$, A.R. GAVRIK ${ }^{1}$, A.I. PASECHNIK ${ }^{2}$, \\ S.A. POLONETS ${ }^{2}$, V.G. DEDOV ${ }^{3}$ and V.P. GORELOV ${ }^{3}$ \\ ${ }^{1}$ E.O. Paton Electric Welding Institute, NASU \\ 11 Bozhenko Str., 03680, Kiev, Ukraine. E-mail: office@paton.kiev.ua \\ 2 «Donetskenergoremont» Ltd \\ 1 Umov Str., 83008, Donetsk, Ukraine. E-mail: postmaster@er/donetsk/ua \\ ${ }^{3}$ Company «Alchevsk Iron \& Steel Works» \\ 4 Shmidt Str., 94202, Alchevsk, Lugansk region, Ukraine. E-mail: amk@amk.lg.ua
}

\begin{abstract}
Manufacture of exhaust-heat boiler of steam-gas plant of 150 MW capacity for Alchevsk Iron \& Steel Works allowed using the secondary metallurgical gases as alternative to the nature gas. Its modular design, high closeness of arrangement in heat-exchange blocks of thin-walled small-diameter pipes of heating surfaces decreased the dimensions of the plant and increased its efficiency factor up to $44.6 \%$. Due to a narrow gap between the pipes the butts of these pipes occurred to be hard-to-reach for welding and control. This caused the increase in the amount of inadmissible defects in welds, and also made the welded joints of pipes almost not suitable for the repair. The making of welded joints on different stands by applying methods of argon-arc and combined welding allowed improving the quality, gave an opportunity to perform repair and to realize their X-ray, ultrasonic and visual-optic control. The manufactured heat-exchange blocks withstood the hydraulic test without appearance of leakage in welded joints, were installed and put into service. 3 Ref., 1 Table, 5 Figures.
\end{abstract}

Keywords: secondary gas fuels, steam-gas plant, heat-exchange blocks, piping of heating surfaces, header, arc welding, quality control

Significant saving of fuel for industrial enterprises of the metallurgical industry is the application of secondary fuel gases, such as blast furnace, converter, coke gases, forming during the metallurgical processes. Their application as a fuel, alternative to natural gases, was feasible by using steam-gas plants (SGP) of a combination cycle. In these plants the gases are mixed to form the safe concentration and required heat-generating ability and are burnt out, and the generated heat is converted into mechanical and electric energy. At Alchevsk Iron \& Steel Works (AMK) a complex of SGP of total power of $300 \mathrm{MW}$ (two blocks of $150 \mathrm{MW}$ ) was manufactured. The designing of SGP was made by the Mitsubishi Heavy Industries Company (Japan) with participation of Industrial Union of Donbass [1]. Construction of steam-gas electric plant for utilization of blast furnace, converter and coke gases (similar to AMK) was planning at F.E. Dzerzhinsky Dneprovsky Iron \& Steel Works. The Iron \& Steel Works «Azovstal» also announced about implementation of two SGP [2]. At AMK the operation of two steam-gas blocks allows providing the almost full need in electric power, keeping the standards for harmful gas blow-outs, accepted in EU.

One of the SGP main components is an exhaust-heat boiler, which was designed from heatexchange modules of the evaporator, steam superheater and economizer.

The heat-exchange modules were assembled of header panels, each of them has inlet and outlet headers (Figure 1, $a, b$ ) with three rows of $A, B$ and $C$ holes on the lateral surface, in total $40 \mathrm{pcs}$ in each one (Figure 2, $a$ ). Concentrically to these holes the connecting pipes are welded-on by fillet weld, which in turn are joined by butt weld to pipes of heating surfaces (Figure 2, $b$ ). The fillet joints of connecting pipes and butt joints of pipes of heating surfaces were made with a full penetration. Connecting pipes in the middle and edge row were bent at 25 and $50^{\circ}$ angle, respectively. Diameter of pipes and connecting pipes is 31.8 , 38.1 and $50.8 \mathrm{~mm}$, depending of panel purpose, however, their wall thickness is similar $2.7 \mathrm{~mm}$. 


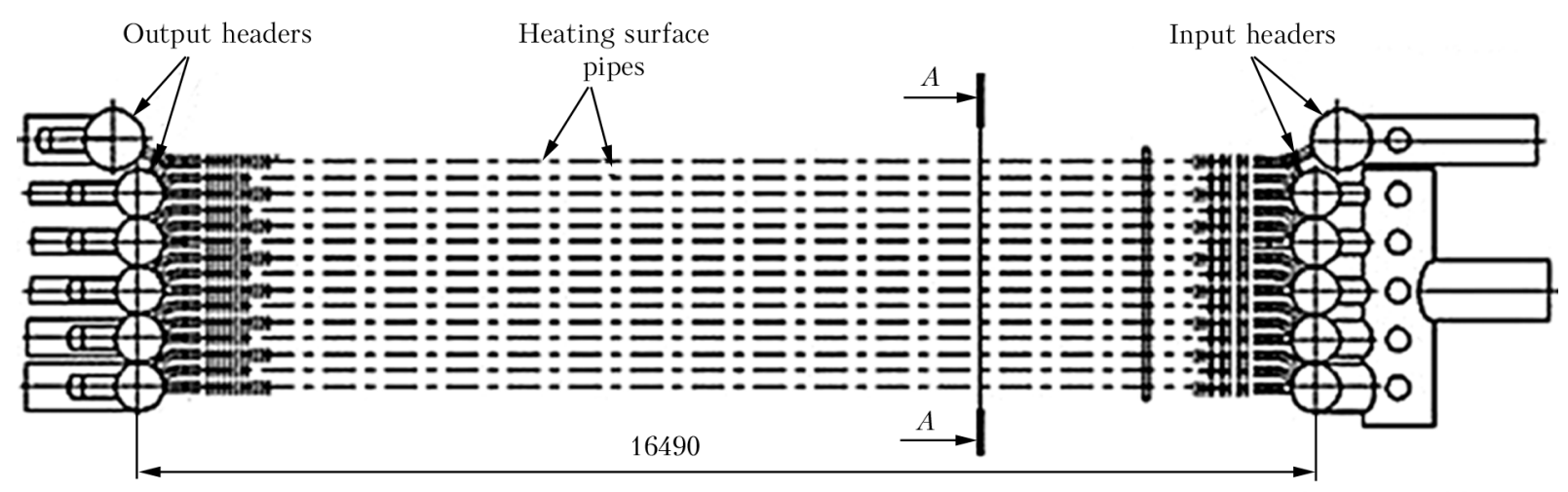

$A-A$
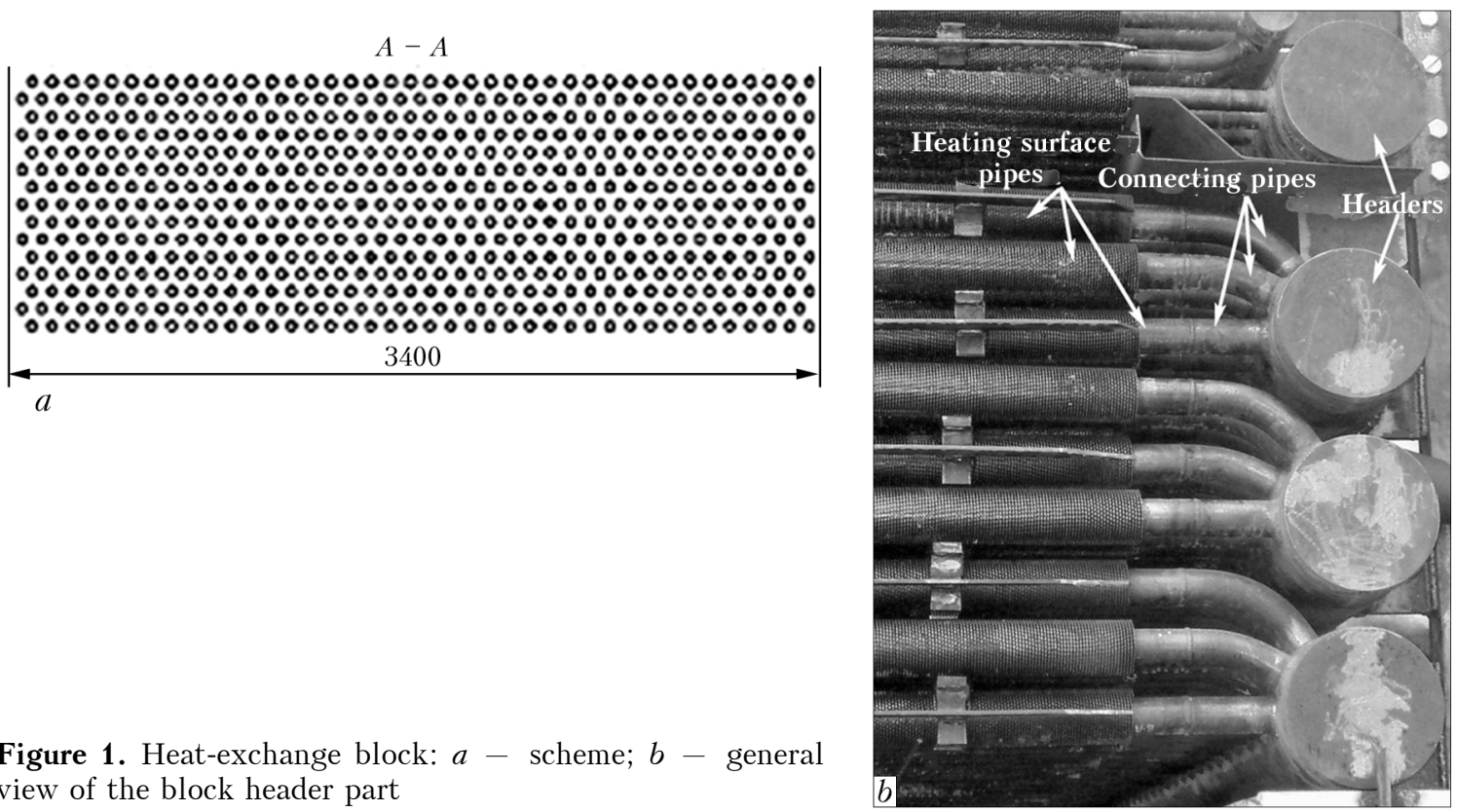

Figure 1. Heat-exchange block: $a-$ scheme; $b-$ general view of the block header part

As pipes of heating surfaces the finned pipes of ASME standard of steel SA 192 (analog to steel 20) and steel SA 213T11 (analog to steel $15 \mathrm{KhM}$ ) (the Table) are used for service at temperatures up to $300{ }^{\circ} \mathrm{C}$ and higher, respectively. Casings of header are made of pipes of steels 20 and $12 \mathrm{Kh} 1 \mathrm{MF}$ (see the Table) (TU 14-3-460 and TU 14-3R-55) of 219, 220, $240 \mathrm{~mm}$ diameter with 9, 15 and $22 \mathrm{~mm}$ wall thickness, respectively.

Application of bent connecting pipes allowed decreasing greatly a gap (to $15 \mathrm{~mm}$ ) between fins of pipes of heating surfaces, increasing the number of pipes in block up to $600 \mathrm{pcs}$, and closeness of their arrangement in pipe bundle up to $250 \mathrm{pcs} / \mathrm{m}^{2}$. This contributed to increase in the efficiency factor of the plant up to $44.6 \%$ and decrease in its dimensions.

These peculiarities of the block design hinder greatly the access to butts of edge rows of pipes in welding and repair and make it almost impossible for connections of internal rows of the block piping. This predetermined the high requirements to welding and methods of control for each joint, avoiding the need in repair of its defects after manufacture of panels and block.
The main principles of technology of welding
of pipes of heating surfaces were defined by the standard document [3]. However, it has no recommendations for welding of panels and blocks with high closeness of arrangement of pipes of heating surfaces, the butt and fillet welded joints of which were made with a complete penetration.

The present work was aimed at optimizing the technology of welding the heat-exchange panels with account for peculiarities of their design.

Decisive in providing the high quality is the development of optimum variant of sequence of making the welded joint, which will provide the best access to the butt areas. Two main variants are possible:

1. Firstly the fillet joints are made for connecting pipes with inlet and outlet headers, and then - butt joints of these connecting pipes with pipe of heating surface. After manufacture of the panel the assembly and welding of next panel is made from the top and so on up to manufacture of the whole block. Moreover, the works on assembly, welding and quality control of panels and the block as a whole are performed on the same stand. 


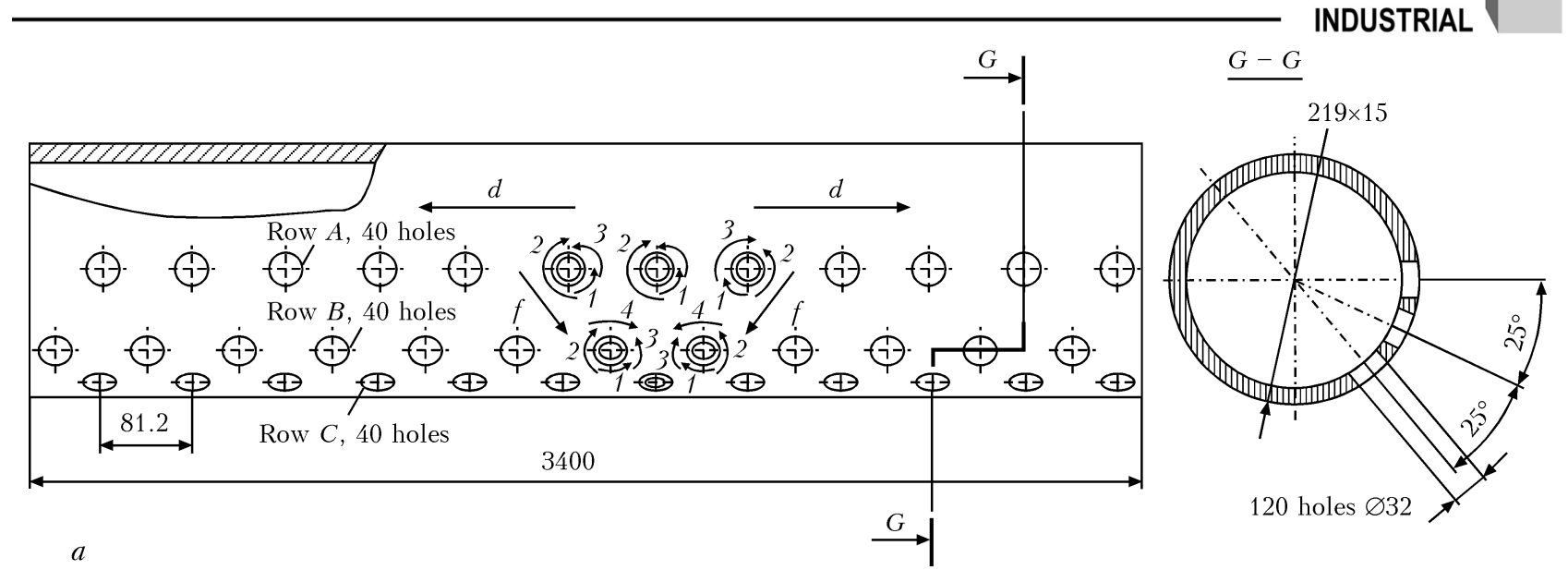

2. Firstly the butt joints are made for connecting pipes with pipe of heating surface with formation of so called «pipe section», and then the fillet welds of «pipe section» with inlet and outlet headers are made. Moreover, the works on welding and quality control are performed on two stands: stand for assembly and welding of butt joints of connecting pipes with heat-exchange pipe, and stand for assembly and welding of heat-exchange pipe with header.

The second variant as compared with the first one requires almost 2 times more industrial area and the presence of high-load capacity cranes for transfer of panels in assembly of heat-exchange blocks.

The technology of welding was optimized on model headers, design of which provided the same difficult access to weld areas, as in a real product. Weld of butt joints of specimens were made in two layers by argon arc welding with tungsten electrode using filler wire (TIG), and fillet welds were made in three layers by TIG welding or manual arc welding with covered electrodes (MAW). The combined method of welding of fillet weld, at which a root weld was made by TIG welding, and the rest ones - by MAW, was also tested. The quality of welding was evaluated by visual-optic, ultrasonic or radiographic methods of control, and metallographic examinations by optic microscope were also carried out.

During welding according to the first variant the hard-to-reach places are areas 1, 3 and 4 both of butt and also fillet weld. During works fulfillment according to the second variant the hardto-reach places are only areas 4 of fillet welds. Welding in the direction of arrows $d$ and $f(\mathrm{Fi}-$ gure $2, a$ ) makes the welding of the area 1 , located in overhead position of weld, more convenient.

At the hard-to-reach areas of butt the visualization of welding zone and its process are rather difficult. At violation of welding procedure the gas shielding of welding zone, formation of weld

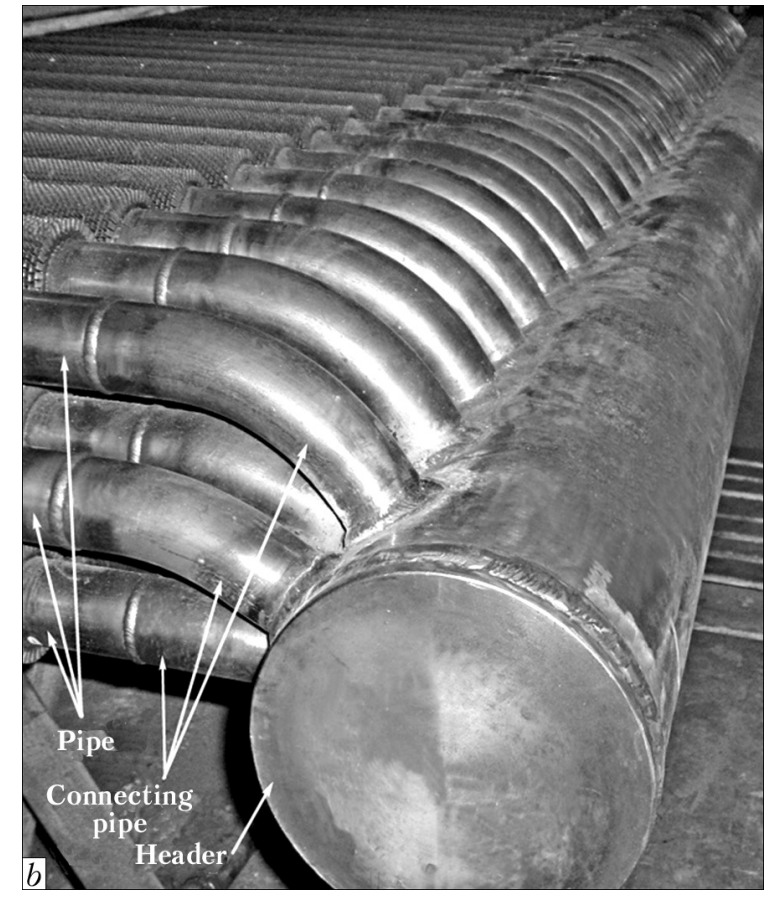

Figure 2. Header unit of heat-exchange panel: $a-$ scheme of arrangement of connecting pipes on header (1-4 - sequence of welding of weld areas; $b-$ general view of header unit; arrows show sequence of welding-on of connecting pipes)

are deteriorated that leads to the formation of pores. The most sensitive to the pores are butt joints due to low energy input of their welding as compared with the fillet welds and also due to lower silicon content in pipe metal than in header metal (see the Table). The percentage of rejection of butt joints due to formation of pores in welds during TIG welding according to the first variant reached up to $40 \%$.

During MAW the joining of hard-to-reach weld areas becomes much easier and resistance to pore formation is increased, however, the inadmissible metal sagging and slag overlaps are formed in the weld root layer. Therefore this method cannot be applied for welding of small-diameter pipes with a complete penetration. 
INDUSTRIAL

Chemical composition of pipe metal, \%

\begin{tabular}{|c|c|c|c|c|c|c|c|c|}
\hline Steel grade, standard & $\mathrm{C}$ & $\mathrm{Si}$ & $\mathrm{Mn}$ & $\mathrm{P}$ & $\mathrm{S}$ & $\mathrm{Cr}$ & Mo & $\mathrm{V}$ \\
\hline SA 192, ASME & $0.06-0.18$ & $\leq 0.25$ & $0.27-0.63$ & $\leq 0.035$ & $\leq 0.035$ & - & - & - \\
\hline $\begin{array}{l}\text { Protocol of steel analysis } \\
\text { SA } 192\end{array}$ & 0.097 & 0.17 & 0.45 & 0.007 & 0.003 & - & - & - \\
\hline SA 213T11, ASME & $0.05-0.15$ & $0.5-1.0$ & $0.30-0.60$ & $\leq 0.025$ & $\leq 0.025$ & $1.0-1.5$ & $0.44-0.65$ & - \\
\hline $\begin{array}{l}\text { Protocol of steel analysis } \\
\text { SA } 213 T 11\end{array}$ & 0.11 & 0.58 & 0.48 & 0.005 & 0.002 & 1.22 & 0.56 & - \\
\hline Steel 20, GOST 8731-87 & $0.17-0.24$ & $0.17-0.37$ & $0.35-0.65$ & $\leq 0.035$ & $\leq 0.040$ & $\leq 0.3$ & - & - \\
\hline Protocol of steel 20 analysis & 0.17 & 0.36 & 0.55 & 0.032 & 0.038 & 0.1 & - & - \\
\hline 12Kh1MF, GOST 1133-71 & $0.08-0.15$ & $0.17-0.37$ & $0.40-0.70$ & $\leq 0.030$ & $\leq 0.025$ & $0.9-1.2$ & $0.25-0.35$ & $0.15-0.30$ \\
\hline $\begin{array}{l}\text { Protocol of } 12 \mathrm{Kh} 1 \mathrm{MF} \text { steel } \\
\text { analysis }\end{array}$ & 0.09 & 0.33 & 0.62 & 0.028 & 0.022 & 1.1 & 0.32 & 0.18 \\
\hline 15KhM, GOST 8732-78 & $0.11-0.18$ & $0.17-0.37$ & $0.4-0.7$ & $\leq 0.035$ & $\leq 0.035$ & $0.8-1.1$ & $0.40-0.55$ & - \\
\hline $\begin{array}{l}\text { Protocol of } 15 \text { KhM steel } \\
\text { analysis }\end{array}$ & 0.12 & 0.35 & 0.58 & 0.030 & 0.032 & 0.096 & 0.48 & - \\
\hline
\end{tabular}

During fulfillment of works according to the second variants, assembly and welding of pipes with a connecting pipe on the separate stand ( $\mathrm{Fi}-$ gure $3, a$ ) was made. Its design provides an accuracy and rigidity of assembly of butt, and also free access to all its areas. The possibility of fulfillment of the required procedure of welding allows increasing the safety of gas shielding of welding and improving the formation of finishing and root layer (Figure $4, a, b$ ). Percentage of
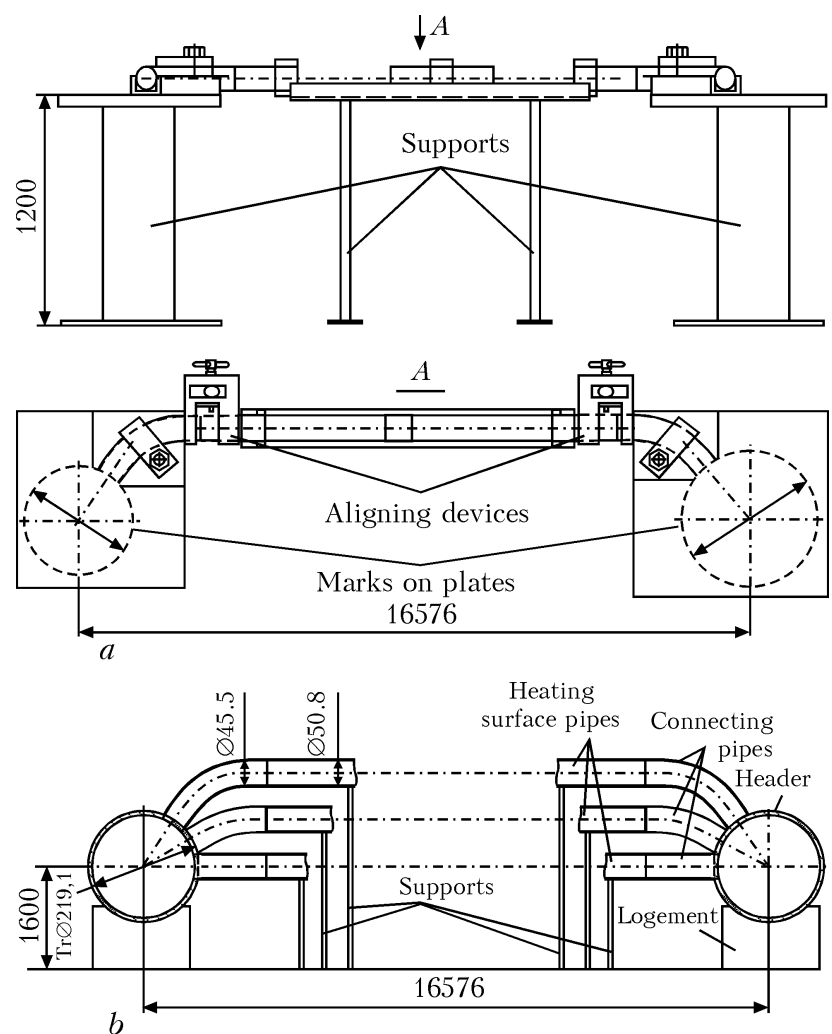

Figure 3. Stands for assembly and welding of butt joints of pipes of heating surfaces with connecting pipes $(a)$ and of fillet joints of header with «pipe section» $(b)$ defective welds due to pore formation was reduced to $0.4 \%$.

Assembly and welding of fillet joint of header with «pipe section» are made on the second stand (Figure 3,b) after checking the quality of butt joint of pipe and connecting pipe. Accuracy of assembly is provided by means of devices.

In TIG welding of fillet weld the pores are more often occur at the 4th region (see Figure 2, a) of the third layer adjacent to the connecting pipe. In the root and the second layer, deposited on header, pores are formed. This can be explained by increased silicon content in these layers, transferred from the base metal of header, in which its content is more than 2 times higher than in pipe metal (see the Table).

In MAW the pores in layers of the fillet weld were not revealed. High resistance against the pores at this method is explained by the more safe gas-slag protection of the welding zone than in TIG welding. In this connection, it is recommended to perform welding of fillet weld by the combined method: root layer by TIG welding and next layers by MAW.

The small diameter of covered electrode for MAW as compared to sizes of torch for TIG welding allows making welding without any problems in hard-to-reach areas, providing the safe shielding of the welding zone. During welding in the upward direction the often occurred defects of the fillet joint are a sharp transition from deposited metal surface to the surface of connecting pipe and formation of slagging at the «locks» area. The downward welding allows improving the shape of the fillet weld even at low skill of the welder, however, the probability of formation of lacks of fusion and slagging in the lower 

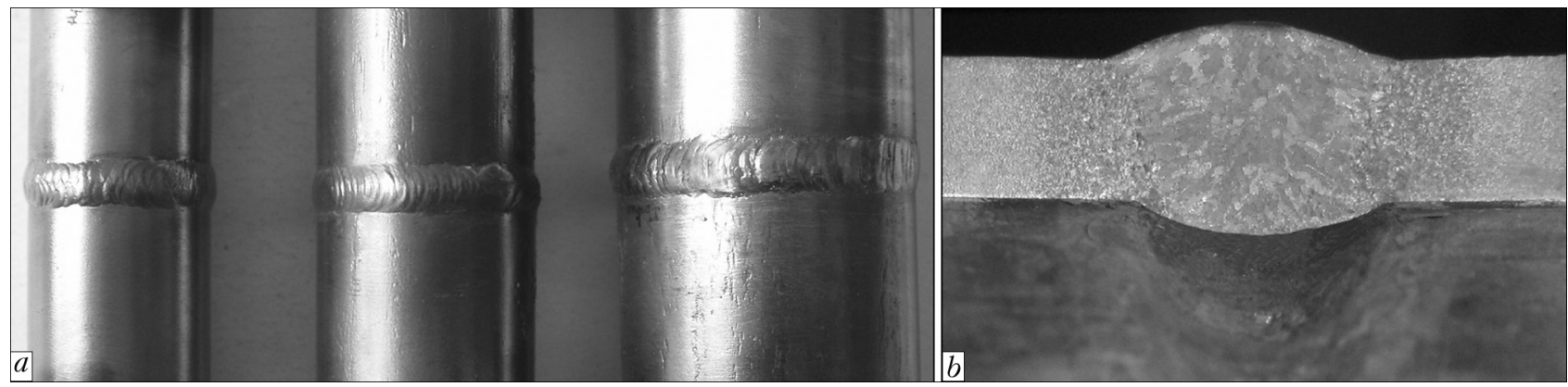

Figure 4. Butt joints of heating surface pipes: $a-$ appearance of joints; $b-$ transverse section of joint

part of the weld is increased. To prevent them the application of special electrodes is required. As there are no such electrodes at the market, the E.O. Paton Electric Welding Institute has started their development. To make upward welding of fillet welds of pipes of heating surfaces of steels SA 192 and SA 213T11 the most suitable are the electrodes TsU-5 and TsL-39 by their welding-technological properties, respectively. They allow producing the quality formation with the higher properties than that of the base metal.

One more type of occurred defects of fillet welds, made by the combined method, are pores and shrinkages in the root bead (Figure 5, a). They are formed in the hard-to-reach areas of the third layer of the weld in case of complete penetration of the connecting pipe wall. At the absence of the gas shielding of root bead the molten metal is saturated with gases, thus leading to the formation of pores, and the oxidized surface of metal deteriorates the formation of root part of penetration and causes the formation of shrinkages. The blowing-in of argon into the pipe in the butt area prevents completely the formation of such defects (Figure 5, b). In this case the reduction in argon consumption to $31 / \mathrm{min}$ is attained by using limiting collars, placed into pipe on both sides from the butt.

The making of welded joints to join the connecting pipe with heating surface pipe according to the second variant on the separate stand allows the X-ray control to be performed in the separate room. This makes its fulfillment more safe without interruption of other works. The feasibility is also appeared in an additional control of integrity of weld metal of butt joints by the ultrasonic method and quality of formation of weld root bead using video endoscope. The $100 \%$ visual-optic, X-ray and $10 \%$ ultrasonic testing could improve greatly the validity of their results. The volume of rejection in butt joints made in welding according to the first and second variants, was 40 and $0.5 \%$, respectively.
The fillet welds of connecting pipe to header are more difficult for the revealing of defects. Their design makes it impossible to apply the X-ray control, dye penetrant or magnetic powder flaw detection. In this connection the procedures of ultrasonic testing of integrity of fillet weld and visual-optic control of quality of the root bead formation were developed.

To improve the validity of results of the ultrasonic testing, the adaptation of parameters of the ultrasonic channel was made for peculiarities of fillet joints of thin-walled small-diameter pipes and chord transducers were applied. Small

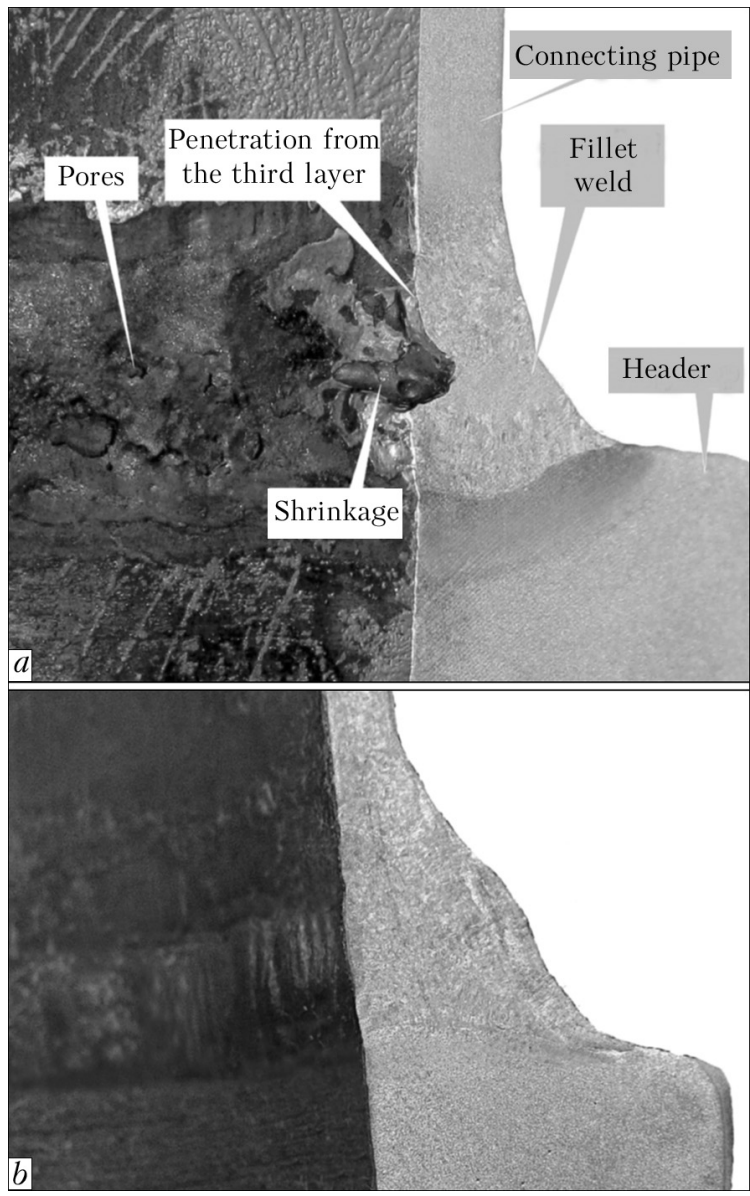

Figure 5. Fillet welded joints of connecting pipe with header: $a$ - transverse section of joint with defects in root bead made without argon blowing-in; $b-$ transverse section of joint made with argon blowing-in 
sizes of the transducers (height $\leq 20 \mathrm{~mm}$, width of $18 \mathrm{~mm}$ ) make it possible to control the welds in hard-to-reach areas of welded joints, and an elastic protector provides a stable acoustic contact. They are especially effective in revealing the volume defects, such as channel pores (flaws), slags, pores and flat defects, cracks, lacks of penetration and lacks of fusions.

The feasibility of control of the root bead formation of both butt and also fillet welds was obtained due to application of the modern model of the endoscope. It has the flexible probe of $6 \mathrm{~mm}$ diameter and length of up to $3.5 \mathrm{~m}$ with the light guide and small-sized optic head at vision angle up to $120^{\circ}$. The unit allows changing the depth resolution and direction of examination, making visualization of examining area on the monitor and photo-video recording of examination results into the flash-map memory. When pores in the root bead, inadmissible sagging or shrinkages in joint areas were revealed, the joints were rewelded before fulfillment of joints of next pipes which close the welding zone. In addition, the foreign objects, for example paper, electrode stubs, chips, etc., which should be obligatory removed, were revealed inside pipes and header by using the endoscope.

Thus, the fulfillment of works according to the second variant of assembly and welding of panels of heat-exchange blocks allows more qualitatively performing both butt, and also fillet joints, realizing control of their quality within $100 \%$ volume and repairing of the defective welds. The carried out production certification of technology of welding showed that joints are equal by their strength to the base metal. The manufactured heat-exchange blocks have passed successfully the leakage tests by hydraulic testing and were installed in exhaust-heat boilers of the steam-gas electric plant of $150 \mathrm{MW}$ capacity at Alchevsk Iron \& Steel Works.

\section{Conclusions}

1. Heat-exchange blocks of modules of exhaustheat boiler of $150 \mathrm{MW}$ SGP have a high closeness of arrangement of thin-walled pipes of heating surfaces. During welding and assembly of heat- exchange blocks on one stand this peculiarity of design makes the butt and fillet joints of these pipes as hard-to-reach ones for fulfillment of welding and control, promotes the increased defect formation and leads to impossibility for their repair after welding.

2. The most frequently occurred defects in welds of butt joints made by TIG welding are pores, and a sharp transition from weld surface to connecting pipe surface, slagging on «locks», pores and shrinkages in the root bead are typical of fillet joints made by the combined method. These defects are formed, as a rule, in hard-toweld areas in MAW and are repaired by technological methods, improvement of skill and experience of the welder.

3. The most effective technological method of improvement of quality of welds of butt and fillet joints of pipes of heating surfaces is the fulfillment of their assembly and welding on separate stands, providing the more free access to butts in welding and feasibility of repair and control of their quality in $100 \%$ volume.

4. Increase of resistance against formation of pores and shrinkages in root bead of fillet welds of pipe surfaces is attained by a gas shielding of root bead using argon blowing-in inside the pipe.

5 . To improve the validity of the quality control of butt and fillet welded joints, the procedures of ultrasonic and visual-optic control by using the chord transducers and endoscope were applied respectively.

1. Falkov, M.I. (2007) Increase in power efficiency of application of by-product fuels on iron industry enterprises. Electron journal EXPO of power service company «Ecological systems», 6. http://Www. esco-ecosys.narod.ru /2007_6/art103/.thm

2. Fomina, O. (2014) Application of blast-furnace, converter, coke gases in combined-cycle plants contribute to reduce electric power consumption of national power network on metallurgical works. http://masters.donntu.org / 2011/feht/tovshchik/library/arti cle7.htm

3. RTM-1s-89: Guiding technical document. Welding, heat treatment and control of pipe systems of boilers and pipelines in erection and repair of power plant equipment. Moscow: NPO OBT.

Received 20.11.2014 


\title{
EVALUATION OF OPERABILITY OF WWR-M REACTOR PRIMARY CIRCUIT PIPING WITH WELDED JOINT DEFECTS
}

\author{
O.V. MAKHNENKO, A.S. MILENIN and G.Yu. SAPRYKINA \\ E.O. Paton Electric Welding Institute, NASU \\ 11 Bozhenko Str., 03680, Kiev, Ukraine. E-mail: office@paton.kiev.ua
}

\begin{abstract}
Evaluation of load-carrying capacity of critical welded piping elements based on the results of technical diagnostics of their state is an important stage of a package of measures to confirm their operability and remaining safe operating life. In particular, in the case of detection of various defects of material discontinuity, it is necessary to perform static strength analysis of the piping and analysis of its strength factor correspondence to design requirements. If it is confirmed that the detected defects only slightly lower the piping load-carrying capacity, it can be allowed to operate in precised modes of force and corrosion impact. It is proposed to apply ductile fracture criterion based on multidimensional finite-element analysis of elastoplastic strain development. Admissibility of crack-like defects is substantiated by brittle-ductile fracture criteria. The case of an aluminium piping element of WWR-M research reactor primary circuit with detected multiple discontinuities of the weld (gas pores, nonmetallic inclusions) was used to show the sequence and main principles of analysis of defective piping load-carrying capacity. Community of the proposed methodological approaches allows their application at confirmation of operability of critical piping and pressure vessels from aluminium alloys and high-strength steels. 14 Ref., 1 Table, 7 Figures.
\end{abstract}

Key words: aluminium piping, defect admissibility, mathematical modeling, brittle-ductile fracture, stress strain state, numerical evaluation, load-carrying capacity

Radiographic testing of circumferential welded joints, performed after mounting primary circuit piping in WWR-M research reactor, revealed metal discontinuities in the form of pores and oxide film inclusions. Dimensions of individual discontinuities exceed the admissible limits according to currently valid rules and norms [1]. Normative documents [1,2] specify the possible deviations from the requirements. These deviations are documented by the joint decision of the design organization, manufacturing plant, etc. Then, they are coordinated with the head materials science organization, customer or operator.

In order to substantiate the operability without repairing the rectilinear sections of piping with discontinuities detected in circumferential welded joint zone, a computational study of the above discontinuity behaviour at working pressure in operation and at hydro-testing was performed.

Computational evaluation of stress-strain state in welded joint zone. Evaluation of nominal wall thickness in linear part of piping $\left(D_{a}=\right.$ $=370 \mathrm{~mm}, S=10 \mathrm{~mm}$ ) from aluminium alloy AMg3 in operation and at hydro-testing was performed in keeping with the normative document [3].

(C) O.V. MAKHNENKO, A.S. MILENIN and G.Yu. SAPRYKINA, 2015
Nominal wall thickness of the linear part in operation ( $p \leq 0.15 \mathrm{MPa}, T=55{ }^{\circ} \mathrm{C}$ ) is equal to $S_{R}=0.60 \mathrm{~mm}$, and at hydraulic testing ( $p=$ $\left.=0.32 \mathrm{MPa}, T=20{ }^{\circ} \mathrm{C}\right)-S_{R}=1.26 \mathrm{~mm}$.

Considering that the piping is designed for operation with distilled water at $T=55{ }^{\circ} \mathrm{C}$ and AMg3 alloy is corrosion-resistant, we can assume that $c=0.5 \mathrm{~mm}$ ( $c$ is the addition to wall thickness, allowing for its thinning because of corrosion over 50 years of operation).

Actual thickness of piping walls is more than 7 times greater than the nominal thickness, satisfying the static strength condition for the range of working and test pressures $(0.15-0.32 \mathrm{MPa})$.

Stress-strain state in the zone of piping butt welded joint is determined taking into account the following main components:

- working stresses from operating or test internal pressure; and

- residual stresses related to manufacturing or subsequent repair technology (multipass welding, possible local heat treatment in high tempering mode).

Calculation of stresses in the walls of piping linear part induced by working pressure in stationary temperature mode under normal operation conditions and by pressure at hydro-testing was performed allowing for the assumption of the piping geometrical and structural homogeneity [3]: $\sigma_{\beta \beta}=\left(p D_{a}\right) / 2 S$ are the circumferential and $\sigma_{z z}=\left(p D_{a}\right) / 4 S$ are the axial stresses. Cir- 


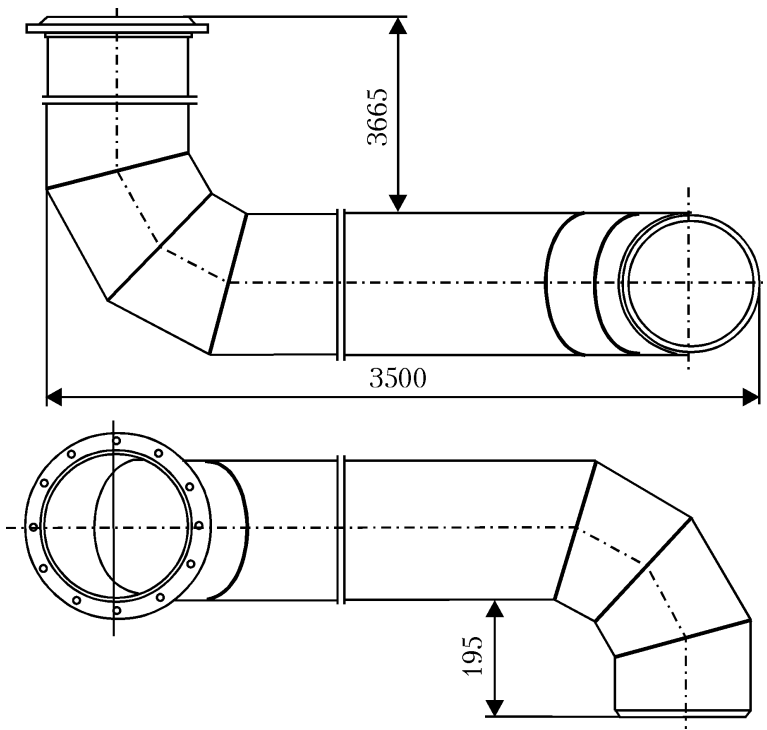

Figure 1. Schematic of piping from aluminium alloy AMg3 of WWR-M research reactor primary circuit

cumferential and axial components of stresses from working pressure are uniformly distributed across the piping thickness in its linear part. At working pressure $p=0.15 \mathrm{MPa}$ stresses in the wall are equal to $\sigma_{\beta \beta}=2.8 \mathrm{MPa}$ and $\sigma_{z z}=$ $=1.4 \mathrm{MPa}$, and at $p=0.32 \mathrm{MPa}$ stresses in the
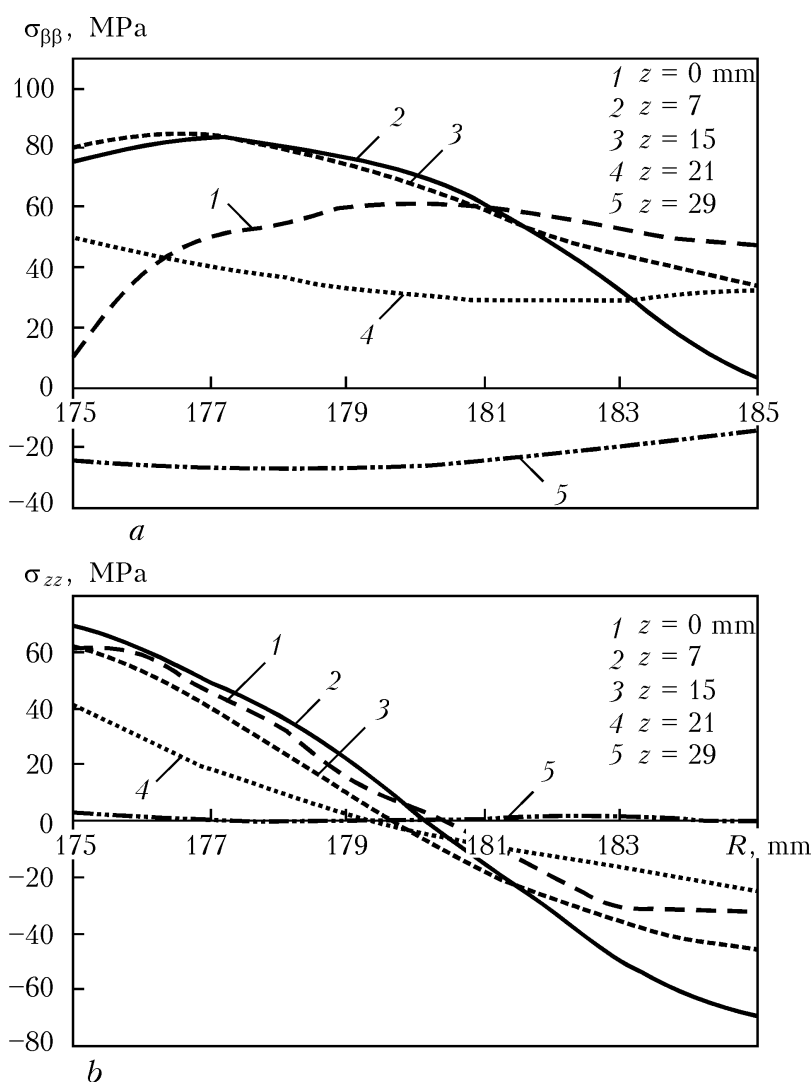

Figure 2. Distribution of residual stresses across the wall thickness in the zone of butt welded joint of piping $\left(D_{a}=\right.$ $=370 \mathrm{~mm}, S=10 \mathrm{~mm} ; R-$ pipe radius) from aluminium alloy AMg3 at different distances in the axial direction $z$ from welded joint center: $a-$ circumferential component $\sigma_{\beta \beta} ; b-$ axial component $\sigma_{z z}$ wall are equal to $\sigma_{\beta \beta}=5.9$ and $\sigma_{z z}=3.0 \mathrm{MPa}$, respectively.

Each of the two piping bends (Figure 1) was made by welding and consists of two sectors, connected to each other and to piping linear parts by three circumferential welded joints. To determine the peculiarities of stress distribution in welded joint zone, calculations were performed using a finite-element model of the bend in the case of internal pressure application. Results of calculation of circumferential and axial stress components in the piping bend zone from internal pressure showed that at $p=0.15 \mathrm{MPa}$ maximum tensile circumferential and axial stresses in the wall are determined on the external surface of the bend inner part (radius) and their value reaches 4.5 $\mathrm{MPa}$.

On the internal surface maximum tensile circumferential stresses are lower - up to $\sigma_{\beta \beta}=$ $=3.0 \mathrm{MPa}$, and axial stresses are up to $\sigma_{z z}=$ $=2.1 \mathrm{MPa}$. At $p=0.32 \mathrm{MPa}$ maximum tensile circumferential and axial stresses in the wall on the external surface of the bend inner part (radius) reach 9.6 $\mathrm{MPa}$. On the internal surface maximum tensile circumferential stresses $\sigma_{\beta \beta}$ reach $6.4 \mathrm{MPa}$, and axial stresses are up to $\sigma_{z z}=$ $=4.5 \mathrm{MPa}$. Thus, increase of stresses (maximum by $60 \%$ ) in the piping bend wall from internal pressure is of a local nature. Here, on the bend internal surface maximum stresses exceed those in the piping linear part by $10 \%$.

Distribution of residual welding stresses was calculated using FEM numerical procedure and computer program, included into the Weldpredictions system, developed at PWI [4, 5] and validated during performance of various studies [6]. Calculations showed that with the used technology of multipass welding of piping butt joints residual stressed state is characterized by quite high (on the level of AMg3 material yield point) circumferential $\sigma_{\beta \beta}$ and axial $\sigma_{z z}$ stresses on the wall internal surface (Figure 2).

In further calculations distribution of residual stresses and strains from internal pressure for circumferential welded joints in the piping bend part was assumed to be the same as for welded joints in the linear part, as welding was performed by the same technology, and $30^{\circ}$ angle of the sector (of the bend in the welded joint zone) is relatively small, and local increase of stresses from internal pressure in the bend part by 1.73.7 $\mathrm{MPa}$ (by $0.3-0.5 \mathrm{MPa}$ on the internal surface), compared to residual stresses (up to $80 \mathrm{MPa}$ ) can be ignored.

Numerical evaluation of load-carrying capacity of welded aluminium piping at internal 
pressure, allowing for the known degree of weld damage (pores formed in welding). Structure limiting state at static loading by internal pressure was described by limit hydrostatic pressure right up to initiation and development of ductile fracture processes in the area of geometrical and physical concentrators. It was believed that the structure state is inadmissible (limiting pressure has been reached) in the case of appearance of ductile fracture micropores, due to plastic flowing of metal.

In this work analysis of the stress-strain state of a welded structure in terms of ductile fracture was performed on the basis of a numerical solution of the problem of nonstationary thermoplasticity by tracing the elastoplastic strains from the moment of the start of multipass welding right up to complete cooling of the structure and at subsequent loading up to the limiting state within the finite-element model. Relation between stresses and strains was determined by Hooke's law and associated plastic flow rule, taking into account the postulates of complete Gurson-Tvergaard-Needleman model, proceeding from the following relationships [7]:

$$
\begin{gathered}
\Delta \varepsilon_{i j}=\psi\left(\sigma_{i j}-\delta_{i j} \sigma_{m}\right)+ \\
+\delta_{i j}\left(K \sigma_{m}+\Delta \varepsilon_{m}+\Delta f / 3\right)- \\
-\frac{1}{2 G}\left(\sigma_{i j}-\delta_{i j} \sigma_{m}\right)^{*}+\left(K \sigma_{m}\right)^{*},
\end{gathered}
$$

where $f$ is the volume concentration of ductile fracture micropores; $K=(1-2 v) / E ; G=$ $=E /(2(1+v)) ; E$ is the Young's modulus; $v$ is the Poisson's ratio; $\psi$ is the function of material state; determined by plastic flow condition in keeping with Mises criterion, additionally allowing for decrease of finite element load-carrying net-section as a result of formation of a discontinuity within Gurson-Tvergaard model:

$$
\begin{gathered}
\psi=\frac{1}{2 G,} \text { if } \sigma_{i}<\sigma_{s}=\sigma_{\mathrm{y}} \times \\
\times \sqrt{1+\left(q_{3} f^{*}\right)^{2}-2 q_{1} f^{*} \cosh \left(q_{2} \frac{3 \sigma_{m}}{2 \sigma_{\mathrm{y}}}\right)} \\
\psi>\frac{1}{2 G} \text { if } \sigma_{i}=\sigma_{s},
\end{gathered}
$$

where $q_{1}=1.5, q_{2}=1, q_{3}=1.5$ are the constants; $\sigma_{m}$ are the membrane stresses; $f^{*}$ is the equivalent volume concentration of pores allowing for their interaction in the finite element.

Magnitude of pore equivalent concentration is determined from the following relationship [8]:

$$
f^{*}=\left\{\begin{array}{l}
f, \text { if } f \leq f_{c}, \\
f_{c}=\frac{f_{u}^{*}-f_{c}}{f_{F}-f_{c}}\left(f-f_{c}\right), \text { if } f>f_{c},
\end{array}\right.
$$

where $f_{c}$ is the critical value of discontinuity concentration, below which the individual pores do not interact, it is taken to be $0.15 ; f_{F}$ is the pore concentration, at which finite element fracture takes place; $f_{u}^{*}=1 / q_{1}$.

It is assumed that pore initiation in the area of structural defects and discontinuities (socalled primary pores) is associated with an essential development of plastic strains and can be described using Odqvist parameter [8]

$$
\kappa=\int d \varepsilon_{i}^{p},
$$

where $d \varepsilon_{i}^{p}=\frac{\sqrt{2}}{3} \sqrt{d \varepsilon_{i j}^{p} d \varepsilon_{i j}^{p}} ; d \varepsilon_{i j}^{p}$ are the components of the tensor of plastic strain increment.

Accordingly, a condition of pore initiation in isothermal case is the current value of Odqvist parameter exceeding critical value $\kappa_{c}$.

Growth of initiating pores depends on the stress state rigidity and intensity of metal plastic strains and is described by Rice-Tracey law, namely [8]:

$$
d R=R_{0} K_{1} \exp \left(K_{2} \frac{\sigma_{m}}{\sigma_{i}}\right) d \varepsilon_{i}^{p},
$$

where $R, R_{0}$ are the current and initial pore radius; $\sigma_{m}=\left(\sigma_{x x}+\sigma_{y y}+\sigma_{z z}\right) / 3$ is the membrane stress; $\sigma_{i}=\sqrt{\left(\sigma_{i j} \sigma_{i j}\right) / 2}$ is the stress intensity; $\sigma_{m} / \sigma_{i}$ is the stressed state rigidity parameter; $K_{1}=0.28, K_{2}=1.5$ are the constants.

Figure 3 shows the results of technical diagnostics (roentgenoscopy) of welds and the most hazardous clusters of defects of gas pore type, the influence of which on piping load-carrying capacity was studied within the above procedure. Proceeding from computational results, data are given on limiting pressure for defect-free piping and piping with defects (the Table). Limiting pressure in this case does not allow for the system of safety factors specified for the given structure, but is a characteristic of the structure limiting state in the case of static force impact from internal pressure. The above-mentioned gas pores in the weld lower the piping limiting pressure by $15-23 \%$ and are admissible for piping static conditions only in the case of the respective excess structure safety factor used in design, as well as guaranteed absence of through-thickness pore groups (leaks, microleaks).

Determination of admissibility of discontinuities in the form of coarse inclusions in the 


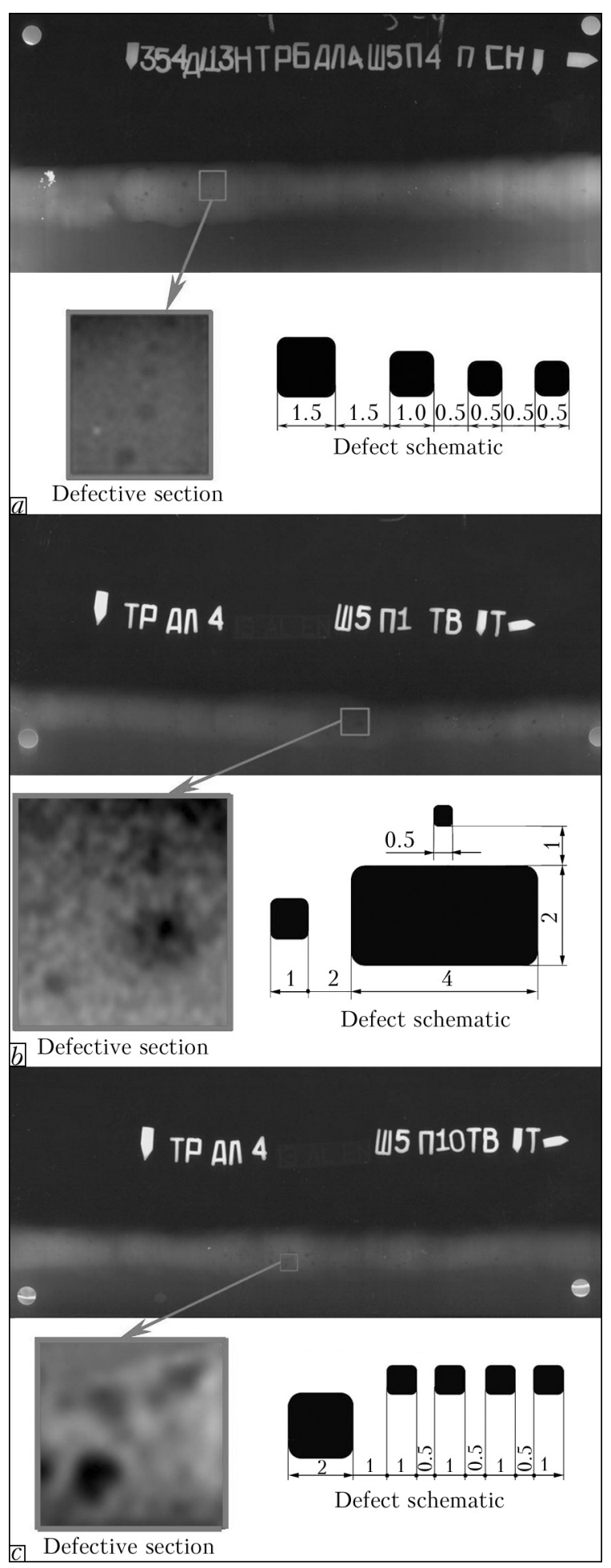

Figure 3. Examples of detected defects and their schematic representation: $a-$ 354AI13NTRBAL4Sh5P4PSN; $b-$ TRAL4Sh5P1TVT; $c-$ TRAL4Sh5P10TV film (see the Table)

zone of circumferential welded joint. Discontinuities in the form of coarse inclusions detected in the zone of circumferential welded joint of this piping, at computational evaluation of their admissibility in service and at hydro-testing, can conservatively be classified as crack-like defects. As inclusions can have different location relative
Results of limiting pressure calculation

\begin{tabular}{|c|l|c||}
\hline $\begin{array}{c}\text { Sample } \\
\text { number }\end{array}$ & \multicolumn{1}{|c|}{ Weld metal state } & $\begin{array}{c}\text { Limiting } \\
\text { pressure, MPa }\end{array}$ \\
\hline 1 & Defect-free metal & 4.9 \\
\hline 2 & $\begin{array}{l}\text { Weld metal with a defect group } \\
\text { (see Figure 3, } a \text { ) }\end{array}$ & 4.2 \\
\hline 3 & The same (see Figure 3, b) & 3.9 \\
\hline 4 & The same (see Figure 3,c) & 3.8 \\
\hline
\end{tabular}

to the pipe external or internal surface, conservative evaluation of their admissibility required considering the most critical case of such a defect, namely a semi-elliptical crack, reaching the internal surface, where welding induces the highest residual tensile stresses. A semi-elliptical crack, simulating the considered discontinuity, is characterized by $a$ (depth) and $2 c$ (length along the surface) (Figure 4). Stress intensity factors $K_{\mathrm{I}}$ in points $D$ and $G$ of the considered semi-elliptical crack can be calculated in keeping with the recommendations [9-12] and taking into account the data on stress distribution across the thickness of piping butt welded joint.

Condition of spontaneous growth (disequilibrium) of such a crack can be determined on the base of R6 approach widely accepted in nuclear power engineering $[13,14]$. In keeping with this approach, crack equilibrium is not disturbed, if the following condition is satisfied (Figure 5):

$$
K_{r}=K_{1} / K_{\mathrm{I} C},
$$

where $K_{r}=K_{\mathrm{I}} / K_{\text {IC }}$ is the ratio of intensity of stresses $K_{\mathrm{I}}$ in the crack tip to critical value of this parameter $K_{\mathrm{I} C} ; L_{r}=\sigma_{\text {ref }} / \sigma_{\mathrm{y}}$ is the ratio of critical stress value $\sigma_{\text {ref }}$, corresponding to ingress of plastic instability for the considered defect, to material yield point $\sigma_{\mathrm{y}}$. Type of function $f_{1}\left(L_{r}\right)$ is found experimentally.

We assume the criterion of spontaneous brittle-ductile fracture by $[13,14]$ in the following form:

$$
\begin{gathered}
K_{r} n=\left[1-0.14\left(L_{r} n\right)^{2}\right]\left[0.3+0.7 \exp \left(-0.65 L_{r}^{6} n^{6}\right)\right] \\
\text { at } L_{r} \leq L_{r}^{\max }=\frac{\sigma_{\mathrm{y}}+\sigma_{\mathrm{t}}}{2 \sigma_{\mathrm{y}}} \\
K_{r}=0 \text { at } L_{r}>L_{r}^{\max }
\end{gathered}
$$

where $n$ is the sought value of the safety factor determining the ratio of limit loads to those applied for the specified fracture; $\sigma_{t}$ is the material ultimate tensile strength.

Criterion of spontaneous brittle-ductile fracture (7) was used to perform calculations for piping with crack-like defects, located on the internal surface of a butt welded joint (in the 


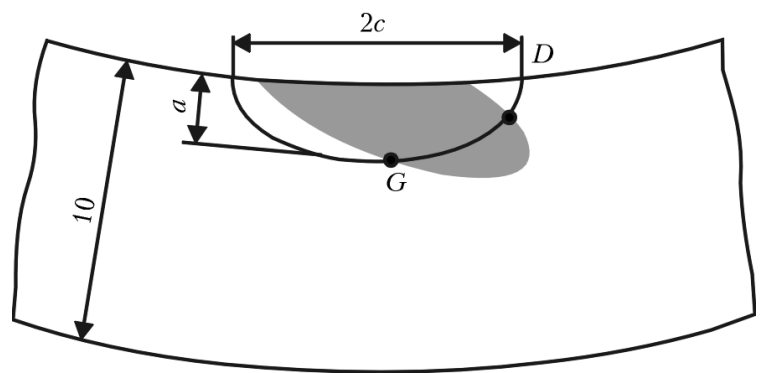

Figure 4. Schematic representation of discontinuity (coarse inclusion) on internal surface of piping butt welded joint by circumferential semi-elliptical crack

zone of maximum tensile stresses). Defect dimensions (depth $a$ and length $2 c$ of semi-elliptical crack) were varied within $10 \mathrm{~mm}$. As exact values of mechanical properties of aluminium piping weld metal are not available, the critical value of stress intensity factor $K_{\mathrm{IC}}$ was varied in the range from 13 up to $30 \mathrm{MPa} \cdot \mathrm{m}^{0.5}$.

Figures 6 and 7 show the results of calculation of safety factor values $n$ for spontaneous growth of the circumferential and axial crack, which is located on the internal surface of piping butt welded joint, depending on its dimensions $2 c$, $a / c=0.9, a / c=0.5$ and critical value $K_{\mathrm{I} C}=$ $=13$ and $30 \mathrm{MPa} \cdot \mathrm{m}^{0.5}$ of weld metal at working $(0.15 \mathrm{MPa})$ and test $(0.32 \mathrm{MPa})$ pressures. It is seen that for all the crack variants of up to $7.7 \times$

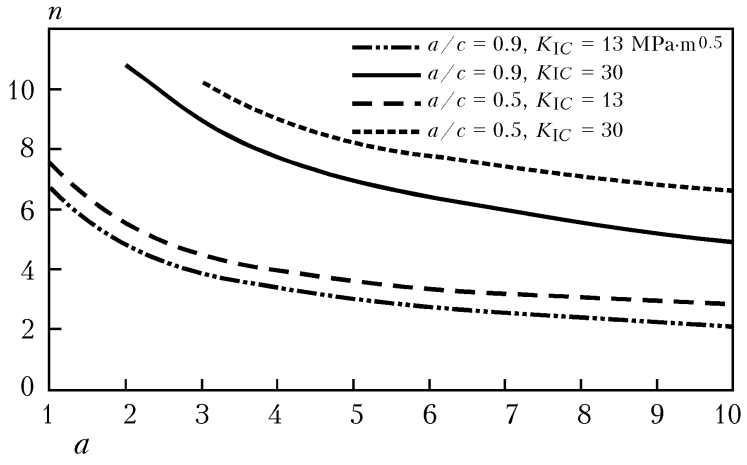

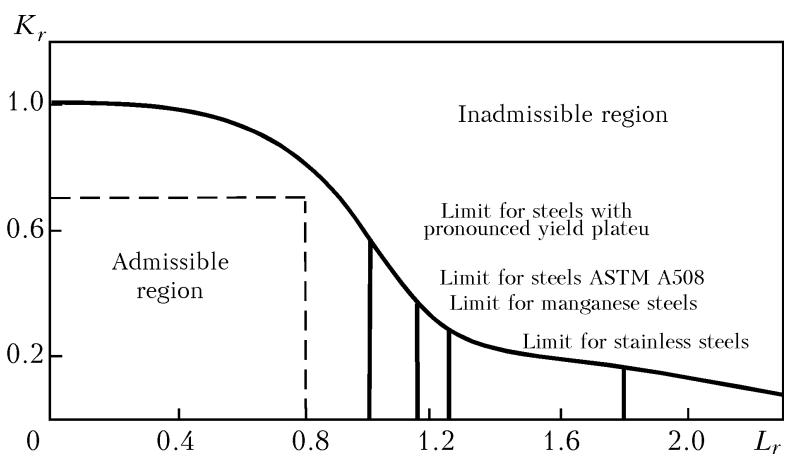

Figure 5. Limiting state diagrams $K_{r} \leq f_{1}\left(L_{r}\right)$ for structural steels of different types [13]

$\times 3.5 \mathrm{~mm}(a / c=0.9), 8 \times 2 \mathrm{~mm}(a / c=0.5)$ size and at assumption of sufficiently conservative fracture toughness value $K_{\mathrm{IC}}=13 \mathrm{MPa} \cdot \mathrm{m}^{0.5}$, safety factor values are higher than or are at the level of $n \geq 2$. Influence of the magnitude of working and test pressure on crack propagation is insignificant, as tensile residual stresses prevail on welded joint internal surface.

Thus, in the absence of corrosion and fatigue fracture mechanisms during operation of the considered piping there are no conditions for spontaneous growth of crack-like defects corresponding to coarse inclusions of up to $6.5 \times 1.5$ and $5.5 \times 3.5 \mathrm{~mm}$ size, found in the zone of circumferential welded joints.

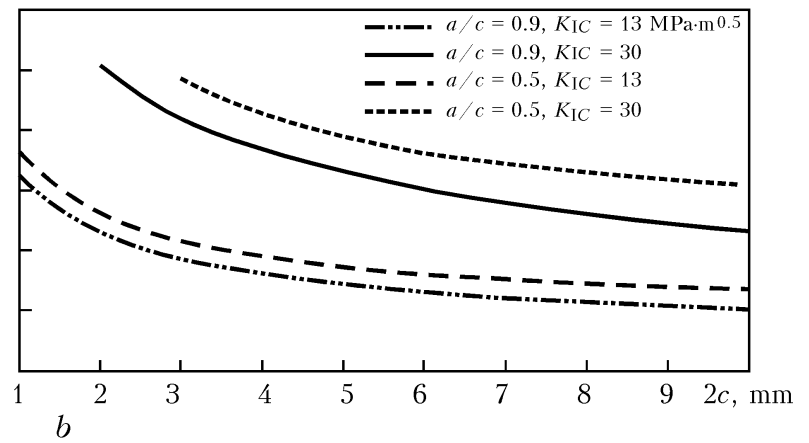

Figure 6. Dependence of safety factor $n$ for spontaneous growth of circumferential crack on its dimensions $2 c, a / c$ and critical $K_{\mathrm{I} C}$ of weld metal at $p_{\text {work }}=0.15(a)$ and $p_{\text {test }}=0.32(b) \mathrm{MPa}$
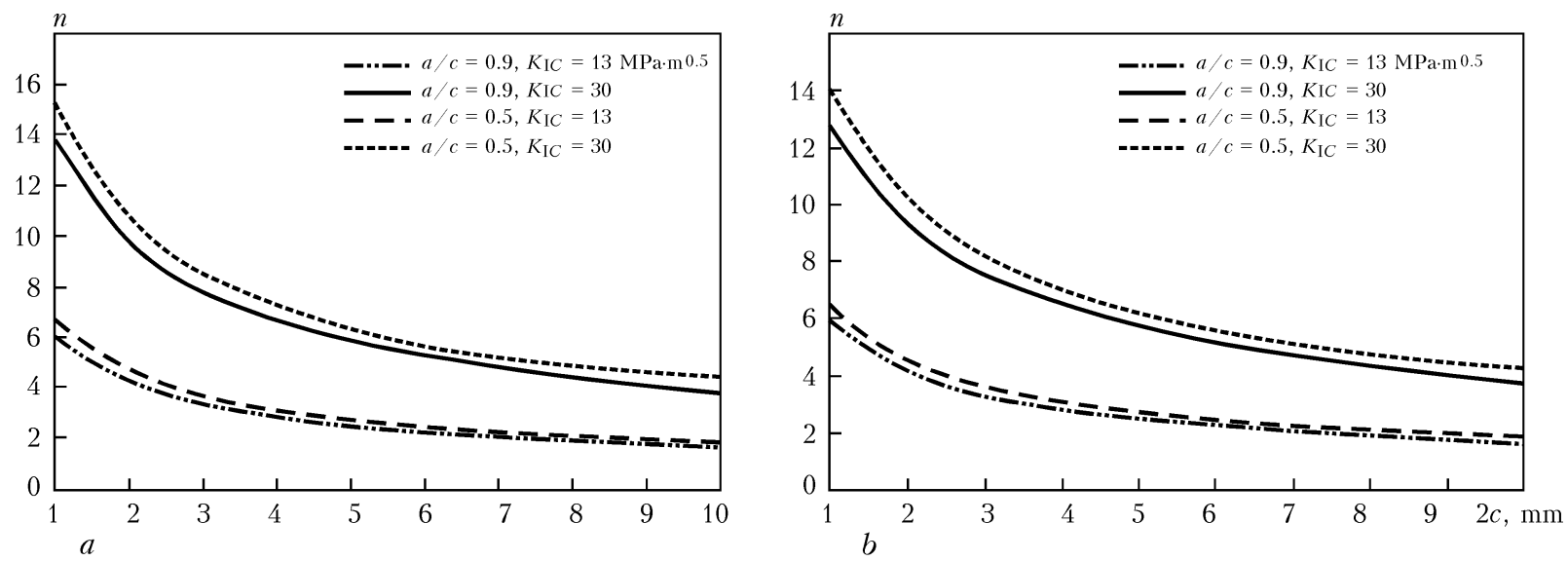

Figure 7. Dependence of safety factor $n$ for spontaneous growth of axial crack on its dimensions $2 c, a / c$ and critical $K_{\mathrm{IC}}$ of weld metal at $p_{\text {work }}=0.15(a)$ and $p_{\text {test }}=0.32(b) \mathrm{MPa}$ 


\section{Conclusions}

1. Computational study of behaviour of discontinuities in the form of pores and coarse inclusions, detected in the zone of circumferential welded joints, has been performed to substantiate the operability of WWR-M research reactor primary circuit piping (diameter $D_{a}=370 \mathrm{~mm}$, wall thickness $S=10 \mathrm{~mm}$ ) from aluminium alloy AMg3. Piping analysis for static strength showed that the actual thickness of piping walls is more than 7 times greater than the nominal thickness, satisfying the condition of static strength for working and test pressure range (0.15$0.32 \mathrm{MPa}$ ).

2. As shown by computation, the limiting state for the considered discontinuities is reached at internal pressure of $3.8-4.2 \mathrm{MPa}$, and in the defect-free section - at 4.9 MPa, i.e. lowering of welded piping ultimate load-carrying capacity is equal to approximately $15-23 \%$. For the range of working and test pressures $(0.15-0.32 \mathrm{MPa})$ the detected discontinuities in the form of gas pores in weld metal do not lower the considered piping load-carrying capacity.

3. Computation based on application of the criterion of spontaneous brittle-ductile fracture of piping with a crack (two-parametral criterion) showed that for inclusions (slag, tungsten or oxide films $)$ of up to $7.7 \times 3.5 \mathrm{~mm}(a / c=0.9)$, $8 \times 2 \mathrm{~mm}(a / c=0.5)$ size, even with the assumption of sufficiently conservative fracture toughness value $K_{\mathrm{IC}}=13 \mathrm{MPa} \cdot \mathrm{m}^{0.5}$ for welded joint metal, the calculated values of safety factor for spontaneous fracture are higher than $n>2$ both at working pressure of $0.15 \mathrm{MPa}$, and at test pressure of $0.32 \mathrm{MPa}$. Thus, in the absence of corrosion and fatigue fracture mechanisms in operation of the considered piping there are no conditions for spontaneous growth of crack-like defects (detected coarse inclusions) of up to $6.5 \times$ $\times 1.5$ and $5.5 \times 3.5 \mathrm{~mm}$ size in the zone of circumferential welded joints.
1. (1991) PNAE G-7-023-90: Equipment and pipelines of nuclear power plants. Aluminium alloy welded joints. Rules of control. Moscow: Energoatomizdat.

2. (1991) PNAE G-7-010-89: Equipment and pipelines of nuclear power plants. Welded joints and deposits. Rules of control. Moscow: Energoatomizdat.

3. (1987) PNAE G-7-002-86: Norms of strength analysis of equipment and piping of nuclear power plants. Moscow: Energoatomizdat.

4. Makhnenko, V.I. (1976) Calculation methods for the study of kinetics of welding stresses and strains. Kiev: Naukova Dumka.

5. Makhnenko, V.I., Velikoivanenko, E.A., Pochinok, V.E. et al. (1999) Numerical methods for the prediction of welding stresses and distortions. In: Welding and Surfacing Rev., Vol. 13. Amsterdam: Harwood Acad. Publ.

6. Makhnenko, V.I., Kasatkin, O.G., Velikoivanenko, E.A. et al. (1998) Calculated-experimental study of welding stresses in the zone of circumferential butts of pipelines DU-300 of ChNPP-3 KMPTs. In: Proc. of 5th Int. Conf. on Problems of Materials Science in Design, Manufacturing and Service of Nuclear Power Plant Equipment (Pushkin, Russia, 1998), Vol. 2, 53-66. St.-Petersburg: FGUP TsNII KM Prometej.

7. Makhnenko, V.I. (2013) Problems of examination of modern critical welded structures. The Paton Welding J., 5, 21-28.

8. Karzov, G.P., Margolin, B.Z., Shvetsova, V.A. (1993) Physical-mechanical modeling of fracture processes. St.-Petersburg: Politekhnika.

9. Procedural recommendations MR-125-01-90: Calculation of stress intensity factors and section weakening for defects in welded joints. Kiev.

10. Zvezdin, Yu.I., Rivkin, E.Yu., Vasilchenko, G.S. et al. (1990) Application of data of nondestructive testing in strength analysis. Tyazh. Mashinostroenie, 3, $12-14$.

11. Procedural recommendations MR-125-02-95: Rules for plotting design diagrams and determination of parameters of loading of structural elements with detected defects. Moscow: NPO TsNIITMASh.

12. Ovchinnikov, A.V., Zubchenko, A.S. (2010) Interpolation formulae of calculation of stress intensity factors for pressure vessels and pipelines. In: Problemy of nuclear science and engineering. Series Safety assurance of NPP. Issue 27: Reactor plants with WWER. Problems of strength, 58-70.

13. Milne, L., Ainsworth, R.A., Dowling A.R. et al. (1988) Assessment of the integrity of structure containing defects. Int. J. Pressure Vessels and Piping, 32(1-4), 3-104.

14. Makhnenko, V.I. (2006) Residual safe operating life of welded joints and sub-assemblies of modern structures. Kiev: Naukova Dumka. 